\title{
Research on Machining Errors Control by Adaptive CNC Machining Process for Near-Net-Shaped Jet Engine Blades
}

\section{Dongbo Wu}

Tsinghua University

Hui Wang ( $\square$ wanghuisx@tsinghua.edu.cn )

Tsinghua University

Jie Yu

AECC Xi'an Aero-engine LTD

\section{Research Article}

Keywords: Near-net-shaped jet engine blade, Machining errors, Adaptive CNC machining process, Onmachine measurement.

Posted Date: April 29th, 2021

DOI: https://doi.org/10.21203/rs.3.rs-456376/v1

License: (c) (i) This work is licensed under a Creative Commons Attribution 4.0 International License. Read Full License

Version of Record: A version of this preprint was published at The International Journal of Advanced Manufacturing Technology on August 17th, 2021. See the published version at https://doi.org/10.1007/s00170-021-07818-5. 


\title{
Research on Machining Errors Control by Adaptive CNC Machining Process for Near-Net-Shaped Jet Engine Blades
}

\author{
Dongbo $\mathrm{Wu}^{1}$, Hui Wang ${ }^{1 *}$, Jie $\mathrm{Yu}^{2}$ \\ ${ }^{1}$ State Key Laboratory of Tribology, Beijing Key Lab of Precision/Ultra-Precision Manufacturing Equipment and \\ Control, Department of Mechanical Engineering, Tsinghua University, Beijing, China 100084 P.R. China. \\ ${ }^{2}$ AECC Xi'an Aero-engine LTD. Xi'an, Shannxi 710021, P. R. China. \\ \#Corresponding Author/E-mail: wanghuisx@gmail.com,TE, TEL: +86-10-62798599
}

\begin{abstract}
This study proposes an adaptive CNC machining process based on onmachine measurement to control the machining error of near-net-shaped blades. The multi-source and multi-process machining error transmission model of a near-netshaped blade is established, and the reduction effect of the machining error transmission chain by the adaptive $\mathrm{CNC}$ machining process is qualitatively analyzed based on the machining error transmission flow model. The effects of the adaptive CNC machining process on the positioning benchmark error, machining position error, and machining contouring error are explored based on an experiment for the adaptive CNC machining process. In particular, the ability of the adaptive CNC machining process to cooperatively control the blade position error and the contouring error is discussed in relation to the stiffness of the blade-fixture system. The results show that the adaptive $\mathrm{CNC}$ machining process can reasonably reduce the machining errors caused by the positioning benchmark. The final deviation band of the blade body is reduced by $60 \%$ based on this adaptive $\mathrm{CNC}$ machining process. The adaptive $\mathrm{CNC}$ machining process can optimize the contouring error and the position error of the blade tenon root with only the stiffness of the blade-fixture system prerequisite being ensured. The adaptive $\mathrm{CNC}$ machining process has the excellent ability to control machining errors to improve the machining quality of the blade.
\end{abstract}

Keywords: Near-net-shaped jet engine blade; Machining errors; Adaptive CNC machining process; On-machine measurement. 


\section{Introduction}

Blades are some of the key parts for the improvement of the performance and service life of a jet engine [1]. Near-net-shaped jet engine blades, such as precision forged blades without margins or precision casted blades without margins, can directly form the complex curved surfaces of blades, which eliminates the material removal of the blade surface. Near-net-shaped jet engine blades possess extremely important applications under high temperature, high pressure, and high speed conditions.

The blade body of a near-net-shaped blade adopts a forming process, and the contouring error of the blade body after the precision forming process is in the range of $0.008 \mathrm{~mm}$ to $0.05 \mathrm{~mm}$, which meets the accuracy requirement of the blade body. Therefore, the blade body of a near-net-shaped blade does not require subsequent computer numerical control (CNC) machining. However, due to the small curvature radius of the blade Leading edges and Trailing edges (LTE) and the high precision requirements of the blade tenon root and tip, the forming process cannot meet the accuracy requirements for the blade LTE and tenon root and tip, and the subsequent $\mathrm{CNC}$ machining process is required.

In the CNC machining process of the blade LTE, tenon root and tip, the positioning and clamping part is only the blade body, which is a complex surface part. At present, the $\mathrm{CNC}$ machining process method for this kind of blade tenon root and tip is a low melting point alloy casting process, and a certain ratio of low melting point alloy, such as tin-bismuth alloy, is used to pour the blade body as a block to improve the stiffness of the blade-fixture system, and the machining accuracy is ensured by benchmark conversion [2]. However, due to the use of low melting point alloy, this method results in environmental pollution and low processing efficiency, and the benchmark conversion leads to low machining accuracy.

Adaptive CNC machining technology is an effective solution for the high precision machining of near-net-shaped blade tenon roots, tips, and LTEs [3]. However, various machining sources affect the blade accuracy and quality during the adaptive CNC machining process, which leads to low machining accuracy for a blade.

The blade machining accuracy is affected by multiple sources of machining error due to the increasingly complex $\mathrm{CNC}$ machining processes for complex thin-walled blade structures, such as the blade material characteristics, machine tools, and fixture. Additionally, the complex coupling relationships of these machining error sources may also introduce the final machining error. These machining errors are constantly 
generated, transmitted, increased, reduced, accumulated, and transmitted to form the dimensional deviation of the final blade. Therefore, it is important to study the machining errors of complex thin-walled blades and further optimize machining error control methods.

At present, the research on the machining error control of complex thin-walled parts focuses on forming a systematic research framework based on two aspects. The first research idea is the machining error formation and transfer mechanism of the interrelation between the cutter and the workpiece during the machining process. The essential concept is the research about the geometry, kinematics, and dynamics principle of the $\mathrm{CNC}$ machining process, and the key research points are the machining errors between the fitted surface and the ideal machining surface formed by the cutter generating motion for a complex surface blade.

E. Budak et al. [4] analyzed the cutting force, structural deformation and surface accuracy of the machining process to improve machining accuracy through machining process optimization. Weifang Chen et al. [5] proposed a multi-objective fixture layout and clamping force optimization method based on a genetic algorithm to reduce the deformation and increase the consistency of surface deformation. K.P. Padmanaban et al. [6] proposed a method for fixture layout optimization to control the elastic deformation by using an ant colony optimization algorithm. However, the above two methods improve the machining accuracy based on the deformation control from a single fixture optimization method.

Abdul Wahid Khan et al. [7] proposed a systematic machining geometric error model, and the machining accuracy was improved through machine tool error identification and analysis. Yan Rong et al. [8] studied the comprehensive stiffness matrix of the overall machining system including the machining parts, machining tools, machining tool spindle, and the cutter, and the stiffness variation laws of the machining system in multi-axis machining of complex curved surfaces was analyzed to improve the machining accuracy through process planning. The above-mentioned studies started with the stiffness of the machining system, with consideration of the stiffness enhancement method and deformation suppression of the entire machining system, which could improve the machining accuracy based on the deformation control for a thin-walled blade weak stiffness machining system. However, these studies improved the machining accuracy by only considering the stiffness factor of the complicated machining system. 
Eduardo Diez et al. [9] proposed a process plan method that could improve the machining accuracy by deformation compensation based on the actual measured cutting force and the estimated deformation. Li-Min Zhou et al. [10] proposed a method for predicting the surface dimensional form errors caused by deflections of both the workpiece and the slender end-mill in the five-axis flank milling of thin-walled parts, and the machining accuracy was improved through deformation prediction during the $\mathrm{CNC}$ machining process for the case of the insufficient stiffness of thin-walled parts. Gururaj Bolar et al. [11] established the relationship between the cutting process parameters and the quality of the machining surface, and they improved the machining quality with cutting process parameter combination optimization. Ziling Zhang et al. [12] researched the feedback mechanism between the cutting force and the milling deformation error, and they established a workpiece deformation error model based on an advanced neural network and improved the machining accuracy through a machining accuracy prediction model. Fountas, NA et al. [13] proposed an optimization of the five-axis sculptured surface finishing machining process to reduce the machining error based on decision making and machining error modelling. The above research reduced the machining deformation through the optimization of the machining process and the method of cutting force prediction for weak stiffness systems, and this research provided research methods for the optimization of the adaptive $\mathrm{CNC}$ machining process of thin-walled blades. However, these machining optimization methods have been carried out under the conditions of fixture layout and accurate benchmarks.

The second research idea is the spatial accumulation and transmission mechanism of machining errors. These research studies consider the transfer relationship between various machining errors in the $\mathrm{CNC}$ machining process.

Ma Yan et al. [14] proposed a global optimization numerical analysis algorithm of complex surface-type positioning and machining. The machined surface was adjusted to obtain the maximum coincidence with the projection of the theoretical surface based on this method, and the surface positioning error was reduced with a simulated annealing algorithm. Walid Ghiea et al. [15] proposed a theory of tolerance band characterization based on a small displacement torsor (SDT). The typical tolerance band was characterized as a series of standardized numerical models by the theory, which laid a strict foundation for the error transfer calculation based on the Jacobian matrix form. Jia Feng et al. [16] considered the cumulative error of the multi-step process of blade manufacturing, and the key processes and their effects on the 
machining errors were analyzed by constructing a workpiece machining error transmission model. A method for workpiece machining error analysis and optimization was proposed, and the multi-source multi-machining procedure process error transfer control method was studied based on the machining error transmission for the multimachining procedure process in a workpiece machining model. SJ Hu et al. [17]. proposed a theoretical method for the error flow of mechanical product assembly based on the error transmission characteristics of multiple parts. D. Ceglarek et al. [18, 19]. further developed the state-space equation method to study assembly error variation relationship modeling and the deviation transmission mechanism, and they applied this method to the quality modeling and process quality control of the multi-process assembly process of auto parts. Although the above research methods and ideas are oriented to the multi-product assembly process, the proposed error cumulative effect in the space domain and the transmission effect in the time domain are the essence of multi-source and multi-process error transmission. That is, the transmission characteristics of the errors in the time domain should be considered, and the cumulative effect of the errors in the space domain should also be considered during research for the multiple sources and multi-process machining errors. Considering the research object, the CNC machining of near-net-shaped blade tenon root, tip, and LTE is a typical multi-source multi-process processing process. Therefore, machining error transmission and accumulation methods research will be of guiding significance for this kind of blade machining error control.

The above two research ideas provide methodological guidance for the machining errors of a thin-walled blade. With the development of on-machine measurement technology, this technology will be an important method to compensate for machining errors with on-machine measurement. Guiassa and Mayer et al. [20] proposed onmachine probing for the correction of the finishing machining process, and the machining error resulting from the deflection and the tool offset error was compensated for solely with data from process-intermittent probing. Bandy HT et al. [21] proposed a methodology for compensating for errors detected by process-intermittent inspection, and this methodology was validated on a prototype system implemented by processintermittent error compensation software (PIECS) on a turning center. Jian-Hua Yu et al. [22] proposed a new method for controlling machining deformation by eliminating surface errors based on an adaptive two-armed fixture, and adaptive technology has been applied in the design and process integration of a fixture. Nuodi Huang et al. [23] 
processed an adaptive deformation error compensation method for a large thin-walled part, and an integrated on-board measurement (OMM) system was developed to obtain the geometry of the part for a typical large thin-walled part for the tank bottom of a rocket, and a machining error compensation algorithm was developed to eliminate deformation errors by modifying machining tool paths.

Therefore, with the continuous development of on-machine measurement technology and the adaptive $\mathrm{CNC}$ machining process, many adaptive $\mathrm{CNC}$ machining techniques based on-machine measurement technology have been applied to the CNC machining of thin-walled parts, which will provide new ideas for blade machining error control. Specifically, for a particular blade, adaptive CNC machining technology can achieve the mutual reduction of some machining errors during the blade CNC machining process. At the same time, some machining errors can be compensated for due to the application of on-machine measurement technology and adaptive compensation technology, which will stop the machining error transmission process in the entire CNC machining process.

Considering the particularity of the structure of a near-net-shaped jet engine blade and the processing technology, this study focuses on analyzing the effect of adaptive CNC machining technology based on the on-machine measurement of the machining error of a near-net-shaped jet engine blade. The sections are arranged as follows. In section 2, the adaptive CNC machining process and the machining errors are theoretically analyzed. In section 3, the conditions and methods of the on-machine measurement, CNC machining, CMM measurement, and blade surface quality test are introduced. In section 4, the results and discussion are analyzed, and the adjustment mechanism and the adjustment ability of the adaptive CNC machining for the positioning benchmark error, machining position error, and contouring error are analyzed. Finally, the conclusion is summarized in Section 5.

\section{Machining errors accumulation model of near-net-shaped blade adaptive CNC machining process}

The manufacturing process of a near-net-shaped jet engine blade is a complex CNC machining process, and it is usually a composite process line based on data flow, which involves synergy among multiple CNC machining processes, and ultimately forms a qualified blade with multiple conversions between the benchmarks. 


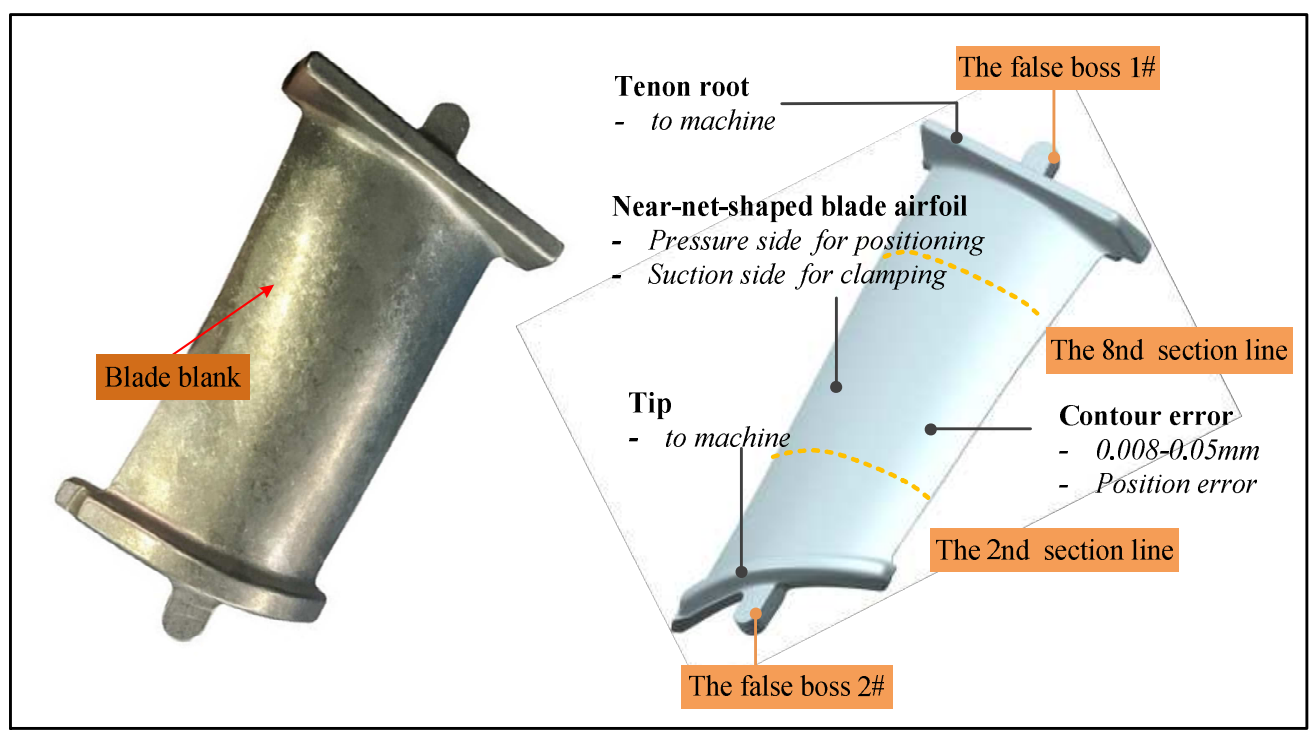

Fig. 1 Near-net-shaped jet engine blade process characteristics

Figure 1 shows the near-net-shaped blade process characteristics. The blade blank is obtained with the previously described precision forging process, and the contour error of the blade body precision forging process which is in the range of $0.008 \mathrm{~mm}$ to $0.05 \mathrm{~mm}$, will inevitably occur. The manufacturing accuracy of the false boss (the false boss \#1 and the false boss \#2 in the Figure 1) must be priority guaranteed for the subsequent CNC machining benchmark of the blade LTE. The precision forging accuracy of the 2 nd and 8th section lines of the blade body are preferentially guaranteed in the precision forging process of the blade for the subsequent CNC machining benchmark of the blade tenon root and tip. Therefore, the available CNC machining benchmarks are only the 2 nd and 8 th section lines of the precision forged blade and the false boss.

The false boss of the blade is used as the benchmark to machine the blade LTE. This is the first CNC machining process step of the blade CNC machining process. In this process, the benchmark error of the false boss leads to the machining error of the blade LTE. The machined blade LTE, and the 2nd and 8th section lines of the blade are used as the positioning benchmark to precisely machine the blade tenon root and tip. In this process, the false bosses that are initially used as the machining benchmark to mill the blade LTE, are removed by the CNC machining process, and the machining benchmark is converted. This process is used as the second step in the blade CNC machining process, which results in a qualified blade tenon root and tip. Finally, the precision-milled tenon root is used as the detection benchmark to detect the position error and the contouring error of the blade body and tenon root and tip with the special 
inspection fixture.

Through the above analysis, the blade CNC machining process is a multimachining procedure process. The machining error is inevitable when the entire multimachining procedure benchmark is repeatedly converted.

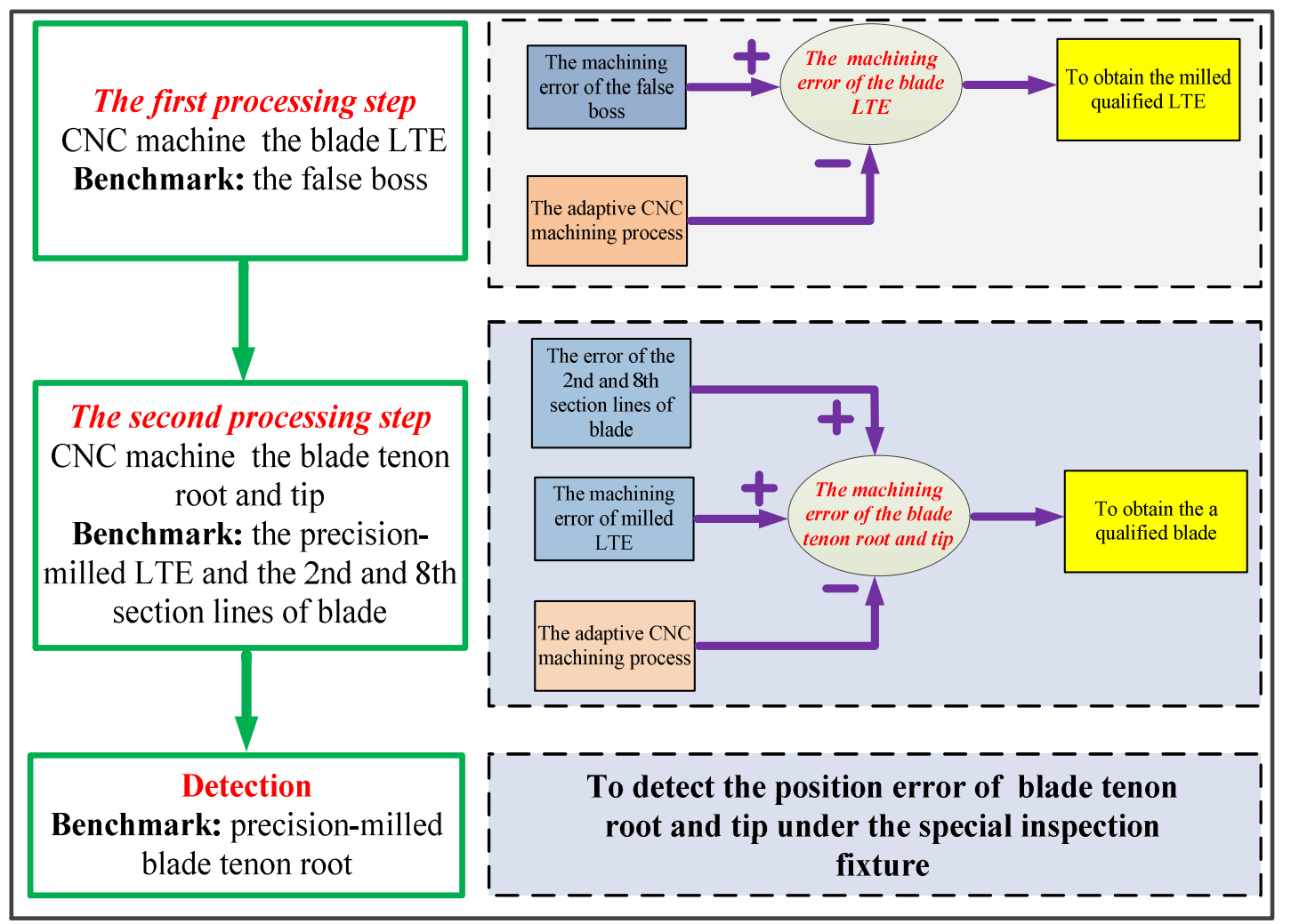

Fig. 2 Multi-source, multi-machining procedure machining errors

Figure 2 shows the machining error formation mechanism of the multi-source, multi-machining procedure process. The final machining error is caused by the source errors, including the blade profile error after the precision forging process and the machining error of the false boss, and the introduced machining errors caused by the previous process include the machining error of the blade LTE and tenon root. All of these errors accumulate in the final machining errors of the blade.

In the CNC machining process of the near-net-shaped blade, the specific machining errors are multi-target machining errors (multiple outputs $(y)$ ), which mainly include the contouring error and the position error of the blade tenon root. At the same time, the machining error influencing factors that affect the final machining error are also numerous (multiple inputs $(x)$ ). These factors mainly include the machine tool errors, errors caused by the tool path position, and errors caused by the instability of the clamping fixture.

The single blade machining error $(y)$ with the machining error source $(x)$ satisfies 
the functional relationship.

$$
Y_{i}=f_{i}\left(x_{1}, x_{2}, \mathrm{~L}, x_{n}\right),(i=1,2,3,4) .
$$

The benchmark conversion is also one of the machining error sources of the blade multi-process machining process. Assuming that the benchmark conversion homogeneous matrix between the blade multi-process steps is $\mathbf{A}_{i-1}^{i}(i=2,3,4)$, the machining error model is generated by the $k$-th blade process, and this model accumulates the machining errors in the $k$-1-th blade process.

$$
Y_{n}=A_{n-1}^{n} \cdot Y_{n-1}+f_{n}\left(x_{1}, x_{2}, \mathrm{~L} x_{n}\right) .
$$

The blade multi-source multi-process machining error transfer model based on Equations (1) and (2), is shown in Formula 3. This model reflects the cumulative effect of the machining errors among multiple processes.

$$
\mathbf{Y}=\left\{\begin{array}{c}
\mathbf{Y}_{1}=f_{1}\left(x_{1}, x_{2}, \mathrm{~L} x_{n}\right) \\
\mathbf{Y}_{2}=\mathbf{A}_{1}^{2} \cdot \mathbf{Y}_{1}+f_{2}\left(x_{1}, x_{2}, \mathrm{~L} x_{n}\right) \\
\mathbf{M} \\
\mathbf{Y}_{n}=\mathbf{A}_{n-1}^{n} \cdot \mathbf{Y}_{n-1}+f_{n}\left(x_{1}, x_{2}, \mathrm{~L} x_{n}\right)
\end{array} .\right.
$$

The differential equation is obtained:

$$
d Y_{n}=A_{n-1}^{n} \frac{\partial f_{n-1}\left(x_{1}, x_{2}, \mathrm{~L} x_{n}\right)}{\partial x_{1}}+\frac{\partial f_{n}\left(x_{1}, x_{2}, \mathrm{~L} x_{n}\right)}{\partial x_{1}} .
$$

In the entire $\mathrm{CNC}$ machining process, the accumulation of various error sources eventually leads to the formation of multi-process processing errors (see Figure 3). Based on Formula 4, in the blade multi-process processing link, the machining error is very sensitive to the error caused by the benchmark conversion. In practice, the various machining errors that affect the blade machining accuracy are interrelated, and some machining errors may cancel each other out, and the clamping scheme and the process parameters optimization are used to achieve the reduction and suppression of some machining errors. The adaptive CNC machining process is one of the main methods of partial machining error reduction. 


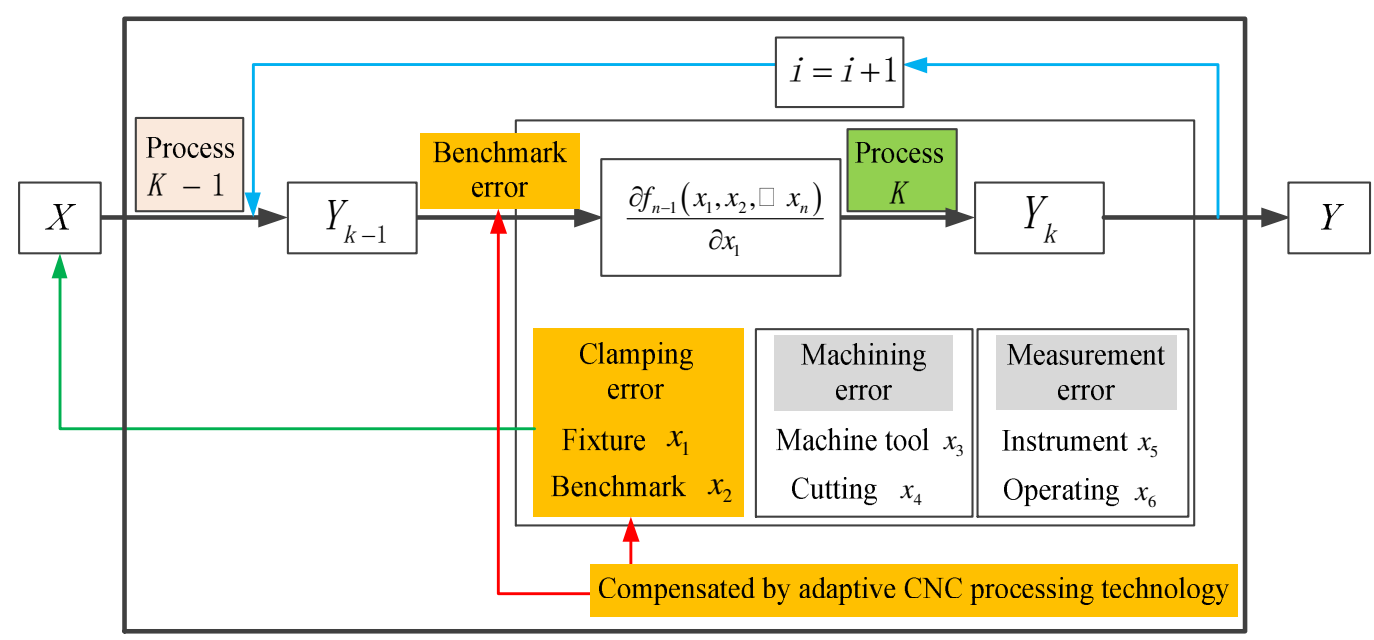

Fig. 3 Machining error accumulation process caused by benchmark conversion

The essence of the adaptive $\mathrm{CNC}$ machining process is the transformation between the two coordinates which are the coordinates of the measuring point obtained by the on-machine measurement and the coordinates of the theoretical model point. Through the transformation of the measuring point and the theoretical point, the best matching between the measuring point and the theoretical point is achieved. Specifically, for a five-axis CNC machine tool, the blade can be translated along the machine tool's $x, y$, and $z$ axes, and rotated along the machine tool's $A, B$, and $C$ axes at the same time. Therefore, the essence of the adaptive adjustment process is the process of machine tool rotation and translation, and the rotation matrix and the translation matrix are as follows. $R=R_{z}(\gamma) \cdot R_{y}(\beta) \cdot R_{x}(\alpha)=\left[\begin{array}{ccc}\cos \beta \cos \gamma & \sin \alpha \sin \beta \cos \gamma-\cos \alpha \sin \gamma & \cos \alpha \sin \beta \cos \gamma+\sin \alpha \cos \gamma \\ \cos \beta \sin \gamma & \sin \alpha \sin \beta \sin \gamma-\cos \alpha \cos \gamma & \cos \alpha \sin \beta \sin \gamma-\sin \alpha \cos \gamma \\ -\sin \beta & \sin \alpha \cos \beta & \cos \alpha \cos \beta\end{array}\right]$

where $\boldsymbol{R}$ is the rotation matrix, $\alpha$ is the rotation angle of the blade along with the machine tool's $A$ axis, $\beta$ is the rotation angle of the blade about the machine tool's $B$ axis, and $r$ is the rotation angle of the blade about the machine tool's $C$ axis.

$$
T=\left[\begin{array}{lll}
C_{x} & C_{y} & C_{z}
\end{array}\right]^{T} .
$$

where $\boldsymbol{T}$ is the blade translation matrix, $C x$ is the blade translation along the $x$ axis, $C y$ is the blade translation along the $y$ axis, and $C z$ is the blade translation along the $z$ axis.

The blade position point coordinates after rotation and translation are obtained according to the existing blade position point coordinates after obtaining the machine tool rotation matrix and translation matrix. Formula (7) describes the blade adaptive adjustment process. 


$$
P_{i}=R P_{i}^{\prime}+T
$$

where $P_{i}^{\prime}$ is the current position coordinate of the blade and $P_{i}$ is the position of the blade after adjustment.

Based on this mathematical principle, first, the CNC machining process of the blade tenon root and tip is a typical fuzzy positioning benchmark machining process due to the contour error of the blade body surface, which is used as the positioning benchmark $i$ in the range of $0.008 \mathrm{~mm}$ to $0.05 \mathrm{~mm}$. The matching function between the theoretical points and the measurement points is set as shown in Equation 8.

$$
\min f_{1}(x)=\sum_{i=1}^{N} d_{1}^{2}(x)=\sum_{i=1}^{N}\left\{\left[R_{1}(x) P_{i}+t(x)-q_{i}\right] \cdot n_{i}-\delta\right\}^{2}
$$

where $\delta$ is the positioning benchmark error compensation value, and this value is uncertain. However, if this value is controlled within the range of $0.008 \mathrm{~mm}$ to 0.05 $\mathrm{mm}$ by the adaptive $\mathrm{CNC}$ machining process, and this value is evenly distributed, at this time, the adaptive $\mathrm{CNC}$ machining process based on on-machine measurement will reasonably reduce the error caused by the benchmark positioning error.

Second, the position of the blade will deviate during the clamping process. When the clamping force or clamping sequence is not appropriate, the adaptive CNC machining process can compensate for the position deviations caused by the clamping process. The matching function between the theoretical points and the measurement points is set as shown in Formula 9.

$$
\min f_{2}(x)=\sum_{i=1}^{N} d_{2}^{2}(x)=\sum_{i=1}^{N}\left[R_{2}(x) \cdot P_{i}+t_{2}(x)-q_{i}\right]^{2} .
$$

Formula 9 describes the mathematical principle of the adaptive $\mathrm{CNC}$ machining process to achieve the position compensation of the clamping process, and this objective function is established with the assumption that there is no local deformation in the clamping process. In fact, the fixture designed for this purpose is a rigid-flexible fixture in order to avoid local deformation of the blade as much as possible [3].

Finally, in the CNC machining process, the aim is to control the contour error of the blade tenon root, and the point on the machined blade tenon root side is used as the measurement point to achieve the adaptive $\mathrm{CNC}$ machining process of the blade tenon root for the control target of the blade tenon root contour error. The matching function between the theoretical points and the measurement points is set as shown in Formula 10. 


$$
\min f_{3}(x)=\sum_{i=1}^{N} d_{3}^{2}(x)=\sum_{i=1}^{N}\left[R_{3}(x) \cdot P_{i}^{3}+t_{3}(x)-q_{i}^{3}\right]^{2} .
$$

The new rotation $R_{3}(x)$ and translation matrix $t_{3}(x)$ at this time will again affect the tenon root position described in Formula 9. That is, it is necessary to ensure the position error of the tenon root relative to the blade body while controlling the contour error of the blade tenon root. At this time, it is assumed that either the rigidity of the system is insufficient or the cutting force in the roughing stage is too large in the blade CNC machining process. The new rotation $R_{3}(x)$ and translation matrix $t_{3}(x)$ will lead to $f_{2}(x)$ being far from the best value. It is assumed that the stiffness of the blade during the $\mathrm{CNC}$ machining process is sufficient to resist the large cutting force load. Then the new rotation $R_{3}(x)$ and the translation matrix $t_{3}(x)$ will have the same trend as that shown in Formula 9.

Therefore, considering the influence of the rigidity of the process system, the blade adaptive CNC machining process algorithm for different target objective functions is as shown in Figure (4).

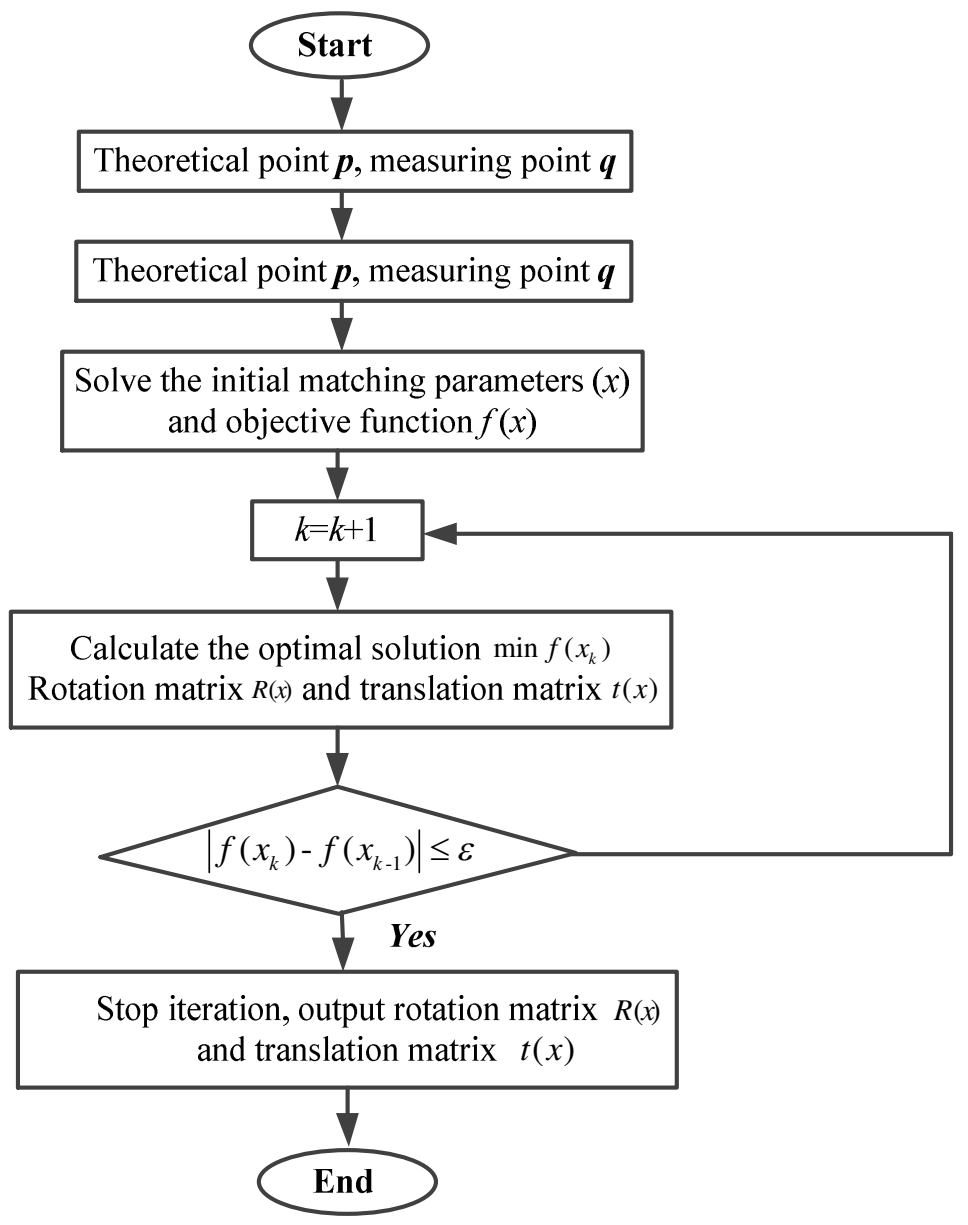

Fig. 4 Calculation process of adaptive $\mathrm{CNC}$ machining process 
Figure 5 shows a flowchart of the adaptive $\mathrm{CNC}$ machining process of a specific blade. The $\mathrm{CNC}$ machining areas are mainly the blade tenon root and tip. The adaptive CNC machining process is mainly used to control the blade positioning benchmark error, machining position error, and contouring error.

First, the blade is clamped in the appropriate position of the fixture with the proper clamping force and clamping sequence, which must match the fixture structure. Second, the blade is roughing milled after the clamping. The measurement path and measurement points are first planned based on the blade structure before roughing milling. Then the measurement data model is obtained and the measurement programming is completed, and the point cloud data of the blade surface is obtained based on the on-machine measurement. The blade measurement model and the theoretical model are established based on the registration algorithm to obtain the CNC machining and reconstruction model of the blade. The specific calculation process is shown in Figure 4. Thirdly, the coordinate system of the blade is adjusted using the rotation matrix and the translation matrix solved for with the registration algorithm, and the machine tool's NC machining program is adjusted at the same time. Finally, the final blade position state is obtained with the adaptive CNC machining process. The on-machine measurement and the adaptive algorithm flow are terminated by judging the uniformity of the machining allowance distribution and the specific value of the machining allowance, and then the next process is begun. 


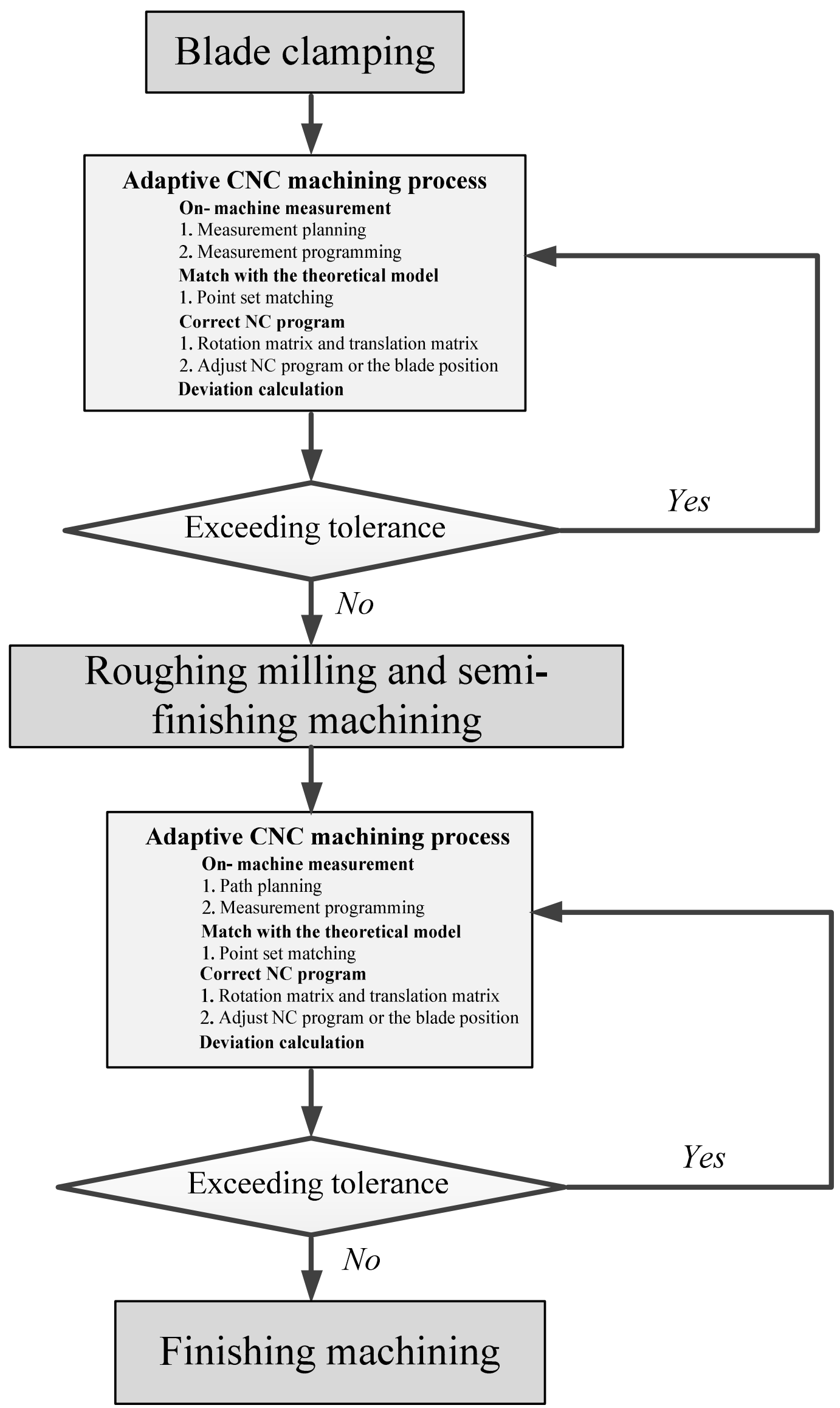

Fig. 5 Adaptive CNC machining process of blade 
Based on the above analysis, it can be seen that the adaptive $\mathrm{CNC}$ machining process cuts off the machining error transfer mode (Equation 2 and Figure 3). The adaptive $\mathrm{CNC}$ machining process can achieve the control of the blade tenon root position error and the contour error.

\section{Conditions and methods}

Based on the theoretical analysis described in the previous section, the experimental conditions and schemes are planned to explore the effect of the adaptive CNC machining process on the reduction of the machining errors of the near-net-shaped blade.

In order to ensure the $\mathrm{CNC}$ machining quality of the final blade, a five-axis $\mathrm{CNC}$ machine tool with an integrated Renishaw probe is used in this experiment. The Renishaw probe is stored in the cutter magazine of the machine tool, and the cutter and the Renishaw probe can be switched in order by the cutter change system of the machine tool. At this time, the CNC machining coordinate system and the on-machine measurement coordinate system of the machine tool are unified in the same coordinate system again due to the integration of the Renishaw probe measuring head and the cutter in the same cutter changing system, and the relative position between the measurement coordinate and the $\mathrm{CNC}$ machining coordinate tends towards $0 \mathrm{~mm}$.

\subsection{Adaptive CNC machining process and positioning benchmark error}

During the CNC machining process of the near-net-shaped blade tenon root, the positioning and clamping surface is only the blade body with a contour error of 0.008 $0.05 \mathrm{~mm}$. More importantly, these contour errors are random with a large uncertainty within the error band of $0.008 \mathrm{~mm}$ to $0.05 \mathrm{~mm}$. The positioning benchmark error is introduced when this part is used as the positioning surface. Therefore, the purpose of this experiment is mainly to explore the effect of the adaptive $\mathrm{CNC}$ machining process on the reduction of the benchmark positioning error. As shown in Figure 6, the blade concave and convex profiles are used as the measurement surface. The measured points of the blade concave and convex profiles on the fixture installation are detected based on the Renishaw probe. The single-point deviation values are obtained using the measured value and the theoretical value. During the measurement process, 24 measurement points in the blade concave (see Figure 6 (c)) and convex profiles (see 
Figure $6(d))$ are planned, and 48 measurement points on the blade concave and convex profiles are measured one time on the five-axis machine tool (see Figure 6 (b)).

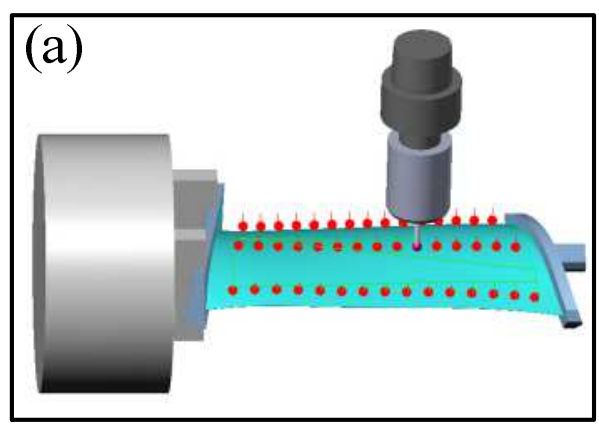

(c)

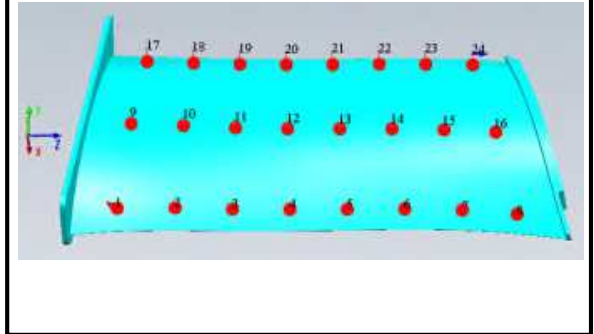

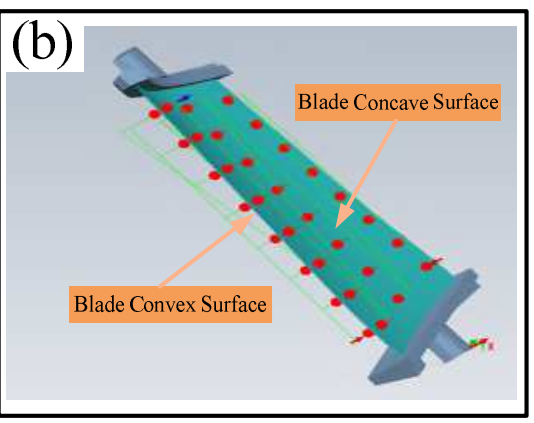

(d)

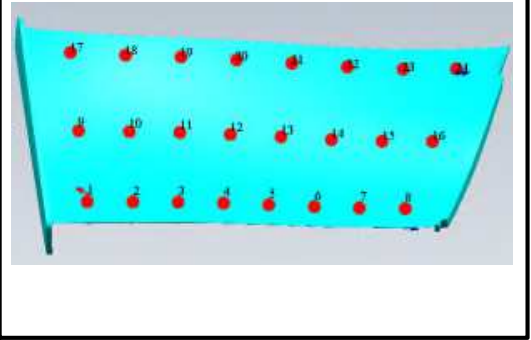

Fig. 6 Blade on-machine measurement process based on the

Renishaw probe, (a) On-machine measurement state, (b)

Measurement path planning, (c) Blade concave profile measurement

points, (d) Blade convex profile measurement points.

The measurement experiment site is shown in Figure 7. The special measuring fixture is used to ensure that the measurement process is reliable without displacement and offset. The special fixture is affixed to the five-axis machine tool, and the measurement points and paths must be ensured for the same state when the multiple adjustments of the adaptive CNC machining process are carried out. It should be noted that this special fixture is only used to explore the effect of the adaptive $\mathrm{CNC}$ machining process on the reduction of the positioning benchmark errors caused by the initial geometric errors, and the special fixture cannot be used for subsequent tenon root CNC machining. 

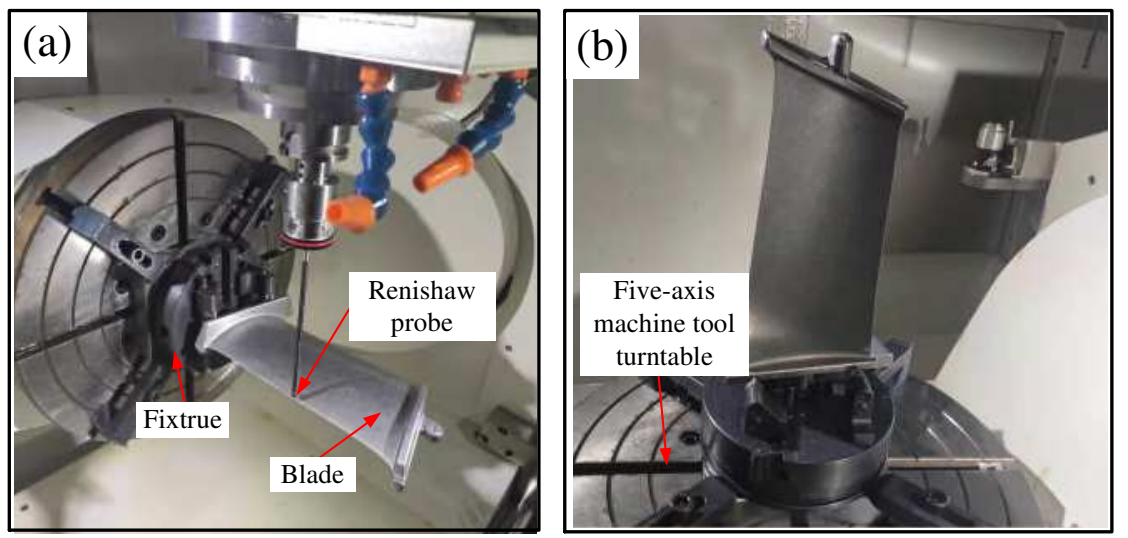

Fig. 7 Blade on-machine measurement process based on the Renishaw probe, (a) Blade profile measurement, (b) Blade special measuring fixture.

\subsection{Adaptive CNC machining process and the blade tenon root machining position error}

This experiment is used to explore the influence of the adaptive CNC machining process on the position error of the tenon root during the tenon root $\mathrm{CNC}$ machining process, and the position error refers to the position of the machining blade tenon root relative to the blade body, which mainly includes the circular position error and the twist position error. The fixture is a special fixture for the tenon root $\mathrm{CNC}$ machining process based on a multi-body rigid-flexible coupling dynamic model design [2].
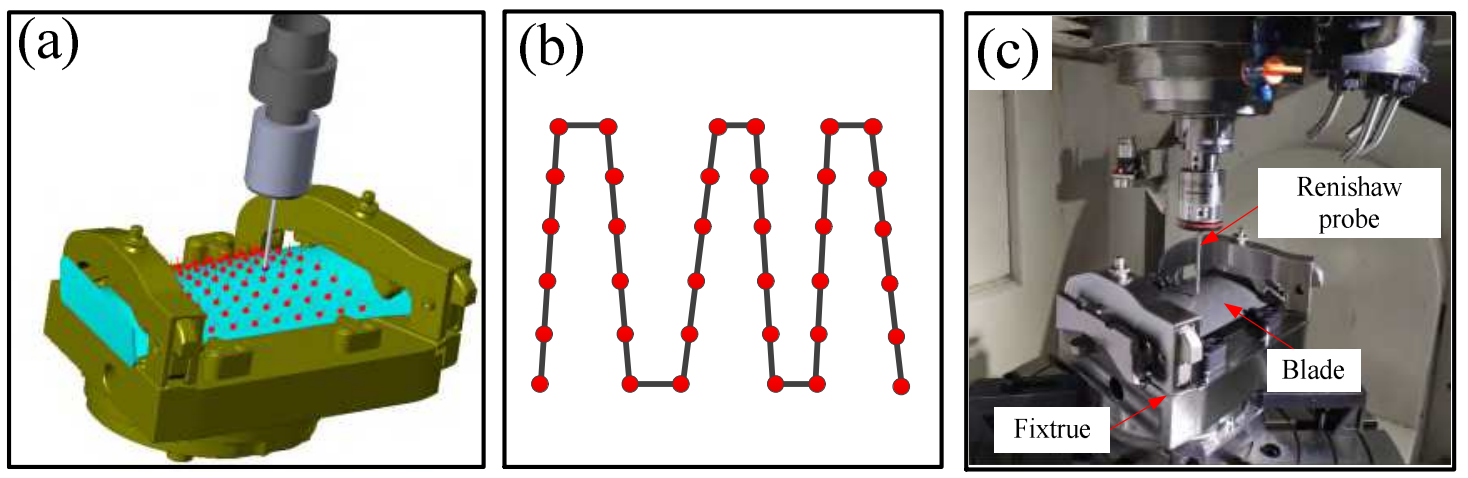

Fig. 8 Blade on-machine measurement process for machining position error control, (a) Measurement points, (b) Measurement path, (c) Measurement process of blade body.

Figure 8 shows the measurement model of the blade according to the fixture structure and the characteristics of the blade body. Eighty typical points are selected as the measurement points on the blade body convex surface. This is because the blade body's concave surface cannot be measured by the Renishaw probe in this fixture. It 
should be noted here that considering the particularity of the processing part, the fixture in Figure 7 cannot be used for the blade tenon root $\mathrm{CNC}$ machining, and the measurement points selection is no longer carried out according to Figure 6 . The blade deviation values between the measured points and the theoretical points are used to obtain the posture relationship of the blade. The measurement trajectory is shown in Figure 8 (b). The normal vector of the measurement is the normal vector of the blade surface. The coordinates of the blade body points are determined by obtaining the position of the center points of the measurement points based on the radius compensation algorithm. The bad measurement points are eliminated according to the distance relationship, angle relationship, and radius relationship of the data points after obtaining the measurement data points, and the useful measurement points are then used for the data calculation of the adaptive CNC machining process [3].

Table 1 Main machining parameters for blade roughing milling

\begin{tabular}{llll}
\hline Rough milling & $\begin{array}{l}\text { Spindle speed } \\
3000 \mathrm{rpm}\end{array}$ & $\begin{array}{l}\text { Feed rate } \\
1200 \mathrm{~mm} \text { per } \\
\text { minute }\end{array}$ & $\begin{array}{l}\text { Cutting depth } \\
0.1 \mathrm{~mm}\end{array}$ \\
\hline Workpiece & Ti-6Al-4V & \\
Cutter & D8R 0.5 mm & \\
& Nose knife & \\
Corkshop & Coated carbide & \\
Temperature & W & \\
Cutting fluid & Water-based cutting & \\
& fluids & \\
\hline
\end{tabular}

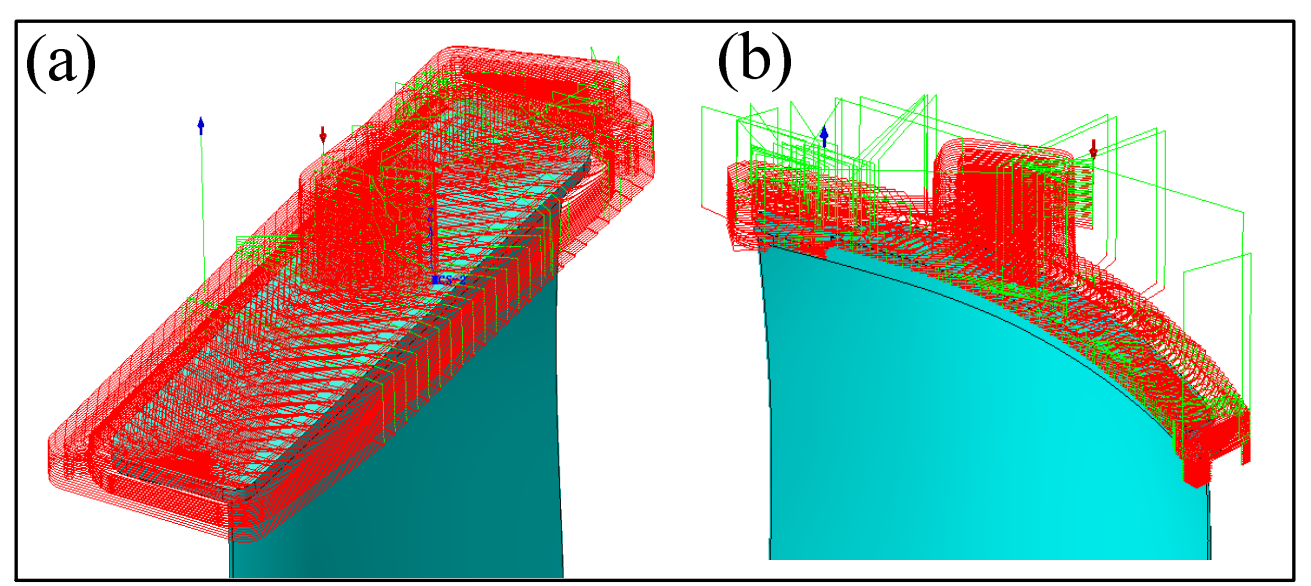


Fig. 9 Tool path for roughing machining of blade tenon root, (a) Tool path of blade tenon root, (b) Tool path of blade tip

The blade tenon root and tip are first roughing machined to remove a large amount of the blade tenon root and tip based on the final blade pose state obtained with the above adaptive CNC machining process. A nose knife cutter and the water-based cutting fluid are selected. The cutting tool path is shown in Figure 9, the main machining parameters for the blade roughing milling are shown in Table 1, and the experimental site is shown in Figure 10.
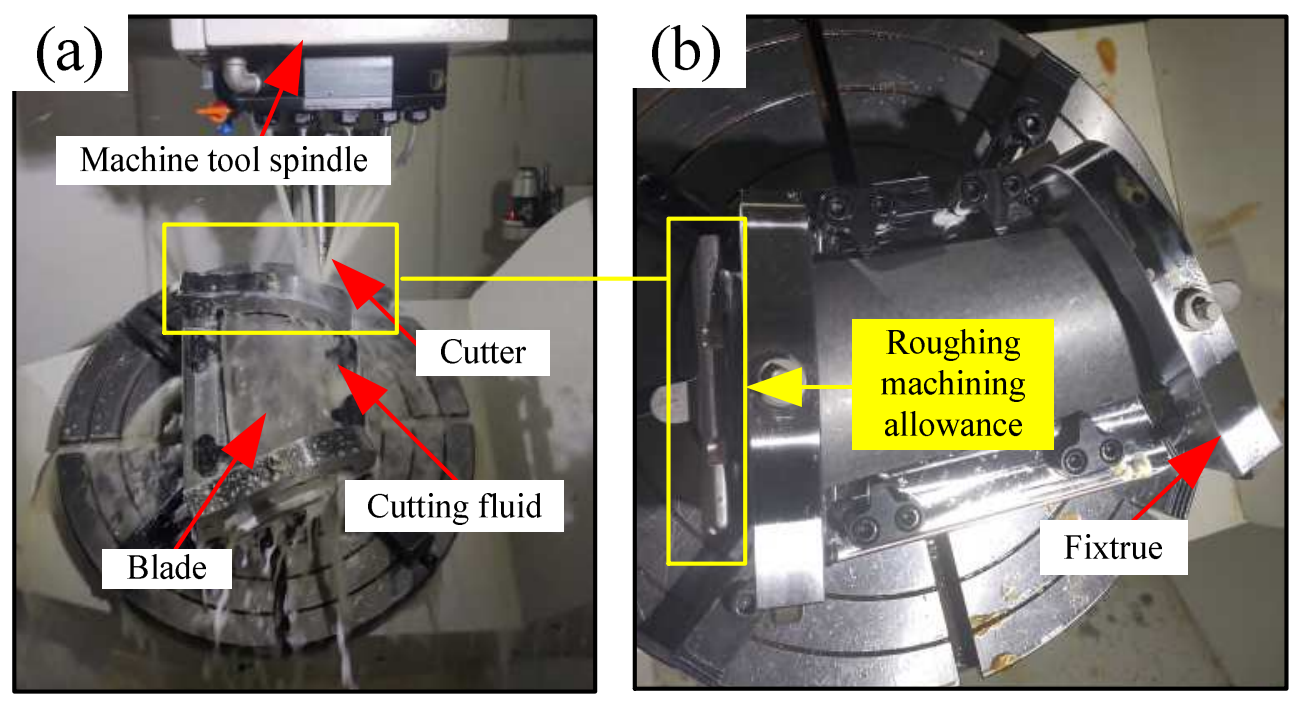

Fig. $10 \mathrm{CNC}$ roughing machining of blade

\subsection{Adaptive $\mathrm{CNC}$ machining process and the blade tenon root machining contouring error}

This experiment is mainly intended to explore the relationship between the adaptive $\mathrm{CNC}$ machining process and the contouring error of the blade tenon root pressure surface under the condition of the positioning error controlling the blade tenon root relative to the blade body.
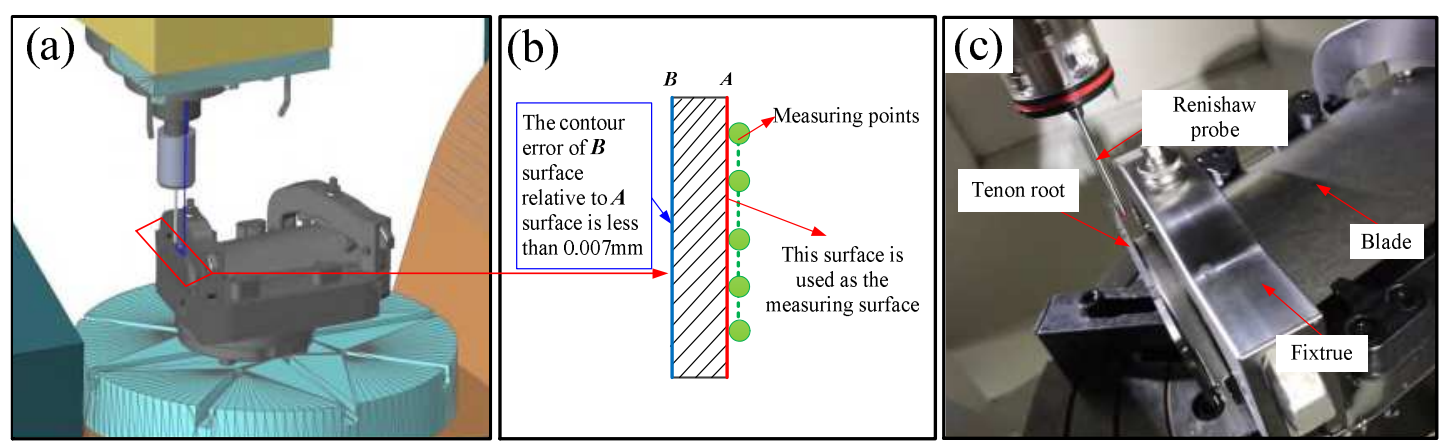

Fig. 11 Blade on-machine measurement process for machining 
contour error control, (a) On-machine measurement model, (b) Blade tenon root measurement point, (c) On-machine measurement process.

First, the assumption is made that the clamping position of the blade in the fixture will change after the roughing process is conducted, which will cause the benchmark to lose its original accuracy position due to the large external cutting force load in the roughing machining process with the large material removed. In this case, the blade tenon root machining contouring error is ensured based on the adaptive $\mathrm{CNC}$ machining process. For this near-net-shaped blade, the contouring error of the tenon root pressure surface is required to be less than $0.007 \mathrm{~mm}$, which is a very high requirement.

As shown in Figure 11, surface $\boldsymbol{A}$ is used as the measuring surface to measure the position deviation of the blade tenon root on the fixture, and the adaptive CNC machining process of the blade tenon root is carried out to ensure that the contour error of surface $\boldsymbol{B}$ is less than $0.007 \mathrm{~mm}$. The position of the blade tenon root will accurately adjust based on the adaptive adjustment process (see Figure 11 (b)). This is because only the blade body profile can be used as the benchmark in the roughing machining process, the blade body profile is the only positioning benchmark, and the positioning error is only controlled within a certain range through the on-machine measurement and adaptive adjustment of the blade body to ensure the position error of the blade tenon root relative to the blade body. However, a relatively accurate tenon root side surface (surface $\boldsymbol{A}$ ) is obtained through the roughing milling process, and the position of the blade tenon root relative to the blade body is ensured during the roughing milling process. This adaptive $\mathrm{CNC}$ machining process is used to ensure the contour error of the blade tenon root. 

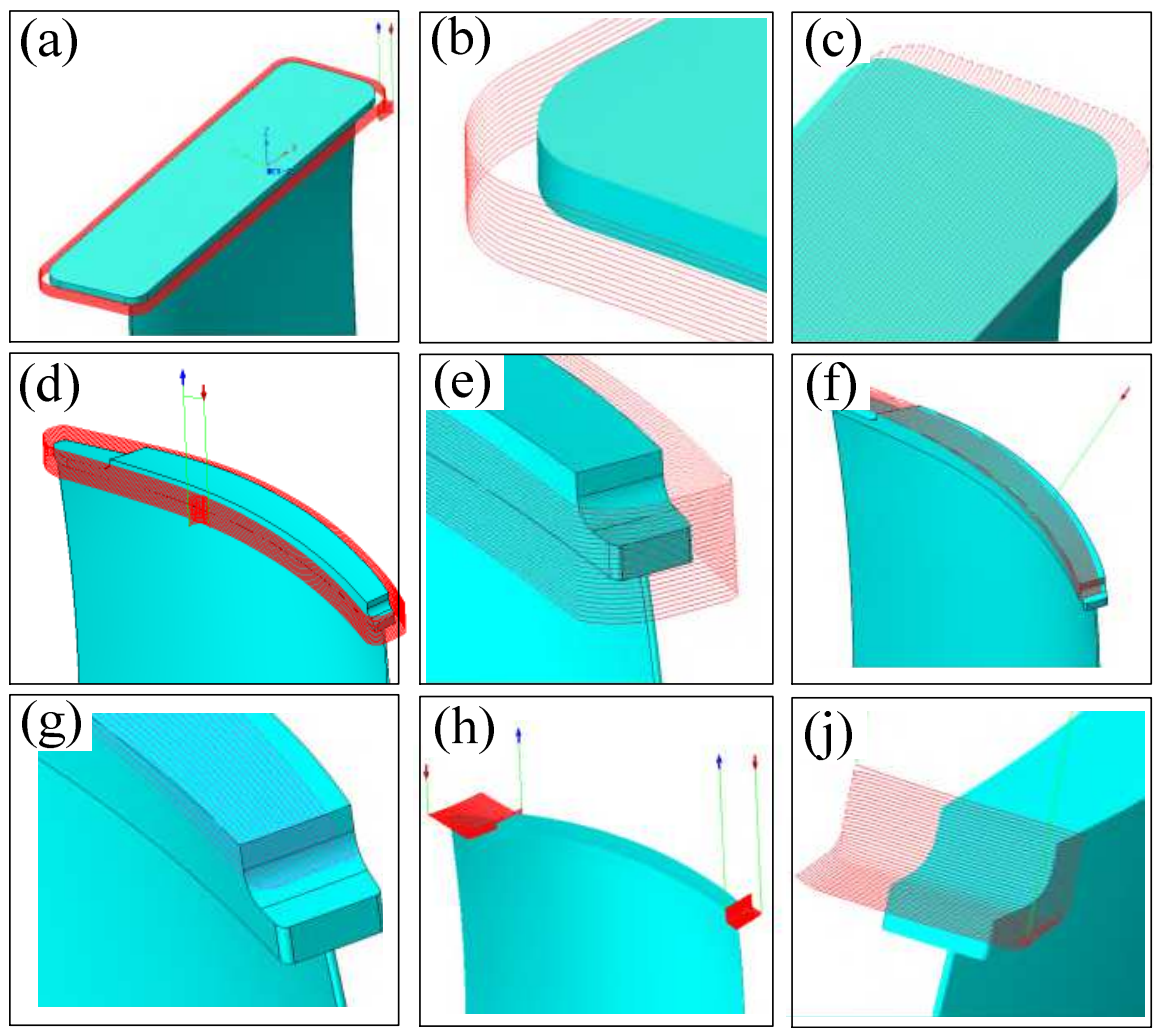

Fig. 12 Tool path for finishing machining of blade tenon root and tip,

(a)-(j) CNC machining model of blade tenon root and tip

In this case, the $\mathrm{CNC}$ machining process is mainly intended to improve the surface quality of the blade tenon root and tip. A ball-nosed cutter is selected to directly mill the $\mathrm{R} 1 \mathrm{~mm}$ area for high-precision milling. Water-based cutting fluid is selected as the lubricating fluid to cool the cutting process. The specific process parameters are shown in Table 2, and the tool paths of each region are shown in Figure 12. The cutting process is at a high speed of $12000 \mathrm{rpm}$, and the milling depth is $0.02 \mathrm{~mm}$. The experimental site is shown in Figure 13.

Table 2 Main machining parameters for blade finishing milling process

\begin{tabular}{llll}
\hline $\begin{array}{l}\text { Finishing } \\
\text { machining }\end{array}$ & $\begin{array}{l}\text { Spindle speed } \\
12000 \mathrm{rpm}\end{array}$ & $\begin{array}{l}\text { Feed rate } \\
1000 \mathrm{~mm} \text { per minute }\end{array}$ & $\begin{array}{l}\text { Cutting depth } \\
0.02 \mathrm{~mm}\end{array}$ \\
\hline Workpiece & Ti-6Al-4V & & \\
Cutter & Radius: R1 mm & & \\
& Ball-end cutter & & \\
& Coated carbide & & \\
Workshop & $20^{\circ} \mathrm{C}$ & \\
Temperature & & & \\
Cutting fluid & Water-based & & \\
\hline
\end{tabular}


cutting fluids
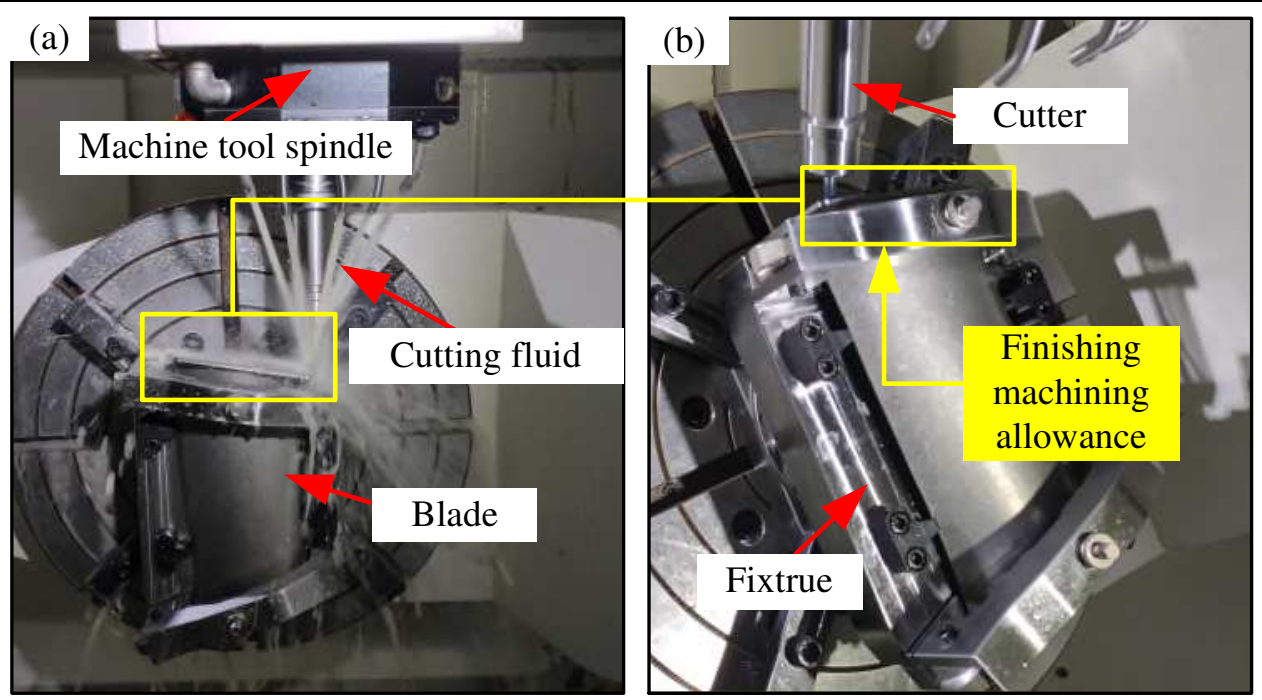

Fig. 13 CNC finishing machining of blade

Finally, the surface quality of the blade after the adaptive CNC machining process is obtained based on the on-machine measurement and the three-dimensional (3D) morphology. The 3D morphology of the blade surface under the clamping force and the milled surface is measured to determine whether local damage occurs. The 3D white light interference surface topography instrument is used to measure the microtopography of the blade surface. The 3D white light interference surface topography instrument is based on the non-contact white light scanning interference principle. The device uses closed-loop feedback piezoelectric ceramics and high linear capacitance sensors to ensure that the precision testing is in the full range of $0.1-150$ $\mu \mathrm{m}$, the repeatability of the RMS is $0.005 \mathrm{~nm}$, the resolution is $0.1 \mathrm{~nm}$, and the surface roughness test accuracy is less than $\mathrm{Ra} 0.1 \mathrm{~nm}$. The 10x lens group is used in this experiment.

\section{Results and discussion}

\subsection{Adaptive CNC machining process for the positioning benchmark error control}

Figure 14 shows the results of the adaptive $\mathrm{CNC}$ machining process for the positioning benchmark error control. It can be seen from Figure 14 that the blade measurement model is far from the theoretical model in the initial installation state relative to the theoretical contour of the blade due to the existence of the initial geometric accuracy of $0.008-0.05 \mathrm{~mm}$, and the single-point deviation value of the blade convex profile is 
greater than $0 \mathrm{~mm}$, while the single point deviation value of the blade concave profile is less than $0 \mathrm{~mm}$ (see Figure 14 (a)). In the first stage of the adaptive CNC machining process regulation, the single-point deviation values of the blade convex profile are all greater than $0 \mathrm{~mm}$, some of the single-point deviation values of the blade concave profile are less than $0 \mathrm{~mm}$, and some of the values are greater than $0 \mathrm{~mm}$. The adaptive adjustment stage plays a very important regulation role in the blade concave profile (see Figure 14 (b)). In the second stage of adaptive CNC machining process regulation, the single-point deviation values of the blade convex profile are all greater than $0 \mathrm{~mm}$, some of the single-point deviation values of the blade concave profile are less than 0 $\mathrm{mm}$, and some of the values are greater than $0 \mathrm{~mm}$. The number of points with deviation values greater than $0 \mathrm{~mm}$ has increased (see Figure 14 (c)). The role of adaptive regulation in the dorsal part of the blade concave profile is more obvious. In the final stage of the adaptive $\mathrm{CNC}$ machining process regulation, the single-point deviation values of the blade convex profile are all greater than $0 \mathrm{~mm}$, and the single-point deviation values of the blade concave profile are all greater than $0 \mathrm{~mm}$, which shows that the adaptive $\mathrm{CNC}$ machining process control stage makes the single deviation value of the blade concave profile change from negative values to positive values. It should be noted that the measurement values of measurement points $\boldsymbol{A}$ and $\boldsymbol{B}$ in Figure 14 have no obvious changes in the entire adaptive $\mathrm{CNC}$ machining process. Therefore, these two points can be understood as invalid measurement points and must be eliminated in the subsequent analysis.

In fact, the blade body surface has an initial geometric accuracy of $0.008-0.05 \mathrm{~mm}$ compared with the theoretical model, which results in a benchmark error, and the benchmark error is a positive error, which shows that the blade is in the correct position only when the single-point deviation values of the blade convex profile and the concave profile are all positive values, and the measuring points are evenly distributed on both sides of the theoretical profile of the blade. 

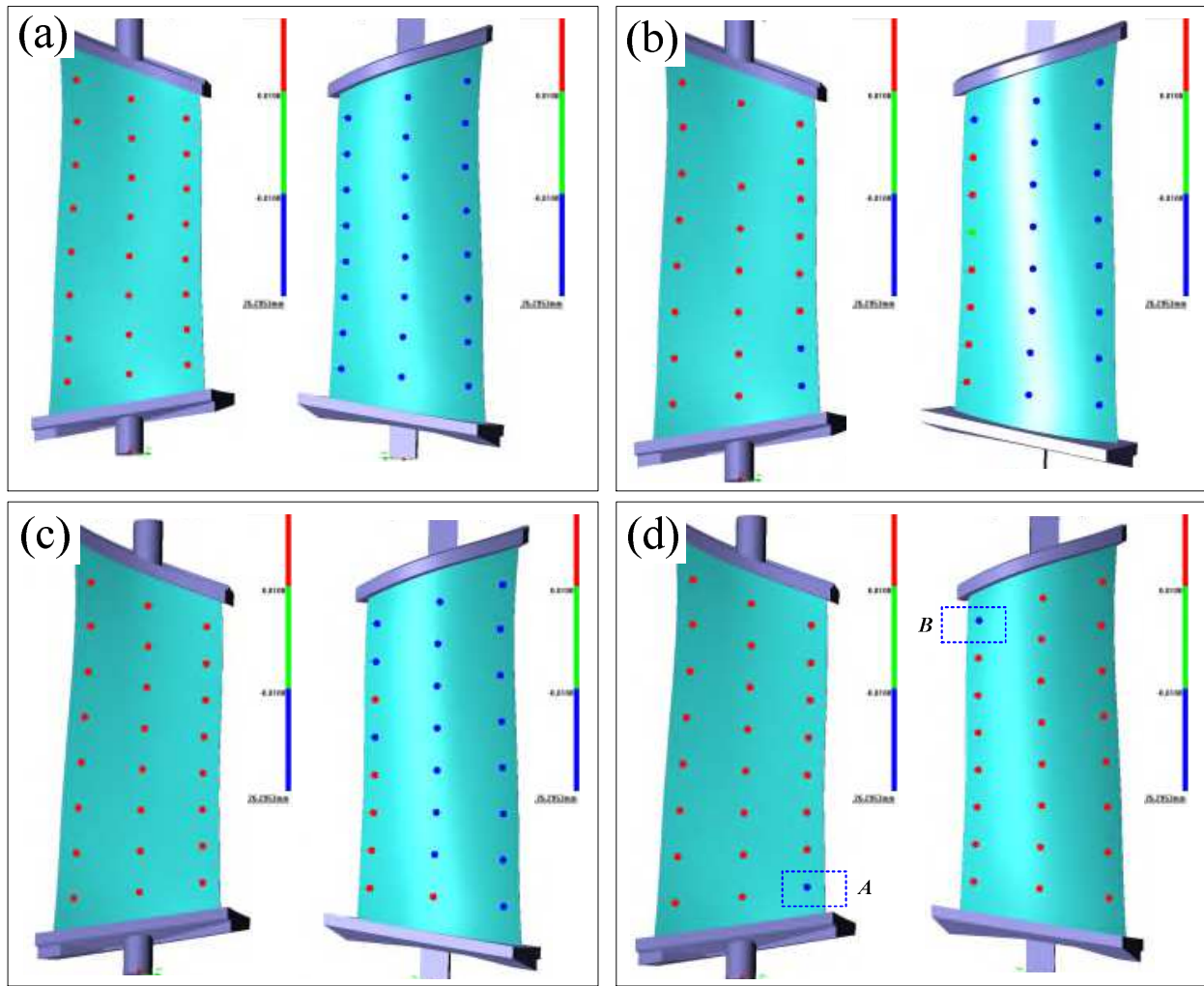

Fig. 14 Single-point deviation of blade concave profile and blade convex profile, (a) In the initial installation state, (b) In the first stage of adaptive regulation, (c) In the second stage of adaptive regulation, (d) For the final adaptive regulation.

The single-point deviation values corresponding to Figure 14 are shown in Figure 15 (a). It can be seen that the initial geometric deviation of the blade is evenly distributed on the theoretical surface of the blade after multiple adaptive regulation, and the single-point deviation of the blade concave profile and the blade convex profile effectively becomes positive with the adaptive regulation. Figure 15 (b) shows that the single-point deviation change value of the blade convex profile is positive in the first stage of adaptive regulation, which shows that the single-point deviation value of the blade convex profile exhibits negative compensation, while the single-point deviation change value of the concave profile is negative, which indicates that the single-point deviation value of the concave profile is positively compensated for. In this way, the two-way compensation of the blade concave profile and the blade convex profile finally achieves single point deviation uniform distribution. In the final adaptive regulation stage, the single-point deviation change value of the blade concave profile and the blade convex profile becomes $0 \mathrm{~mm}$, which indicates that the maximum adaptive regulation has been reached at this time. The blade adaptive regulation has obtained the best regulation performance. It can be considered that the position and posture of the blade 
have been adjusted to the maximum suitable position and attitude.
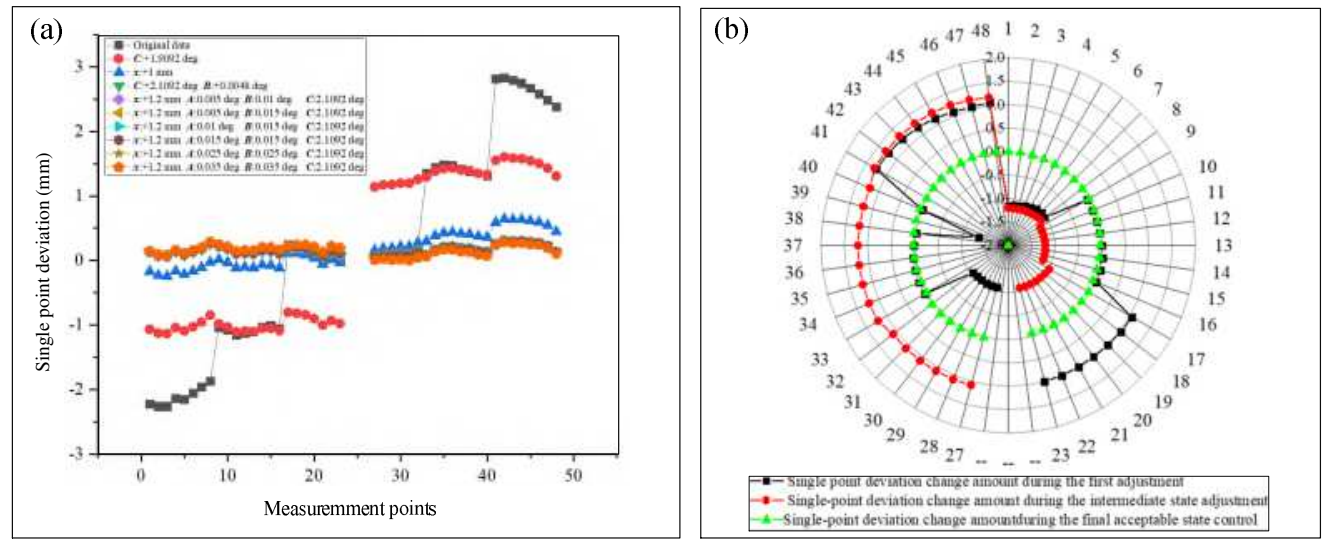

Fig. 15 Single-point deviation value during adaptive regulation, (a)

Deviation value, (b) Deviation change value.

Figure 16 shows the single-point deviation value during the precise adjustment at the end of the adaptive regulation stage. It can be seen that the single-point deviation value during the precise adjustment at the end of the adaptive regulation stage becomes very evenly distributed. However, due to the existence of the initial deviation of the blade geometry of $0.008-0.05 \mathrm{~mm}$, this geometry deviation cannot be completely reduced. However, if these positive geometric deviations are evenly distributed on both sides of the theoretical model of the blade, the benchmark error at this time will be completely reduced, and the position of the blade tenon root can be guaranteed.
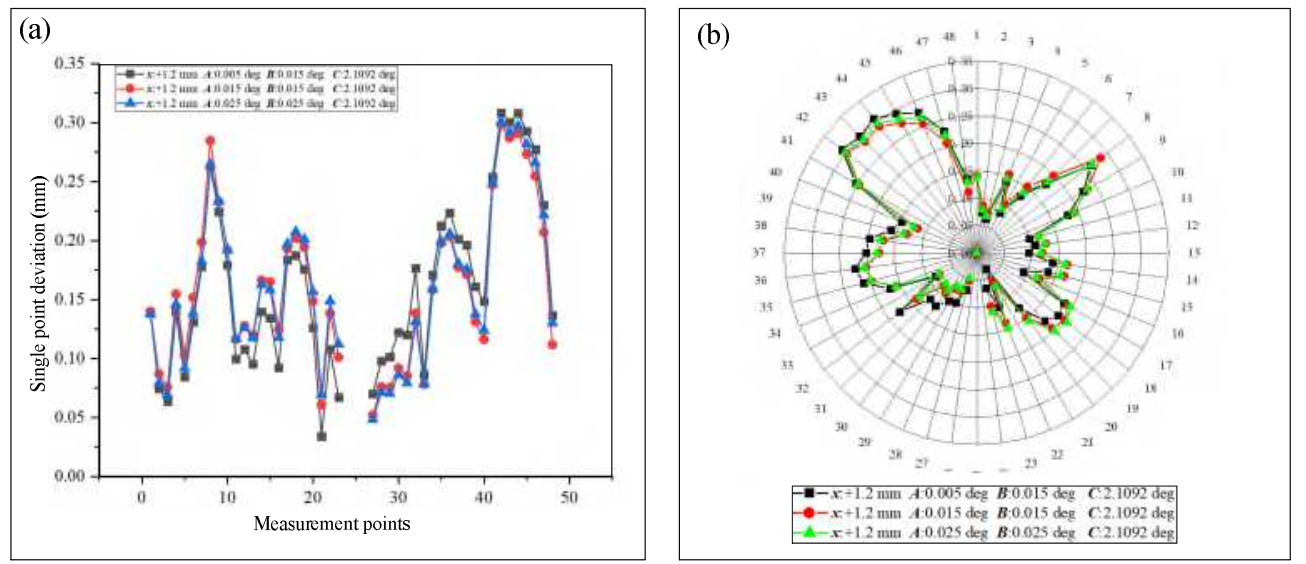

Fig. 16 Single-point deviation value during the precise adjustment at the end of the adaptive regulation stage, (a) Deviation value, (b) Radar chart of single point deviation.

In summary, the single point deviations of the blade concave profile and the blade convex profile are all positive, and they tend to be uniform through adaptive adjustment due to the existence of the initial deviation of the blade geometry of $0.008-0.05 \mathrm{~mm}$. At this time, it can be considered that the blade is in the correct position, and the position 
of the blade tenon root relative to the blade body has been obtained. Therefore, the adaptive $\mathrm{CNC}$ machining process reasonably reduces the inconsistent error of the initial geometric accuracy. However, the prerequisite is that these single-point deviation values must all be positive. This method is only feasible for the case of positive margins, and these positive margins can be evenly distributed on both sides of the blade theoretical model. Therefore, it must be noted that this method cannot be used when the blade margin is negative.

Therefore, it can be concluded that the adaptive CNC machining process can reasonably reduce the machining error of the near-net-shaped blade caused by the positioning benchmark when the positioning surface margin of the near-net-shaped blade is positive and the positive margin of the positioning benchmark surface is evenly distributed on both sides of the theoretical model by the adaptive CNC machining process.

\subsection{Adaptive CNC machining process for machining position error control}

The machining position error refers to the position deviation of the blade tenon root relative to the blade body. Relatively, the deviation value of the measurement point on the blade body can be used to indicate the position error of the blade tenon root when the blade tenon root is used as the measurement benchmark. Figure 17 shows the deviation between the blade on-machine measurement model and the blade theoretical model. Figure 17 (a) shows the deviation value obtained during the first measurement process after the blade is clamped, and the specific deviation distribution value is shown in Figure 18. It can be seen that deviation values of some measurement points of the blade body are negative values (less than $0 \mathrm{~mm}$ ), while the deviation values of some measurement points are positive values (more than $0 \mathrm{~mm}$ ), and the overall position of the blade is inclined in this case. The amount of inclination is caused by the unstable blade clamping process when the displacement deviation also includes the initial deviation of the blade geometry. 


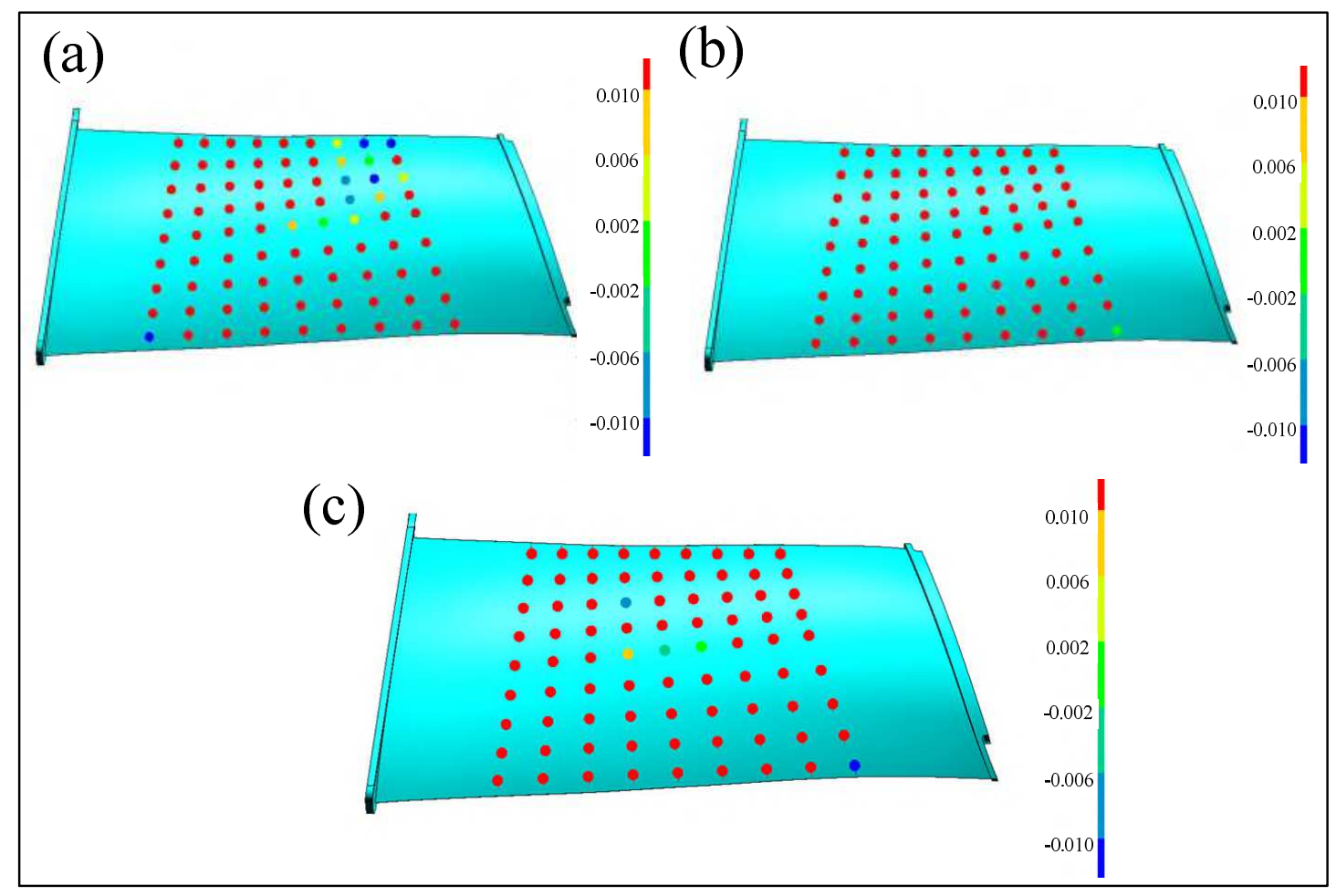

Fig. 17 Measurement results of blade body deviation, (a) The measurement results of the first installation state, (b) The measurement results of the adaptive adjustment intermediate state, (c) The measurement results of the adaptive adjustment final acceptable intermediate state.

Figure 17 (c) shows the blade body deviation value obtained through the adaptive CNC machining process adjustment. The specific deviation distribution value is shown in Figure 18. It can be seen that the overall deviation value of the blade tends to be stable. Figure 17 (b) shows the intermediate process of the intermediate adaptive CNC machining process. Figure 17 (c) shows the final acceptable deviation range after repeated iterations of the adaptive $\mathrm{CNC}$ machining process. 


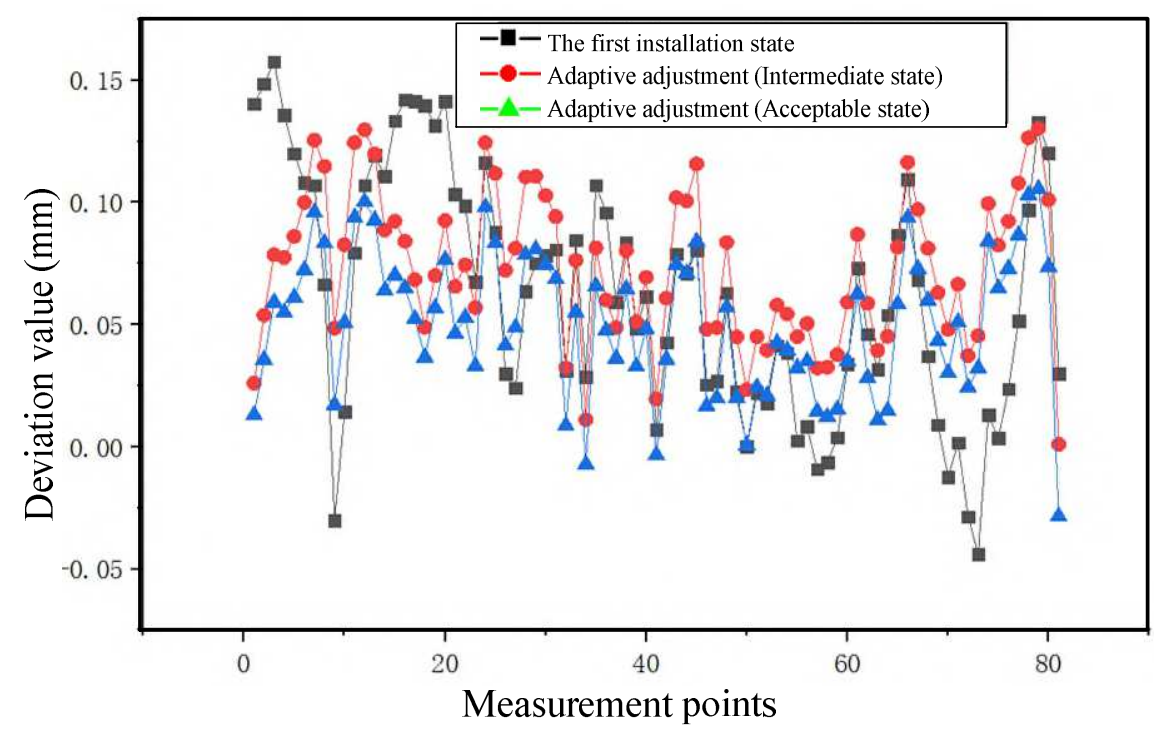

Fig. 18 Measurement point deviation numerical distribution of blade body

Specifically, the adjustment process from Figure 17 (a) to Figure 17 (c) is the overall position rotation and translation process of the blade. In the blade adaptive CNC machining adjustment, an initial translation matrix and a rotation matrix are given first, and then an iterative process is used to repeatedly solve the matching objective equation, which is shown in Formula 5. Finally, a rotation matrix and a translation matrix are determined in order to obtain the final adaptive adjustment position of the blade. The deviation variation amount of the blade position during the adjustment process is shown in Figure 19 (b).
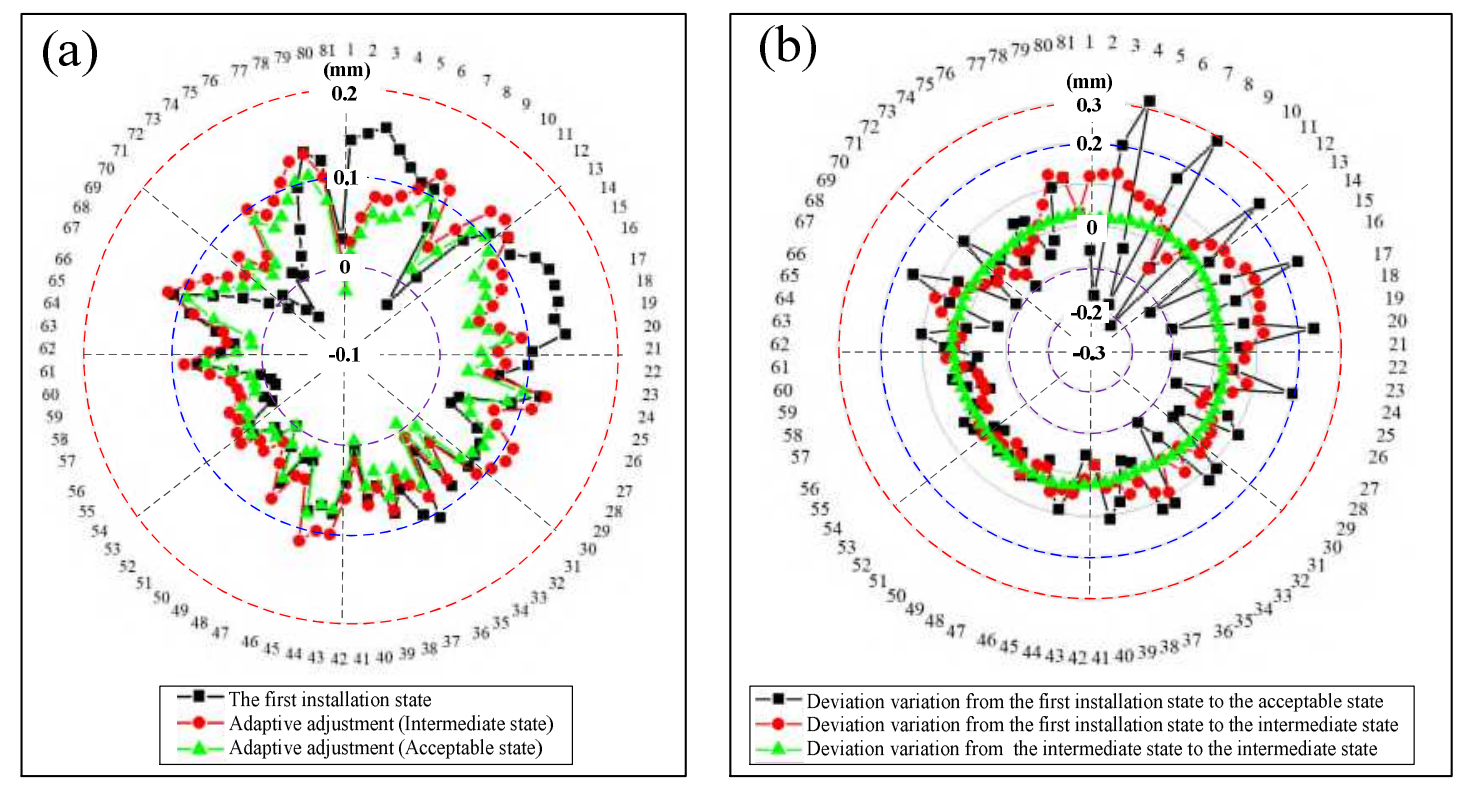

Fig. 19 Deviation numerical distribution of variation of blade body,

(a) Deviation value, (b) Deviation variation amount

The blade body deviation is distributed regularly (see Figure 19 (b)) through the 
blade adaptive adjustment. Figure 19 (b) is the distribution of the deviation variation of the blade during the adaptive adjustment. The deviation variation of the blade is large during the intermediate state of the adaptive adjustment after the clamping is completed, which indicates that the adaptive adjustment plays a key role in the blade position, which has an obviously regulatory effect at this time.

The deviation variation amount is basically $0 \mathrm{~mm}$ during the last adaptive adjustment, which is the acceptable final position of the blade at this time, and the upper limit of the position adjustment capability has been reached, which means that more iterations will be meaningless and the iteration should be stopped.

Table 4 Blade machining position error control capability of adaptive CNC machining

\begin{tabular}{lccccc}
\multicolumn{5}{c}{ process } \\
\hline Machining & Average & Variance & Upper & Lower & Deviation \\
position error & value $(\mathrm{mm})$ & & deviation & deviation & \\
adjustment & $\overline{\mathrm{X}}$ & $\sigma$ & $\bar{x}-3 \sigma$ & $\bar{x}+3 \sigma$ & $6 \sigma$ \\
\hline Clamping state & 0.0631 & 0.0025 & 0.0556 & 0.0706 & 0.015 \\
Acceptable state & 0.0507 & $8.4245 \mathrm{e}-04$ & 0.0482 & 0.0532 & 0.005 \\
\hline
\end{tabular}

Table 4 is the blade machining position error control capability of the adaptive CNC machining process. The corresponding normal distribution curve is shown in Figure 18. For these 80 measuring points on the blade body, the lower deviation of the measurement model relative to the theoretical model is reduced from $0.0556 \mathrm{~mm}$ to $0.0482 \mathrm{~mm}$ after the blade position adjustment by the adaptive $\mathrm{CNC}$ machining process, and the upper deviation of the blade is reduced from $0.0706 \mathrm{~mm}$ to $0.0532 \mathrm{~mm}$, and the blade deviation band is reduced from $0.015 \mathrm{~mm}$ to $0.005 \mathrm{~mm}$, which is reduced by $60 \%$. It can be seen that the adaptive $\mathrm{CNC}$ machining process has good machining position error control ability. 


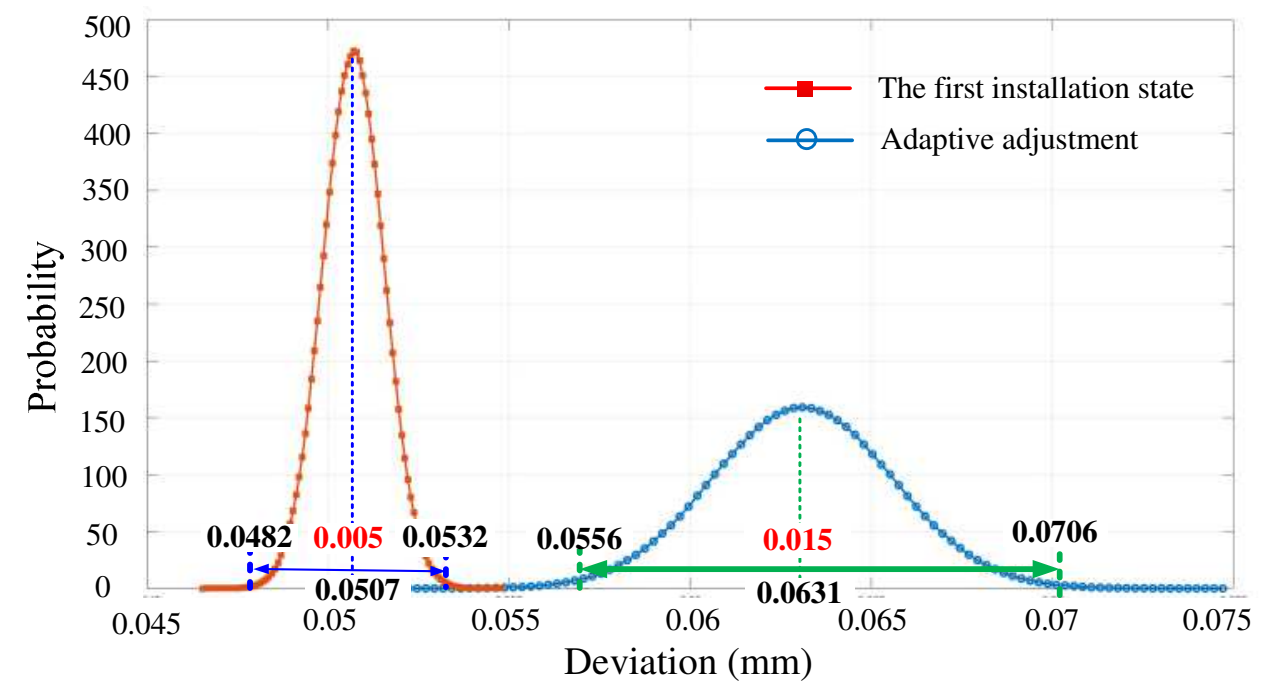

Fig. 20 Normal distribution of blade body deviation value

In the comprehensive comparison analysis, the adaptive adjustment is very reasonable for optimizing the blade position after clamping. The blade body position obtained at this time is used as the benchmark surface to complete high precision the $\mathrm{CNC}$ machining process of the blade tenon root. A more accurate fit between the actual position of the blade body surface and the theoretical surface is obtained with the blade position adaptive adjustment according to the above-mentioned measurement results.

Therefore, it can be concluded that the adaptive CNC machining process has good positioning errors control ability for the near-net-shaped blade, and the lower deviation of the measurement model relative to the theoretical model of the 80 measuring points of the blade body is reduced from $0.0556 \mathrm{~mm}$ to $0.0482 \mathrm{~mm}$ after the blade position and posture adjustment by the adaptive CNC machining process. The upper deviation of the blade is reduced from $0.0706 \mathrm{~mm}$ to $0.0532 \mathrm{~mm}$, and the blade deviation band is reduced from $0.015 \mathrm{~mm}$ to $0.005 \mathrm{~mm}$, which is a reduction of $60 \%$.

\subsection{Adaptive CNC machining process of contouring error control}

Figure 21 shows the deviation of the blade tenon root side obtained with the adaptive CNC machining process. Figure 21 (a) shows the blade position on the fixture after the roughing machining process. It can be seen that the machined blade position deviation from the theoretical model is in the area of $-1.0 \mathrm{~mm}$ to $0.7 \mathrm{~mm}$. In order to correlate the stiffness of the blade-fixture system and the adaptive CNC machining process, it is assumed that these large deformations exist. However, such large deformations may not appear in the actual CNC machining process. This assumption is made to reveal the ability of the adaptive $\mathrm{CNC}$ machining process to control the blade position error and 
the contouring error with the condition of insufficient rigidity. It is assumed that there is a large deviation in the roughing process for the large cutting force and the weak stiffness blade-fixture system. Obviously, such a large position deviation will inevitably cause a larger machining error copy phenomenon according to the machining error transmission model (Formula 3 and of Figure 3). The machining error copy phenomenon will cause the size of the final blade tenon root to be seriously uncontrollable, and the low machining accuracy blade tenon root will lead to an unqualified blade.

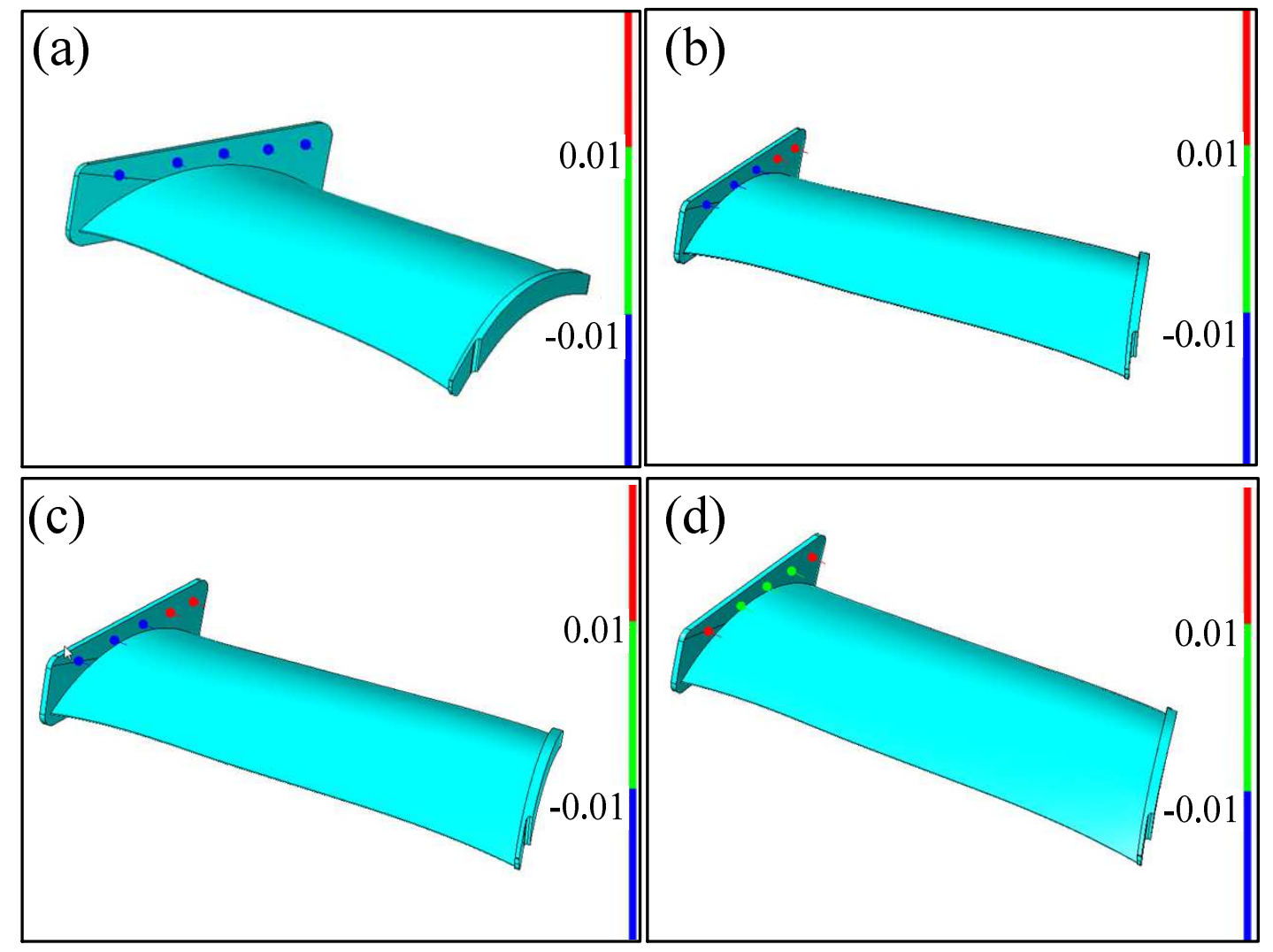

Fig. 21 The deviation value of the blade tenon root side adaptive adjustment, (a) The first adaptive adjustment deviation values, (b) The second adaptive adjustment deviation values, (c) The third adaptive adjustment deviation values, (d) The final acceptable adaptive adjustment deviation values. 

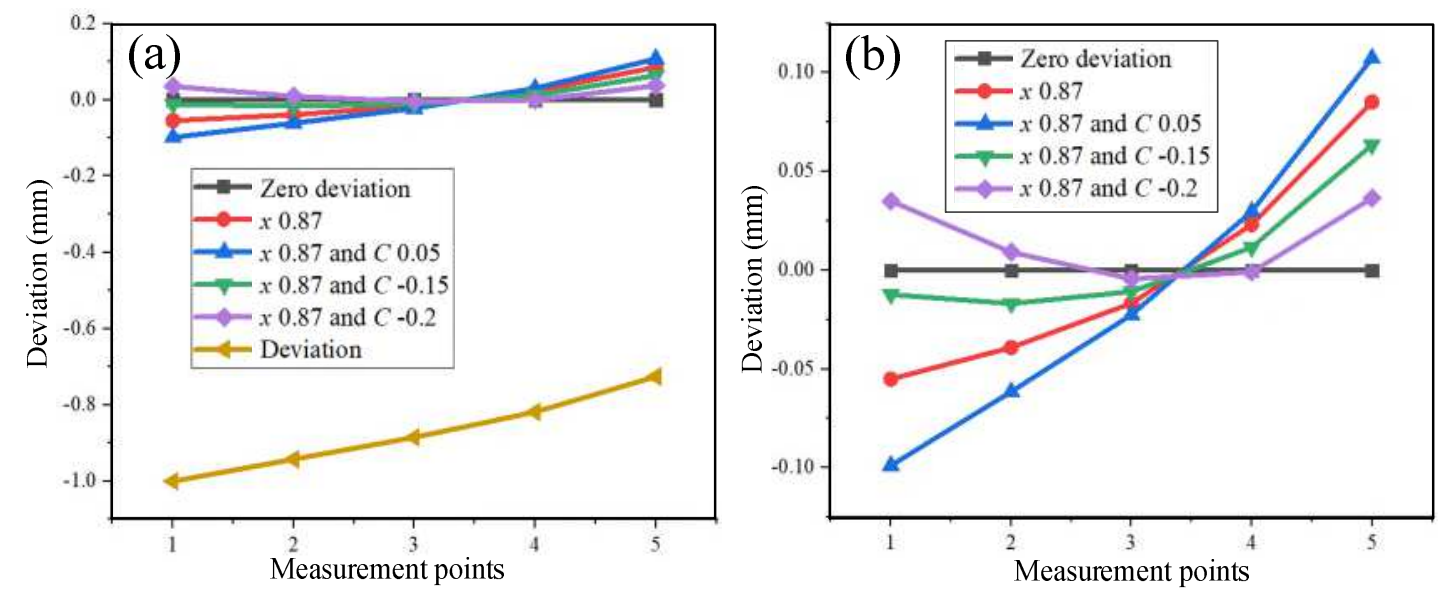

Fig. 22 Deviation curve of blade tenon root, (a) Translation process,

(b) Rotation process

However, the adaptive CNC machining process will cut off this machining error transfer mode according to the previously discussed theoretical models (see Figure 2, Figure 3, and Figure 5). Specifically, in the experimental results, Figure 21 (b) shows the position and status deviation after the first blade adaptive adjustment. The adjustment method is to move $0.87 \mathrm{~mm}$ along the $x$-axis direction, and the translation matrix is:

$$
T=\left[\begin{array}{lll}
0.87 & 0 & 0
\end{array}\right]^{T}
$$

The position of the blade tenon root is distributed around the blade theoretical model into a diagonal line (see Figure 22 (a)) after the blade translation. The position of the blade is tilted, and the blade needs to be rotated along the $C$-axis.

Figure 21 (c) shows the position and status deviation after the second blade adaptive adjustment. The adjustment method is to rotate 0.05 degree along the $C$-axis direction, and the rotation matrix is:

$$
R_{1}=\left[\begin{array}{ccc}
0.9999 & 0.0008 & 0 \\
-0.0008 & 0.9999 & 0 \\
0 & 0 & 1
\end{array}\right]
$$

There are not significant changes in the position deviation of the blade tenon root after the blade rotation. The position of the blade tenon root is still a diagonal line. However, the angle of the diagonal line will change. This means that the adjustment method of rotating by $0.05 \mathrm{deg}$ along the $C$-axis direction has the opposite effect, which makes the blade deviate further from the blade theoretical position. Therefore, it is necessary to change the direction of rotation around the $C$-axis. Further, the direction 
of the rotation around the $C$-axis is $-0.15 \mathrm{deg}$, and the new rotation matrix is

$$
\mathrm{R}_{2}=\left[\begin{array}{ccc}
0.9999 & -0.0026 & 0 \\
0.0026 & 0.9999 & 0 \\
0 & 0 & 1
\end{array}\right]
$$

Figure 21 (c) shows the position and status deviation after the third blade adaptive adjustment. At this time, the blade position and status are close to the theoretical position. However, the position of the blade tenon root is still a diagonal line distributed around the theoretical deviation of the blade. However, the blade position and the status still deviate from the theoretical position. The deviation is unacceptable and needs further adaptive adjustment. Therefore, the direction of rotation around the $C$-axis needs to be rotated again. Furthermore, the rotation around the $C$-axis direction is $-0.05 \mathrm{deg}$. The rotation matrix is:

$$
R_{3}=\left[\begin{array}{ccc}
0.9999 & -0.0008 & 0 \\
0.0008 & 0.9999 & 0 \\
0 & 0 & 1
\end{array}\right]
$$

Figure $21(\mathrm{~d})$ shows the position and status deviation diagram after the fourth blade adaptive adjustment. At this time, the blade position and status are close to the theoretical position and symmetrically distributed along the theoretical position. Additionally, the blade position and status adjustment are completed, and it can be determined that the contouring error of the blade tenon root side meets the requirements. However, the position error of the blade tenon root relative to the blade body may change after the adaptive adjustment due to the contouring error of the tenon root.

Therefore, it is necessary to monitor the position deviation of the blade body to explore whether the blade body position has greatly changed during this adaptive adjustment, which can ensure the position error of the blade tenon root relative to blade body under the condition of ensuring the key position size of the blade tenon root, which refers to the contour error of the blade tenon root. 


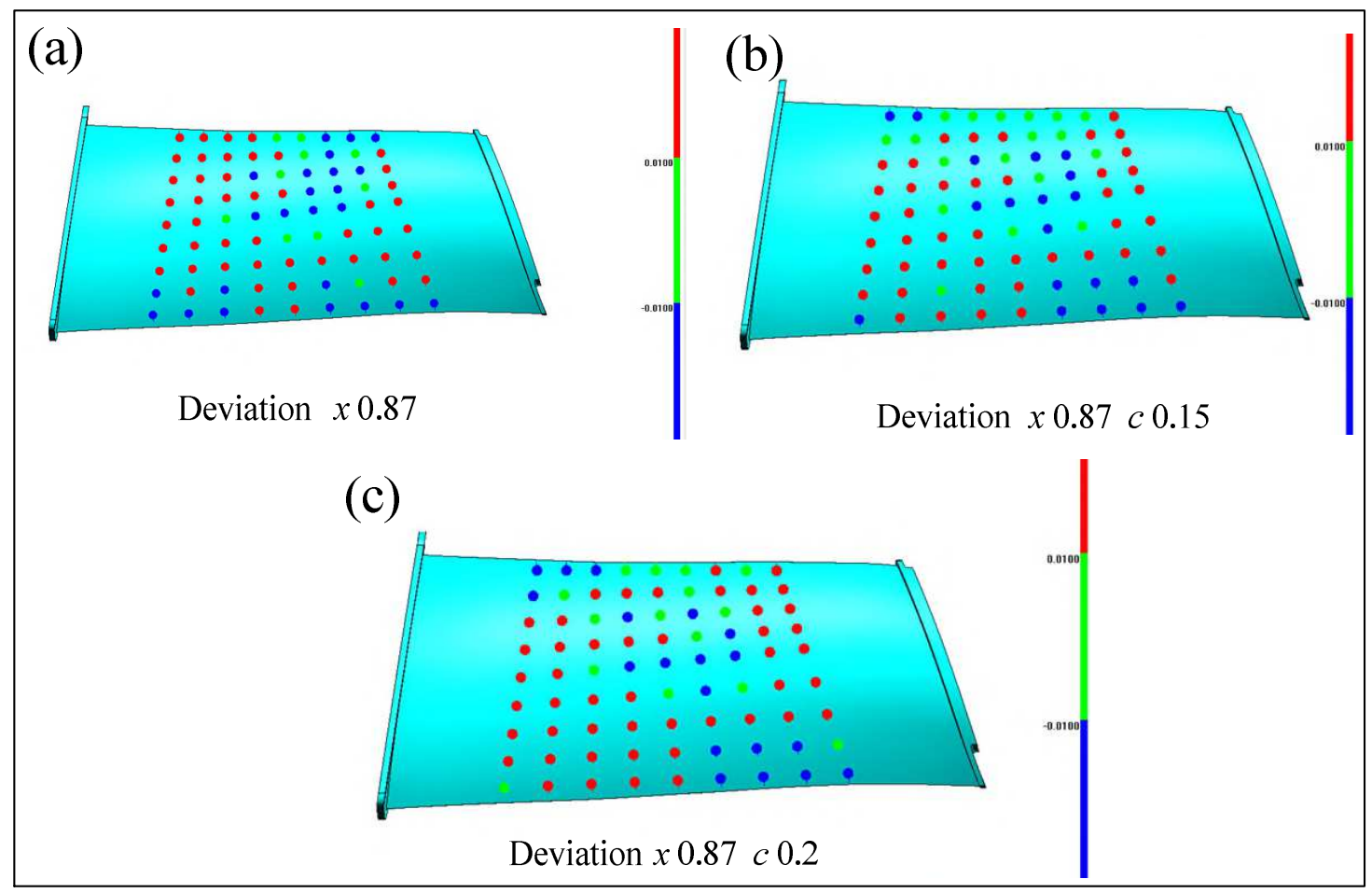

Fig. 23 Deviation of the blade body profile of the adaptive adjustment process corresponding to the measurement data of the tenon root in Figure 21, (a) Translating along $x$ axis $(0.87 \mathrm{~mm})$, (b) Rotating along the $C$-axis $(0.15 \mathrm{deg})$, (c) Rotating along the $C$-axis $(0.2 \mathrm{deg})$

Figure 24 shows the blade body surface deviation data, which is used as the monitoring data when the tenon root side deviation is used as the adjustment target. The corresponding measurement data are shown in Figure 25. It can be seen that the blade body deviation is close to the theoretical data, and the blade body deviation is also controlled with the same rules in the process of rotation and translation. Figure 25 (b) shows the numerical distribution of the variation value of the blade body contour deviation. It can be seen that the deviation becomes smaller during the adaptive adjustment, which indicates that the adaptive adjustment adjusts the position and status of the blade body at this time. 


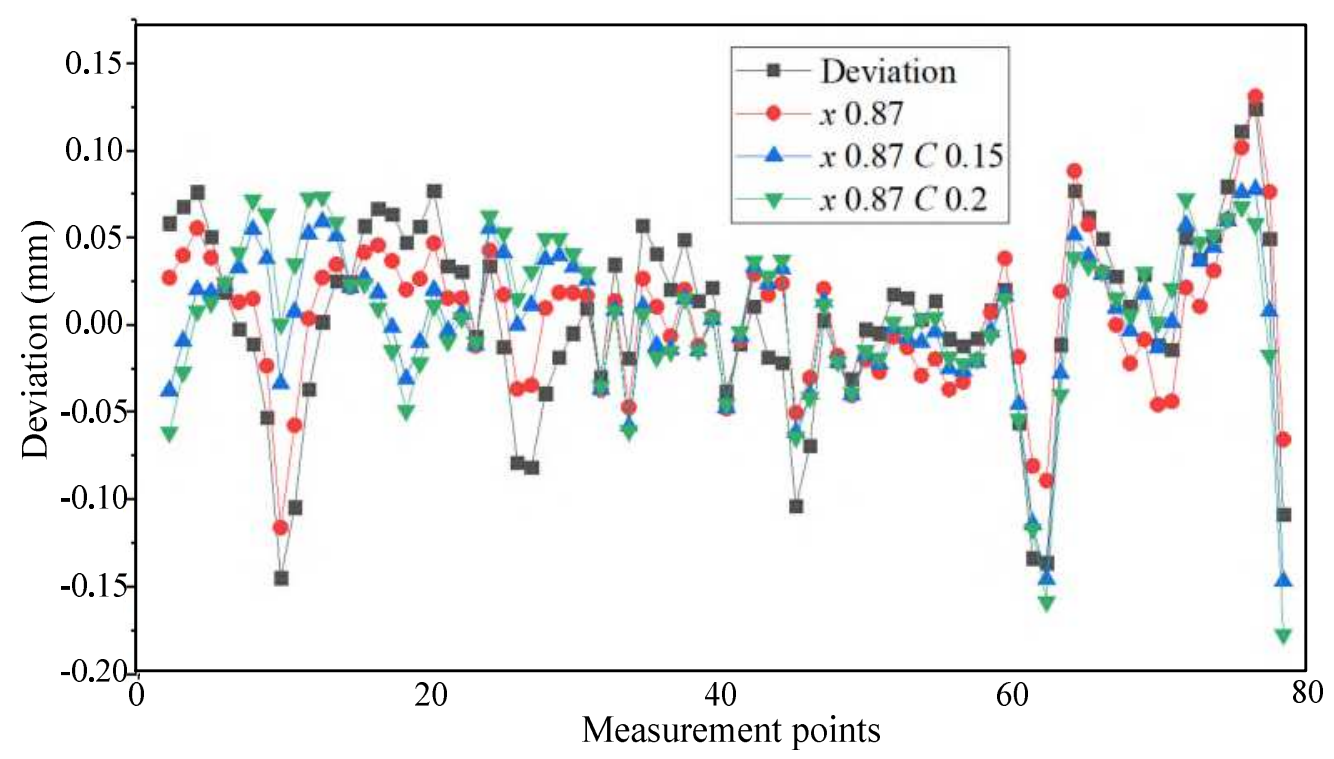

Fig. 24 Profile deviation numerical distribution of blade body

The variation of the deviation amount during the last adjustment is small. The final position and the status of the blade can be adjusted by the blade tenon root side position deviation adaptive adjustment, which reaches the upper limit of the blade position and status adjustment ability. However, it can be seen in Figure 25 (b) that the single-point deviation variation value that reflects the adaptive adjustment capability and the upper limit of adaptive adjustment is not close to $0 \mathrm{~mm}$ at this time, which shows that there is still a big difference between the blade measurement model and the blade theoretical model. The position and the posture of the blade body at this time do not have the best pose compared with Figure 19 (b). The adaptive adjustment process with the goal of minimizing the contouring error of the tenon root pressure surface cannot meet the highest requirements for the position error of the blade tenon root relative to the blade body at the same time. In other words, for the case where the blade has a large displacement deviation produced in the previous CNC machining procedure, the adaptive $\mathrm{CNC}$ machining process cannot accomplish the position error control and contouring error control of the blade at the same time. This experimental phenomenon is particularly important considering the precision requirements of the blade $\mathrm{CNC}$ machining process. Therefore, ensuring the stiffness of the blade-fixture system in the adaptive $\mathrm{CNC}$ machining process is a prerequisite for the adaptive $\mathrm{CNC}$ machining process. 

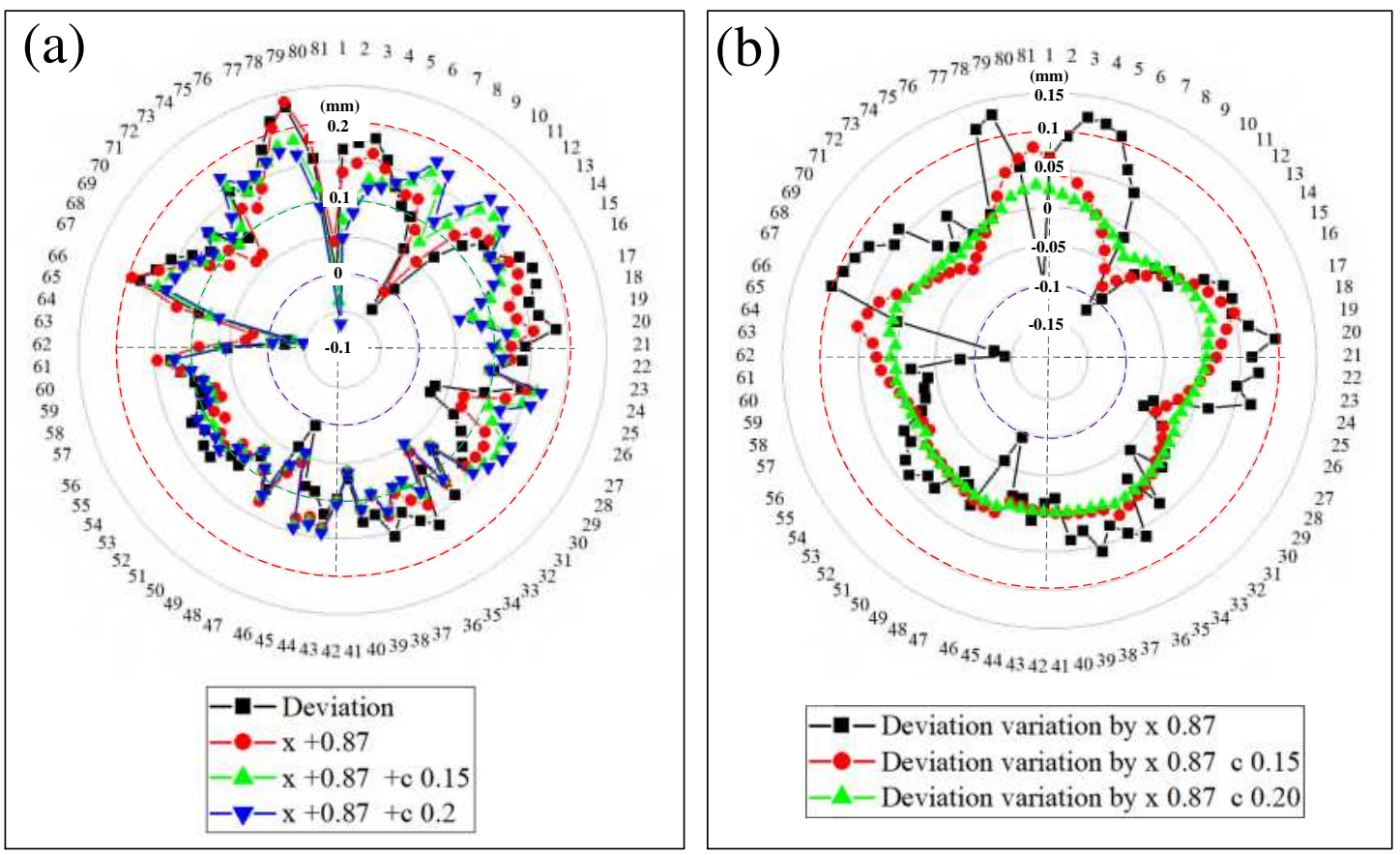

Fig. 25 Numerical distribution of the deviation variation of the blade

body, (a) Deviation value, (b) Deviation variation value

In summary, for the case where the blade has a large displacement deviation produced in the previous $\mathrm{CNC}$ machining procedure, the adaptive $\mathrm{CNC}$ machining process cannot accomplish the position error control and contouring error control of the blade at the same time. The sufficient stiffness of the blade-fixture system in the adaptive $\mathrm{CNC}$ machining process is a prerequisite for the adaptive $\mathrm{CNC}$ machining process.

\subsection{Comprehensive analysis of blade machining error}

Based on the above analysis, for the near-net-shaped blade, the adaptive CNC machining process of the blade is achieved according to the adaptive CNC machining process based on the premise of ensuring the stiffness of the blade-fixture system. The adaptive CNC machining process flow is shown in Figure 5.

Figure 26 shows the machining contouring error of the blade tenon root. Forty measurement points on the side of the blade tenon root are selected (see Figure 26 (a)), and the position deviations of these 40 points relative to the theoretical model are obtained by fitting the 40 points data to obtain the side contouring error of the blade tenon root. It can be seen that the side contouring error of the blade tenon root is below $0.003 \mathrm{~mm}$ (see Figure 26 (b)), which indicates that the adaptive CNC machining process meets the contouring requirement of the blade tenon root, which is less than $0.007 \mathrm{~mm}$. 

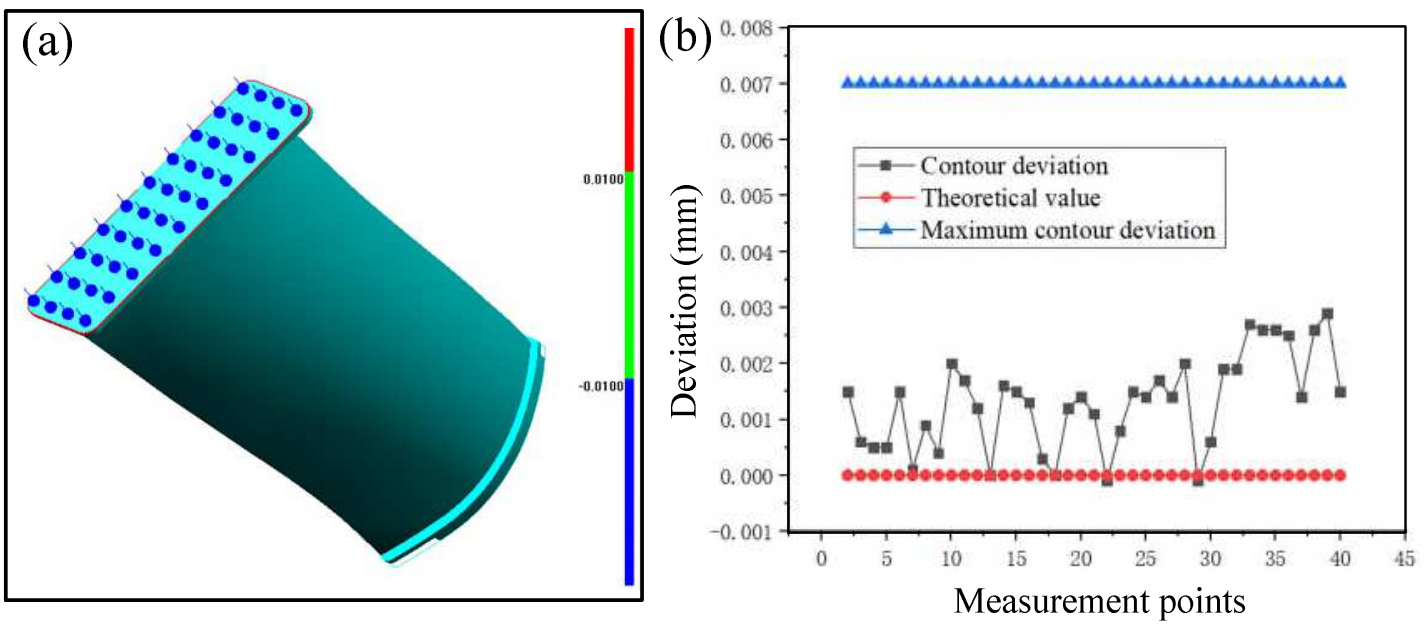

Fig. 26 Contouring error of blade tenon root side, (a) Measurement model, (b) Measurement results 

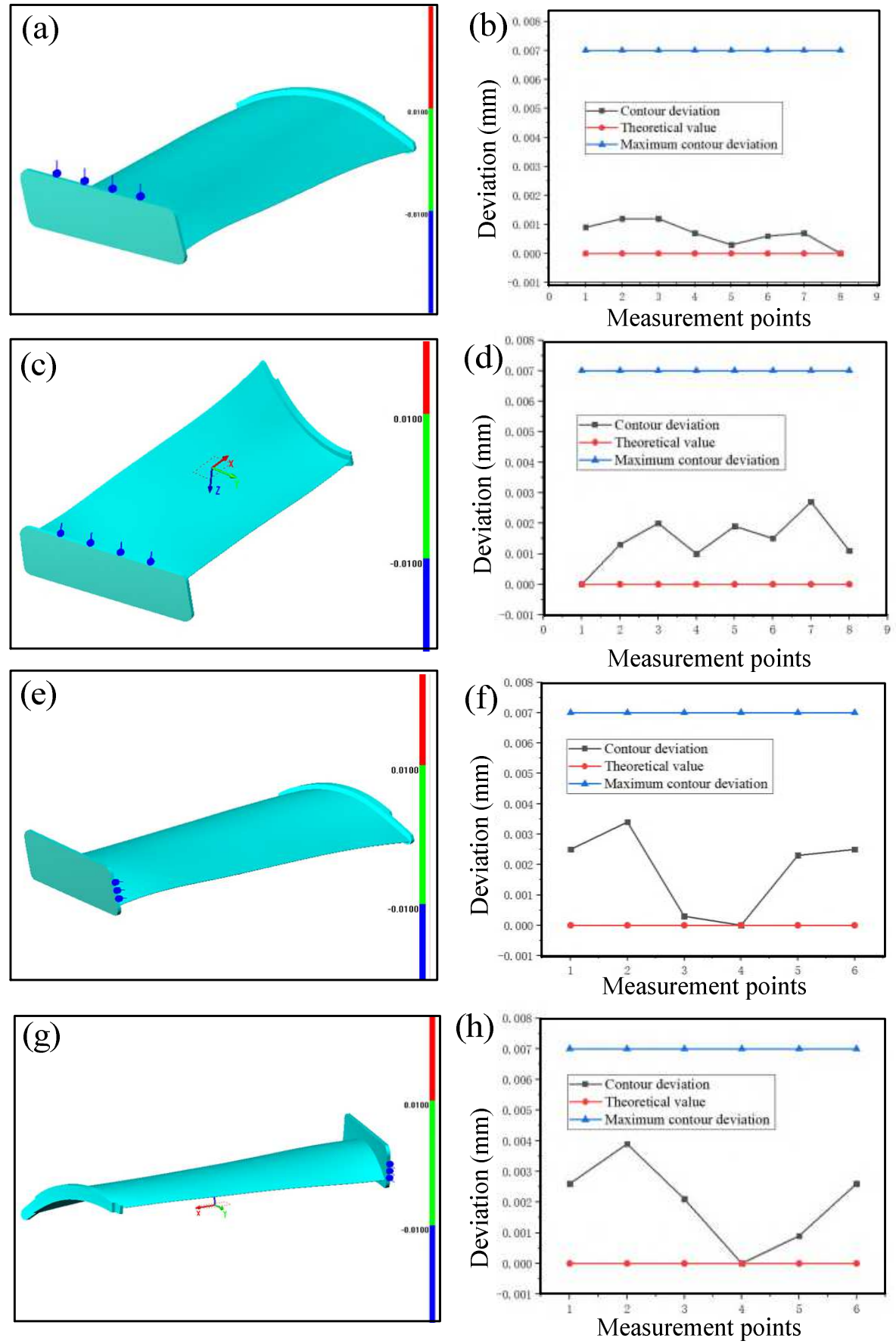

Fig. 27 (a)-(h) Contouring error of blade tenon root

Similarly, the contouring error of the blade tenon root and tip is obtained with the same measuring method. It can be seen that the contouring error of the blade is below $0.003 \mathrm{~mm}$ (see Figure 27 and 28), which shows that the adaptive CNC machining process meets the contouring error requirements of the blade tip and tenon root. 

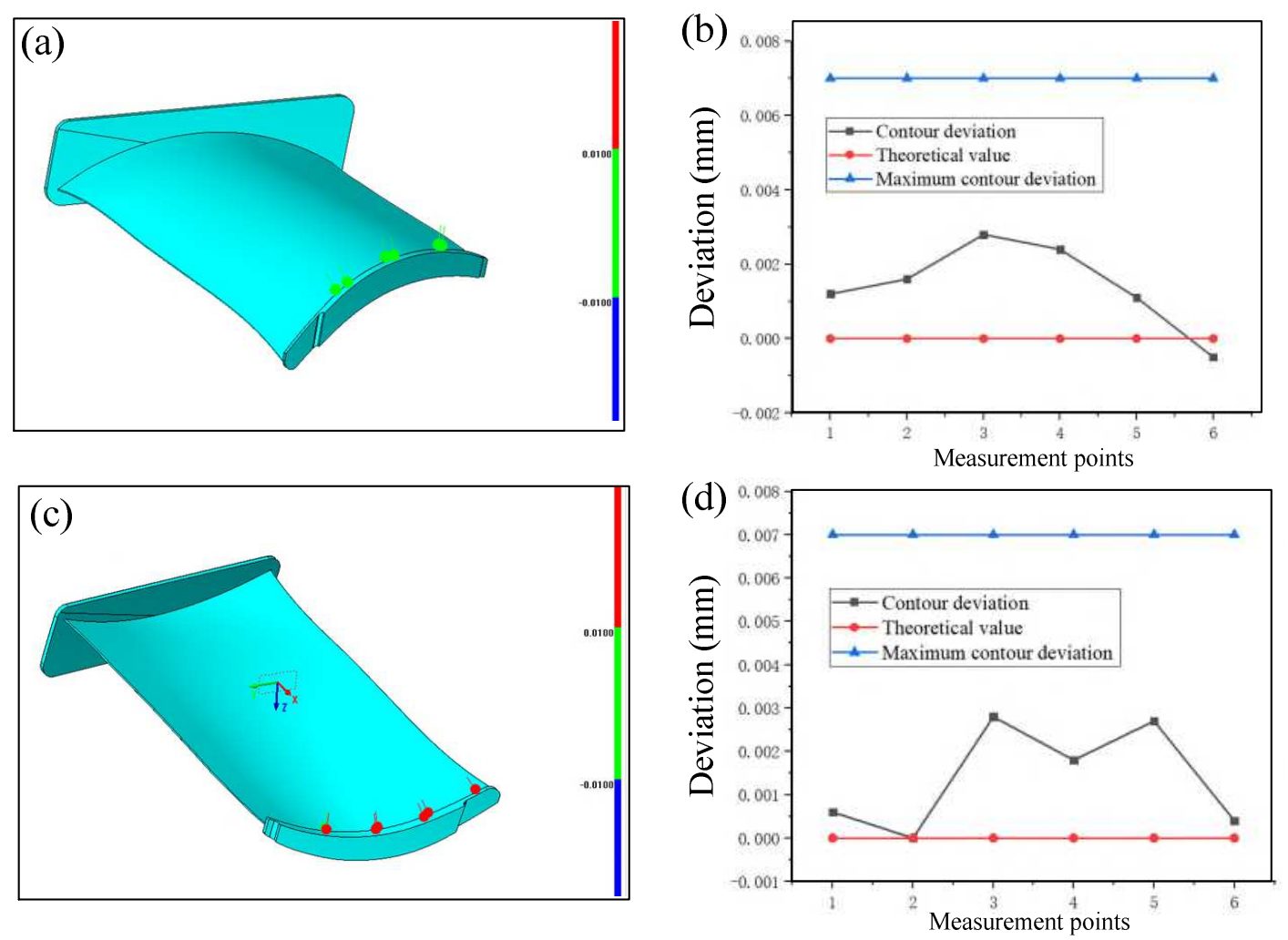

Fig. 28 (a)-(d) contouring error of blade tip

Figure 29 shows the surface roughness test results of different parts of the blade tenon root and tip. It can be seen from the figure that the surface roughness of the flat part of the blade tenon root and tip is below $\mathrm{Ra} 0.2 \mu \mathrm{m}$. The surface roughness at the arc transition and some rounded corners is less than $\mathrm{Ra} 0.4 \mu \mathrm{m}$. This is because the actual cutting depth and the theoretical cutting depth are inconsistent due to the cutting path deviation of the cutter at the arc. In general, the surface roughness of the blade is below $\mathrm{Ra} 0.4 \mu \mathrm{m}$, which meets the requirements of blade surface milling precision. 


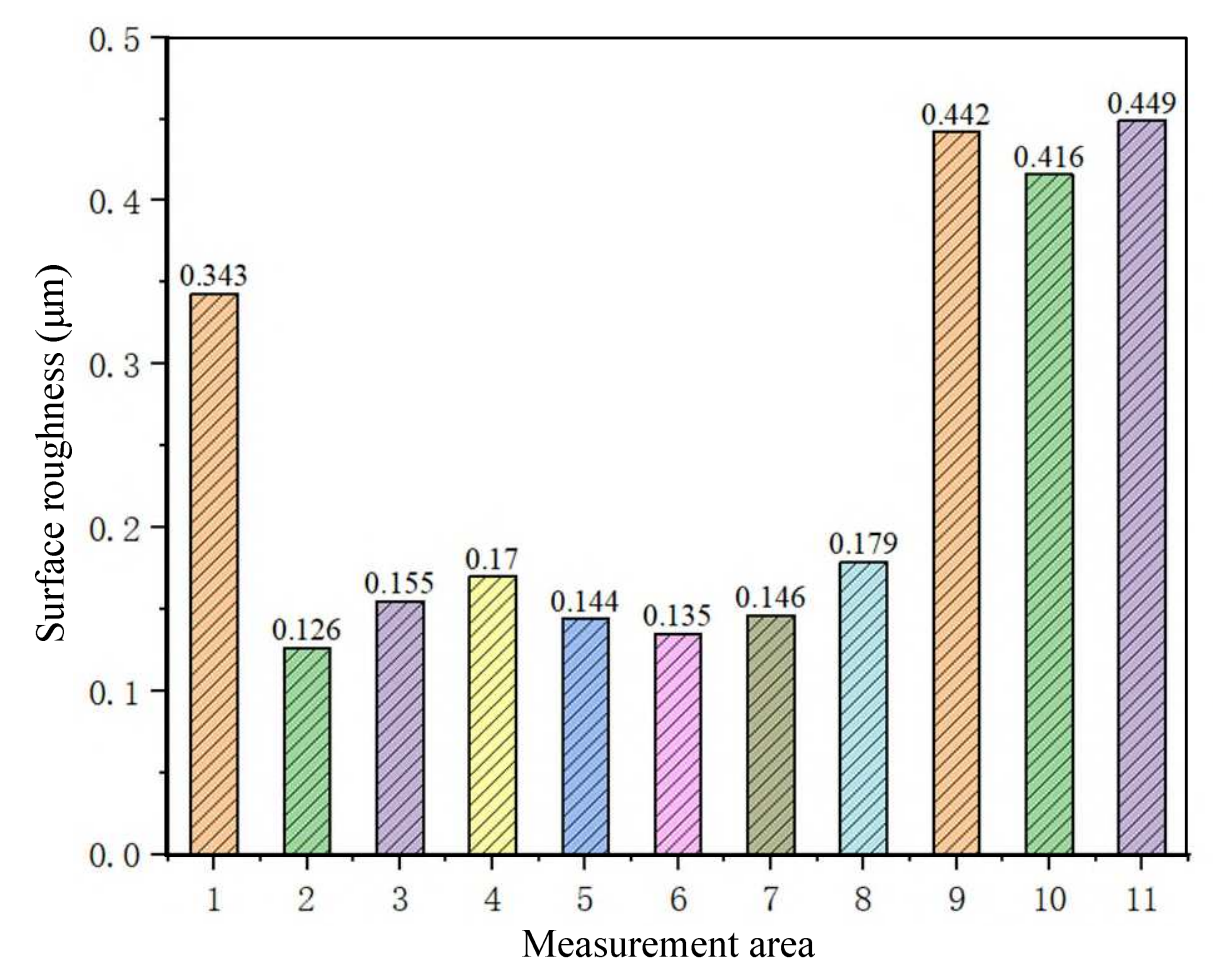

Fig. 29 Blade surface roughness

(a)

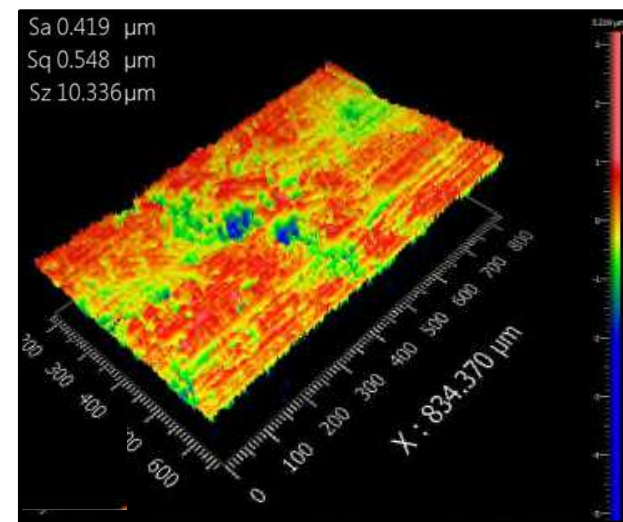

(c)

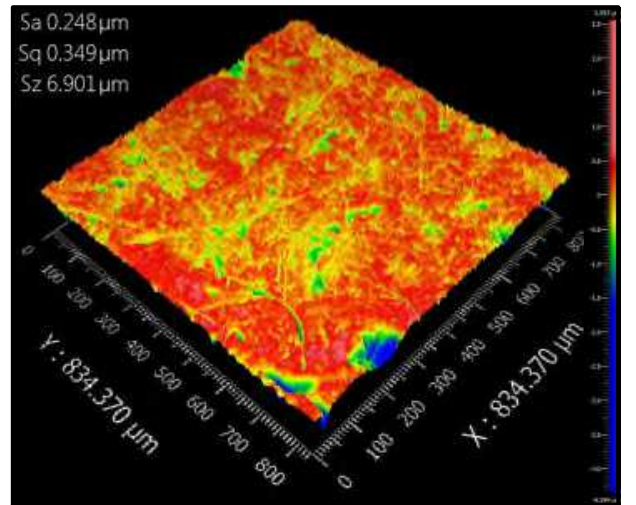

(b)

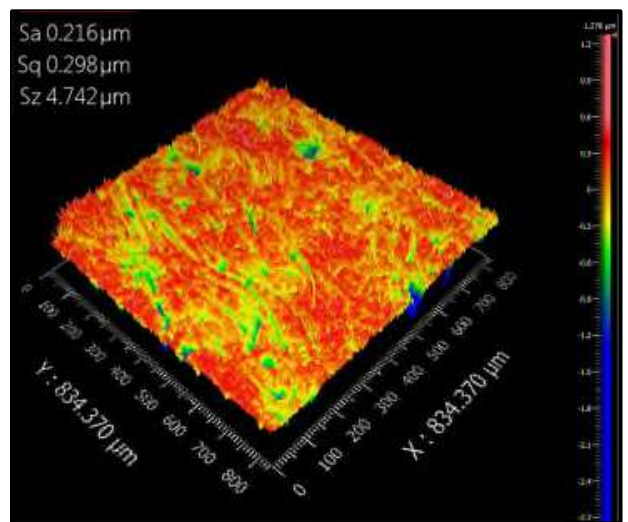

(d)

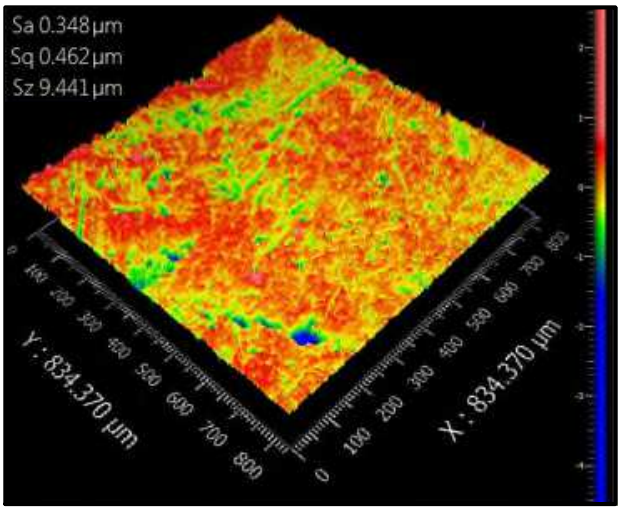

Fig. 30 Micro-morphology of blade body surface, (a)-(d) Different parts of blade

Figure 30 shows the micro-topography of the blade surface. The blade body is formed by the precision forged process, and the surface roughness of the blade after the precision forged process is about $\mathrm{Ra} 0.4 \mu \mathrm{m}$, which meets the blade requirements. 
Figure 30 (a) shows the micro-topography of the blade convex surface, and Figure 30 (b) shows the micro-topography of the blade concave surface. It can be seen that there is not an obvious law for the local small pits on the blade surface obtained by the precision forging process. However, the surface roughness satisfies the requirements of blade surface technology. Figure 30 (c) shows the micro-morphology of the blade convex surface near the fixture compaction point of the fixture, and Figure 30 (d) shows the micro-morphology at the fixture compaction point after the blade adaptive CNC machining process. It can be seen from the figures that the blade clamping process does not cause local damage on the blade body surface. This is because the fixture used in this adaptive $\mathrm{CNC}$ machining process is a rigid-flexible coupling structure fixture, and the clamping elements and positioning elements used in this study are PEEK-G30. The modulus of elasticity of the material is $1 / 15$ of the modulus of the blade material, which is Ti-6Al-4V in this study [3], which can protect the blade from local deformation well.

(a)

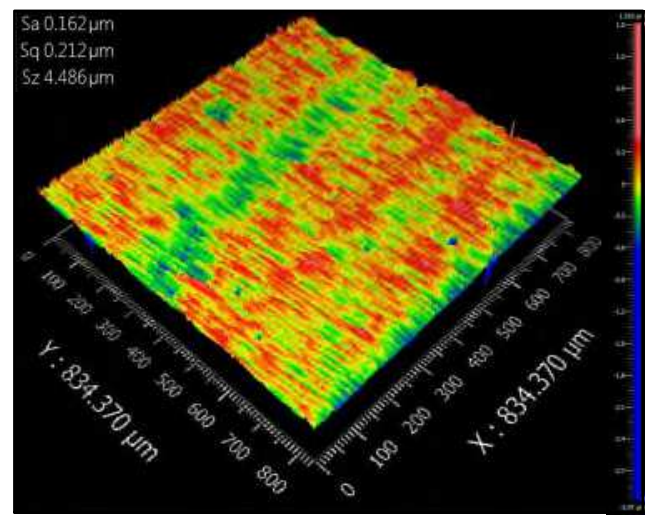

(c)

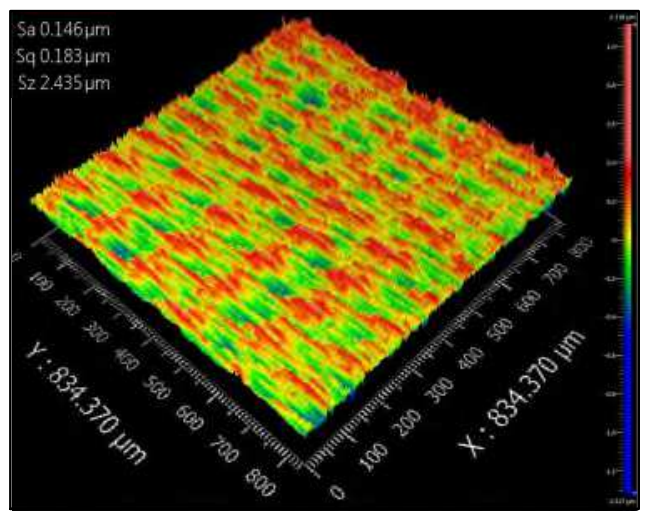

(b)

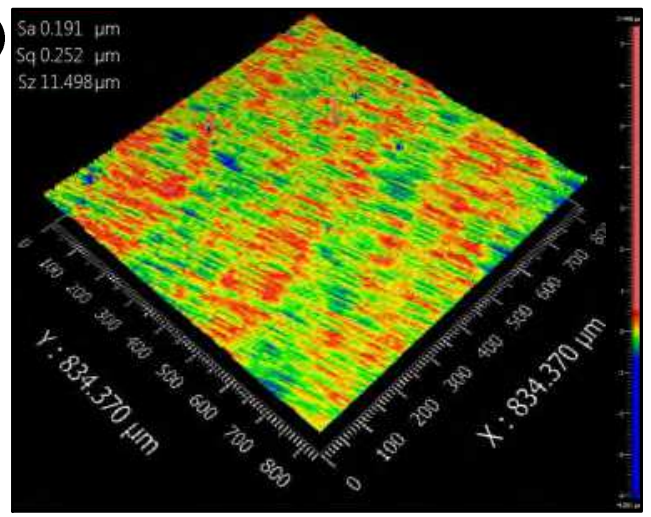

(d)

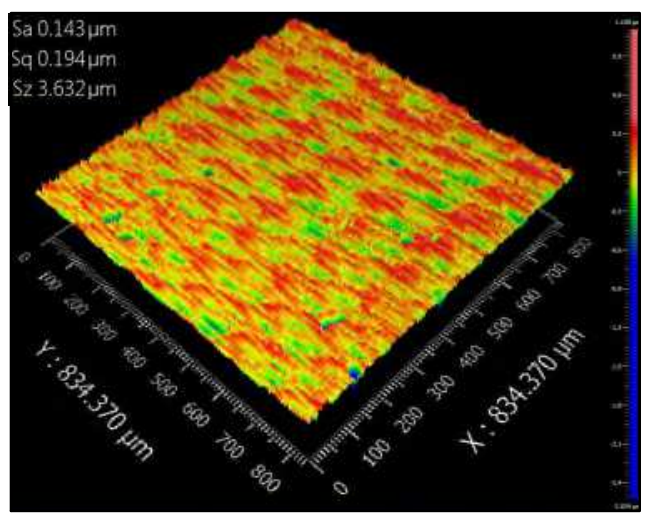

Fig. 31 Micro-morphology of blade tenon root and tip surface after adaptive CNC machining process, (a)-(d) Different parts of the blade tenon root

Figure 31 shows the 3D topography of the blade tenon root top surface after the adaptive CNC machining process. Figure 31 (a) shows the 3D topography of the blade tenon root surface. The surface roughness of the blade tenon root surface is Ra 0.162 
$\mu \mathrm{m}$. There are no scratches, burrs, or other defects on the blade surface, and the blade surface leaves regularly distributed cutting marks. Similarly, Figure 31 (b) shows the 3D topography of the lower surface of the blade tenon root. The surface roughness of the bottom surface of the blade tenon root is Ra $0.192 \mu \mathrm{m}$. Figure 31 (c) shows the 3D shape of the lower surface of the blade tip. The surface roughness of the lower surface of the blade tip surface is Ra $0.146 \mu \mathrm{m}$. Figure 31 (d) shows the 3D topography of the lower surface of the blade tip. The surface roughness of the lower surface of the blade tip is Ra $0.143 \mu \mathrm{m}$. These surfaces are of good quality, with regularly distributed surface knife marks. Moreover, the surface roughness is lower than Ra $0.20 \mu \mathrm{m}$, and there are no obvious defects such as burrs on the blade surface or local damage.

In summary, the blade tenon root and tip obtained with the proposed adaptive CNC machining process have good surface quality. The contouring error and position error of the blade meet the requirements. Therefore, the adaptive $\mathrm{CNC}$ machining process can achieve the control of the machining errors in the blade CNC machining process, and the surface quality of the blade is improved by the adaptive CNC machining process.

\section{Conclusions}

In this work, the adaptive $\mathrm{CNC}$ machining process and the blade $\mathrm{CNC}$ machining errors are investigated with theoretical and experimental analyses. The results can be summarized as follows:

1. The adaptive $\mathrm{CNC}$ machining process can reasonably reduce the machining errors caused by the positioning benchmark when the positioning surface margin is positive, and the positive margin of the positioning surface is evenly distributed on both sides of the theoretical model based on the adaptive $\mathrm{CNC}$ machining process.

2. For a near-net-shaped blade, the adaptive CNC machining process has good positioning error control ability. The lower deviation of the measurement model relative to the theoretical model of the blade body is reduced from $0.0556 \mathrm{~mm}$ to $0.0482 \mathrm{~mm}$ after the blade position and the posture adjustment based on the adaptive CNC machining process, the upper deviation of the blade is reduced from $0.0706 \mathrm{~mm}$ to $0.0532 \mathrm{~mm}$, and the blade deviation band is reduced from $0.015 \mathrm{~mm}$ to $0.005 \mathrm{~mm}$, which is a reduction of $60 \%$.

3. The adaptive CNC machining process has a good effect for optimizing the tenon root contouring error, while the position error of the blade tenon root is not in the best state. Furthermore, the position error and the contouring error can meet the 
requirements at the same time only when the stiffness of the blade-fixture system is a prerequisite.

4. The adaptive $\mathrm{CNC}$ machining process is feasible and it has the excellent ability of machining error control. The adaptive $\mathrm{CNC}$ machining process in the whole $\mathrm{CNC}$ machining process can improve the machining quality of a blade and achieve the highprecision manufacturing of a blade.

However, the adaptive CNC machining process adjustments for the blade machining position error and the contouring error increase the on-machine measurement time and the measurement data processing time, respectively, which will reduce the $\mathrm{CNC}$ machining efficiency. Determining how to reduce the measurement links, reduce the procedures, and improve the processing efficiency will be the research focus of CNC machining optimization.

\section{Authors' contributions}

Dongbo $\mathrm{Wu}$ : experiment, data analysis, original draft writing

Hui Wang: methodology, formal analysis, writing—review and editing

Jie Yu: experiment

\section{Funding}

This research was supported in part by Xi' an Aero-Engine (Group) Ltd. and the National Natural Science Foundation of China [grant number 51575310].

Data availability Not applicable

\section{Compliance with ethical standards}

Ethical approval Not applicable

Consent to participate Not applicable

Consent to publish Not applicable

Code availability Not applicable

Competing interests The authors declare that they have no competing interests

\section{References}

[1] Lin XJ, Wu DB, Yang, BY, Wu G, Shan XF, Xiao QB, et al. Research on the mechanism of milling surface waviness formation in thin-walled blades [J]. International Journal of Advanced Manufacturing Technology 2017; 93, 2459-70. 
[2] Dongbo Wu, Hui Wang \#, Kaiyao Zhang, Bing zhao. Research on adaptive CNC machining arithmetic and process for near-net-shaped jet engine blade [J]. Journal of Intelligent Manufacturing 2020; 31, 717- 744.

[3] Dongbo Wu, Hui Wang\#, Jie Yu. Kaiyao Zhang, Machining fixture for adaptive $\mathrm{CNC}$ processing technology of near-net-shaped jet engine blade $[\mathrm{J}]$. Chinese Journal of Aeronautics. 2020; 33, 1311- 1328.

[4] E. Budak, Analytical models for high performance milling. Part I: Cutting forces, structural deformations and tolerance integrity $[\mathrm{J}]$. International Journal of Machine Tools \& Manufacture, 2006; 46, 1478-1488.

[5] Weifang Chen, Lijun Ni, Jianbin Xue, Deformation control through fixture layout design and clamping force optimization [J], International Journal of Advanced Manufacturing Technology, 2008; 38, 860-867.

[6] K.P. Padmanaban, K.P. Arulshri, G. Prabhakaran, Machining fixture layout design using ant colony algorithm based continuous optimization method [J], International Journal of Advanced Manufacturing Technology, 2009; 45, 922-934.

[7] Abdul Wahid Khan, Chen Wuyi. Systematic Geometric Error Modeling for Workspace Volumetric Calibration of a 5-axis Turbine Blade Grinding Machine [J]. Chinese Journal of Aeronautics. 2010; 23, 604-615.

[8] Yan Rong, Chen Wei, Peng Fangyu, Lin Sen, Li Bin, Closed-chain stiffness field modeling and stiffness performance analysis of multi-axis machining system [J]. Journal of Mechanical Engineering, 2012; 48 (1), 176-184.

[9] Eduardo Diez, Hilde Perez, Juan Marquez, Antonio Vizan. Feasibility study of inprocess compensation of deformations in flexible milling [J]. International Journal of Machine Tools and Manufacture, 2015; 94.

[10] Zhou-Long Li, Oguzhan Tuysuz, Li-Min Zhu, Yusuf Altintas. Surface form error prediction in five-axis flank milling of thin-walled parts [J]. International Journal of Machine Tools and Manufacture, 2018; 128.

[11] Gururaj Bolar,Argha Das,Shrikrishna N. Joshi. Measurement and analysis of cutting force and product surface quality during end-milling of thin-wall components [J]. Measurement, 2018; 121.

[12] Ziling Zhang, Yin Qi, Qiang Cheng, Zhifeng Liu, Zhiqiang Tao, Ligang Cai, Machining accuracy reliability during the peripheral milling process of thinwalled components [J]. Robotics and Computer-Integrated Manufacturing, 2019; 59, $222-234$. 
[13] Fountas, NA, Kechagias, J, Benhadj-Djilali, R, Stergiou, CI, \& Vaxevanidis, NM. "Optimizing 5-Axis Sculptured Surface Finish Machining Through Design of Experiments and Neural Networks. "Proceedings of the ASME 2014 12th Biennial Conference on Engineering Systems Design and Analysis. July 25-27, 2014. V001T06A002. ASME.

[14] Ma Yi, Jiang Hong, Yi Min, Wang Xiaochun, Global Optimization Algorithm for Machining and Positioning of Large-scale and Complex Surface-like Blanks [J]. Journal of System Simulation, 2004; 17 (4), 825- 826, 830

[15] Walid Ghiea, Luc Laperriere, Alain Desrochers, Statistical tolerance analysis using the unified Jacobian-Torsor model $[\mathrm{J}]$. International Journal of Production Research, 2010; 48(15), 4609- 4630.

[16] Jia Feng, Jiang Pingyu, Liu Daoyu, Zheng magnesium, Error transfer control method for blade batch processing [J]. Computer Integrated Manufacturing System, 2011; 18 (1), 76- 86.

[17] HU S J. Stream of Variation theory for automotive body assembly[J]. Annals of the CIRP, 1997, 46(1): 1-6.

[18] Ceglarek D, SHI J, WU S M. A Knowledge-based diagnosis approach for the launch of the auto-body assembly process[J]. ASME Journal of Engineer for Industry, 1994, 116(4): 491-499.

[19] Ceglarek D, SHI J. Fixture failure diagnosis for auto-body assembly using pattern recognition[J]. Journal of Engineering for Industry, 1996, 118: 55-66.

[20] Guiassa, R. and Mayer, R. Predictive Compliance Based Model for Compensation in Multi-Pass Milling by On-Machine Probing. CIRP Annals-Manufacturing Technology, 2011; 60, 391-394.

[21] Bandy HT, Donmez MA, Gilsinn DE, Han C, Kennedy M, Ling AV, Wilkin ND, Yee, KW. A Methodology for Compensating Errors Detected by ProcessIntermittent Inspection, NIST Interagency/Internal Report (NISTIR). 2001; 6811: 1-77.

[22] Jian-Hua Yu, Zhi-Tong Chen, Ze-Peng Jiang. A control process for machining distortion by using an adaptive dual-sphere fixture $[\mathrm{J}]$. The International Journal of Advanced Manufacturing Technology, 2016; 86, 9-12.

[23] Nuodi Huang, Chunhui Yin, Liang Liang, Jicai Hu, Shijing Wu. Error compensation for machining of large thin-walled part with sculptured surface based on on-machine measurement [J]. The International Journal of Advanced 
Manufacturing Technology, 2018; 96, 4345- 4352. 
Figures

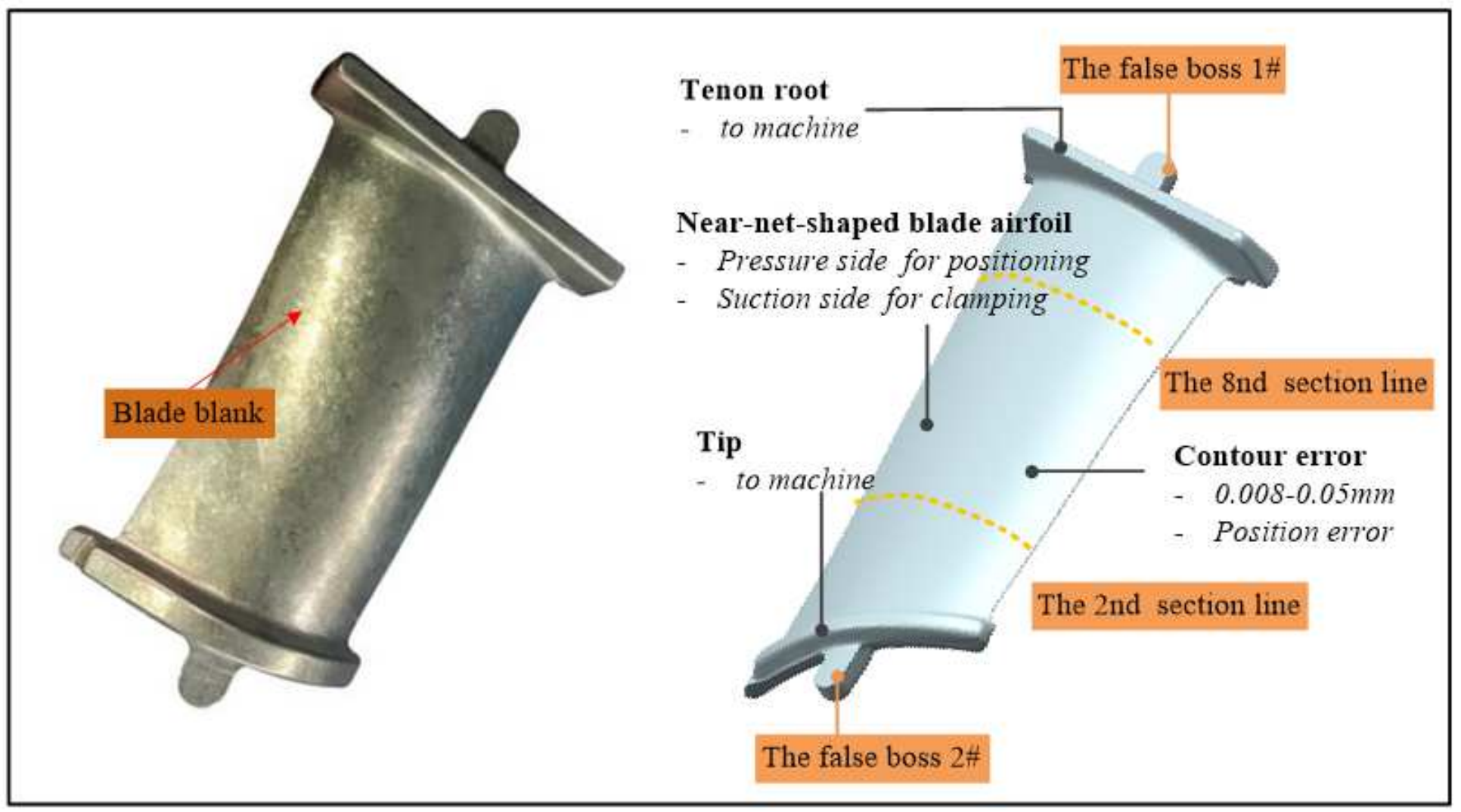

Figure 1

Near-net-shaped jet engine blade process characteristics 


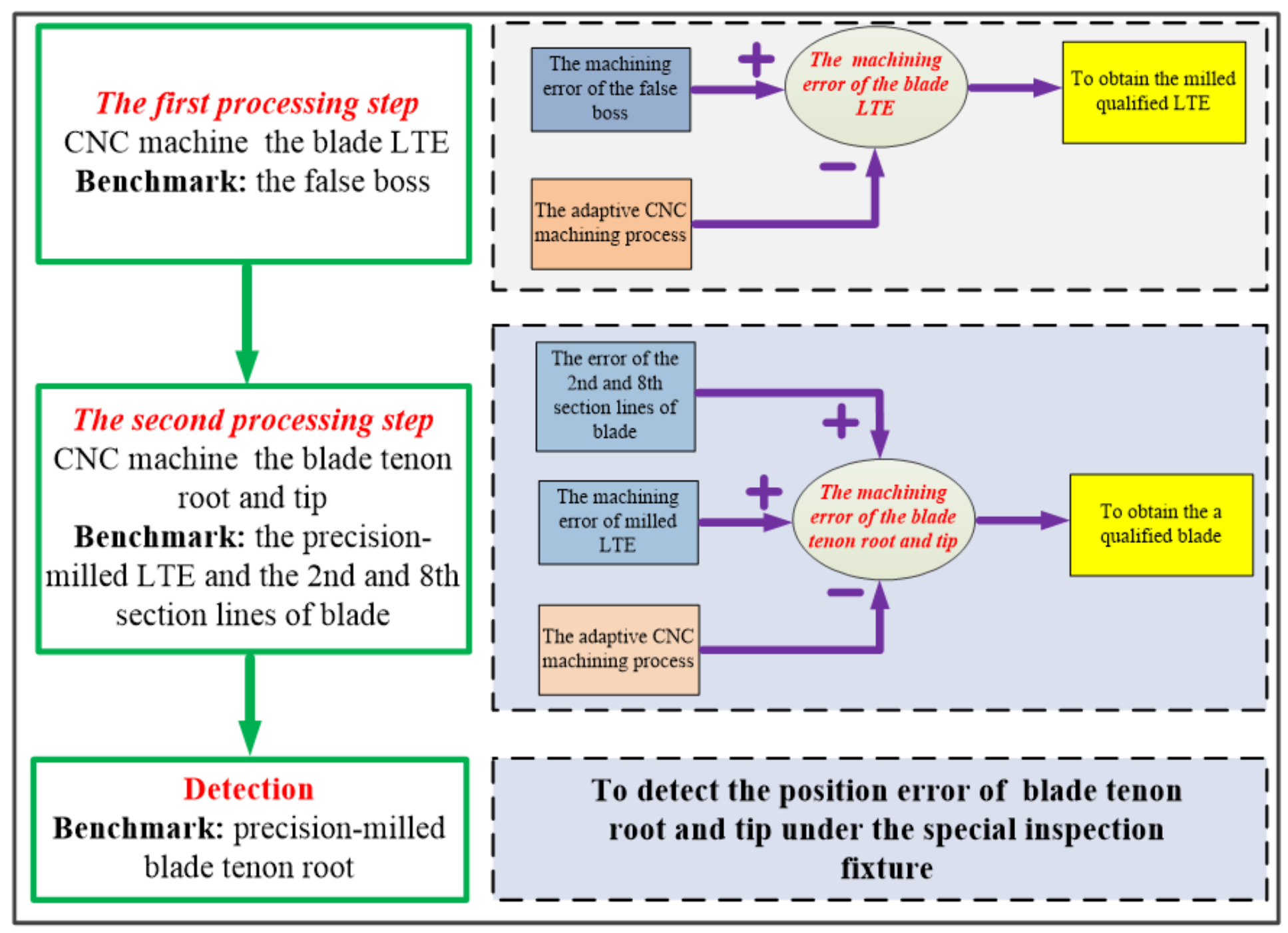

Figure 2

Multi-source, multi-machining procedure machining errors 


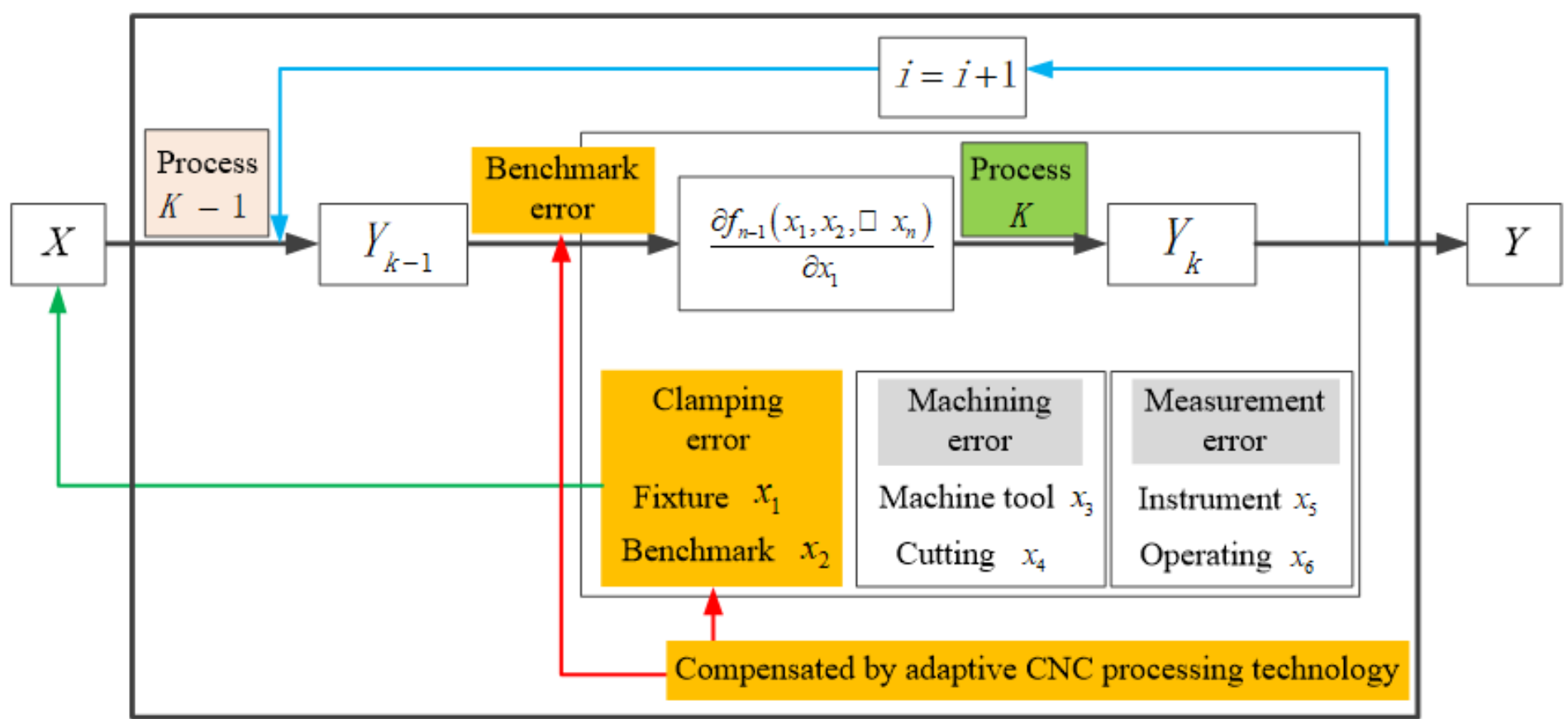

Figure 3

Machining error accumulation process caused by benchmark conversion 


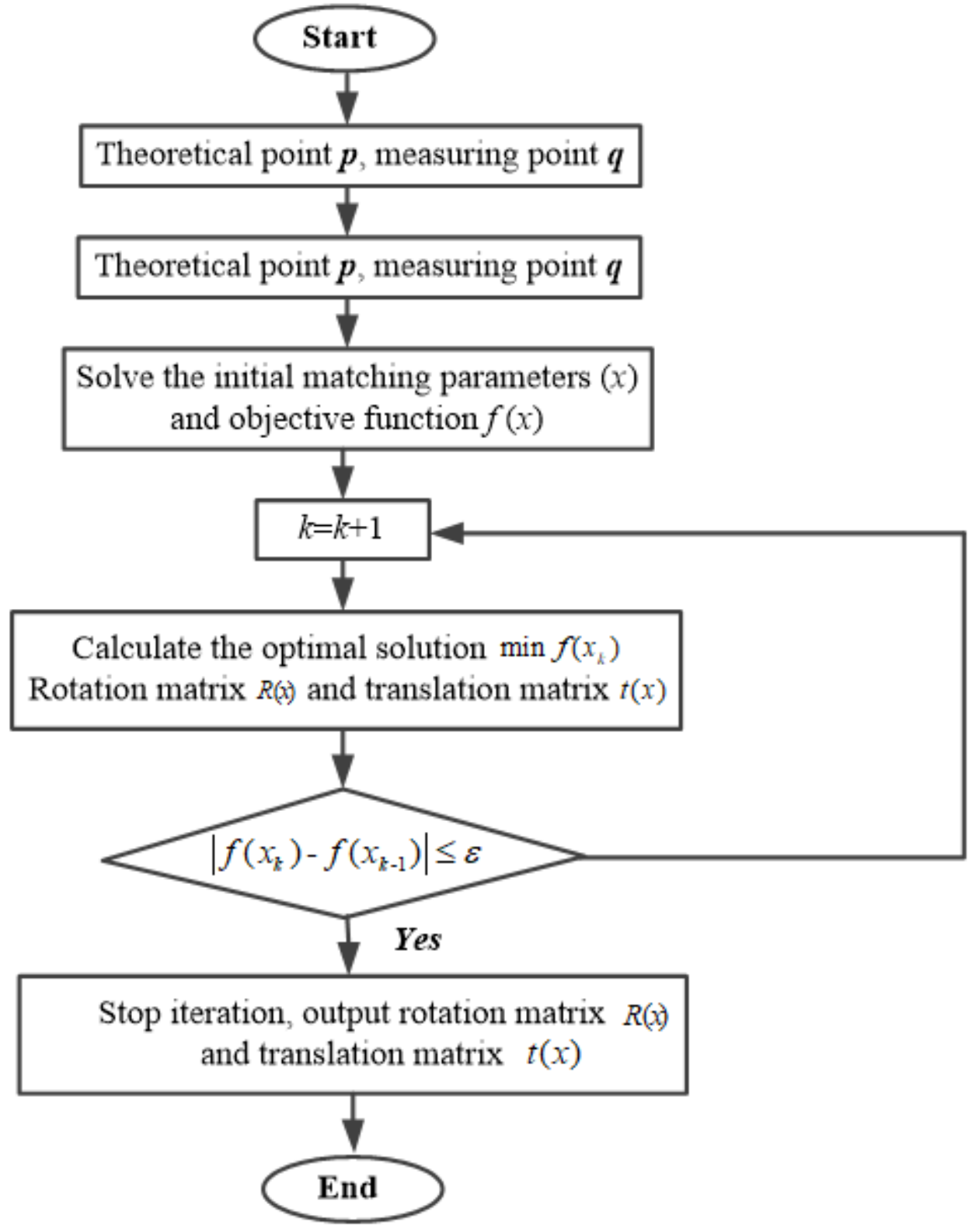

Figure 4

Calculation process of adaptive $\mathrm{CNC}$ machining process 


\section{Blade clamping}

$\downarrow$

Adaptive $\mathrm{CNC}$ machining process

On- machine measurement

1. Measurement planning

2. Measurement programming

Match with the theoretical model

1. Point set matching

Correct NC program

1. Rotation matrix and translation matrix

2. Adjust $\mathrm{NC}$ program or the blade position

Deviation calculation

Exceeding tolerance

No

\section{Roughing milling and semi-} finishing machining

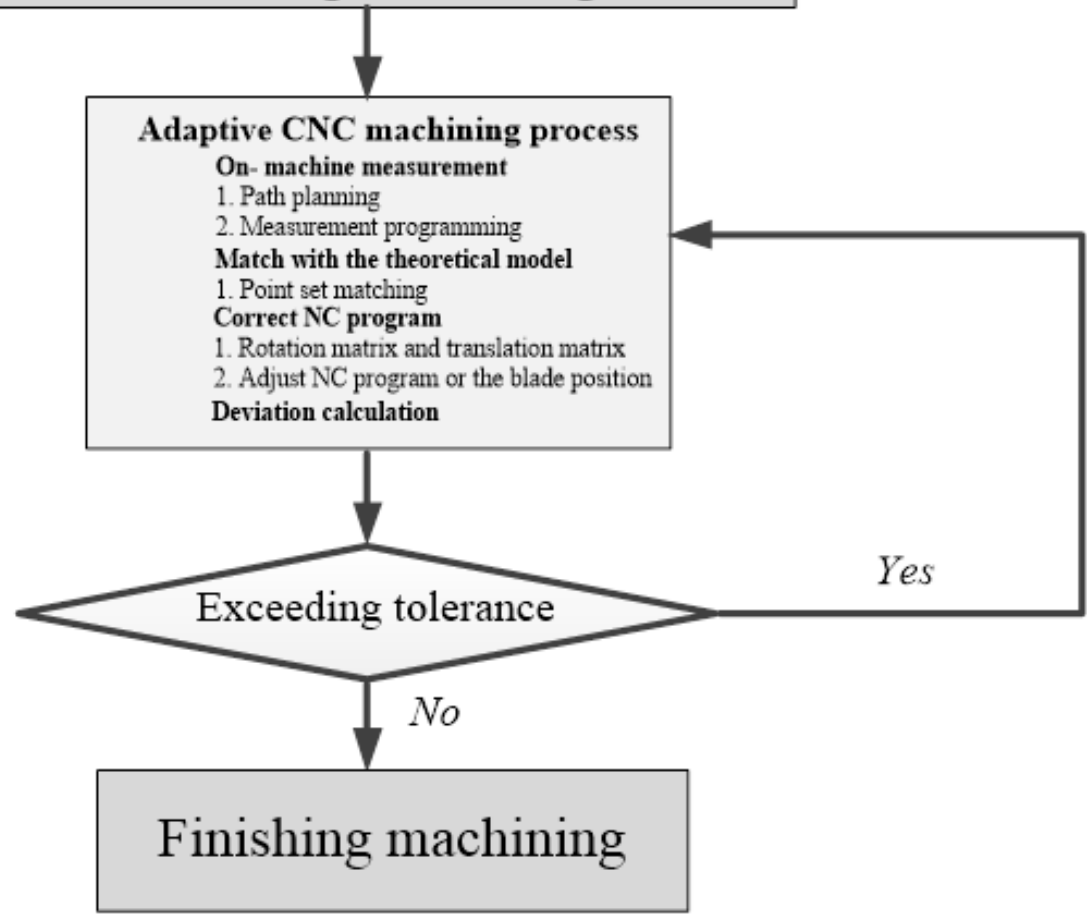

\section{Figure 5}

Adaptive CNC machining process of blade 

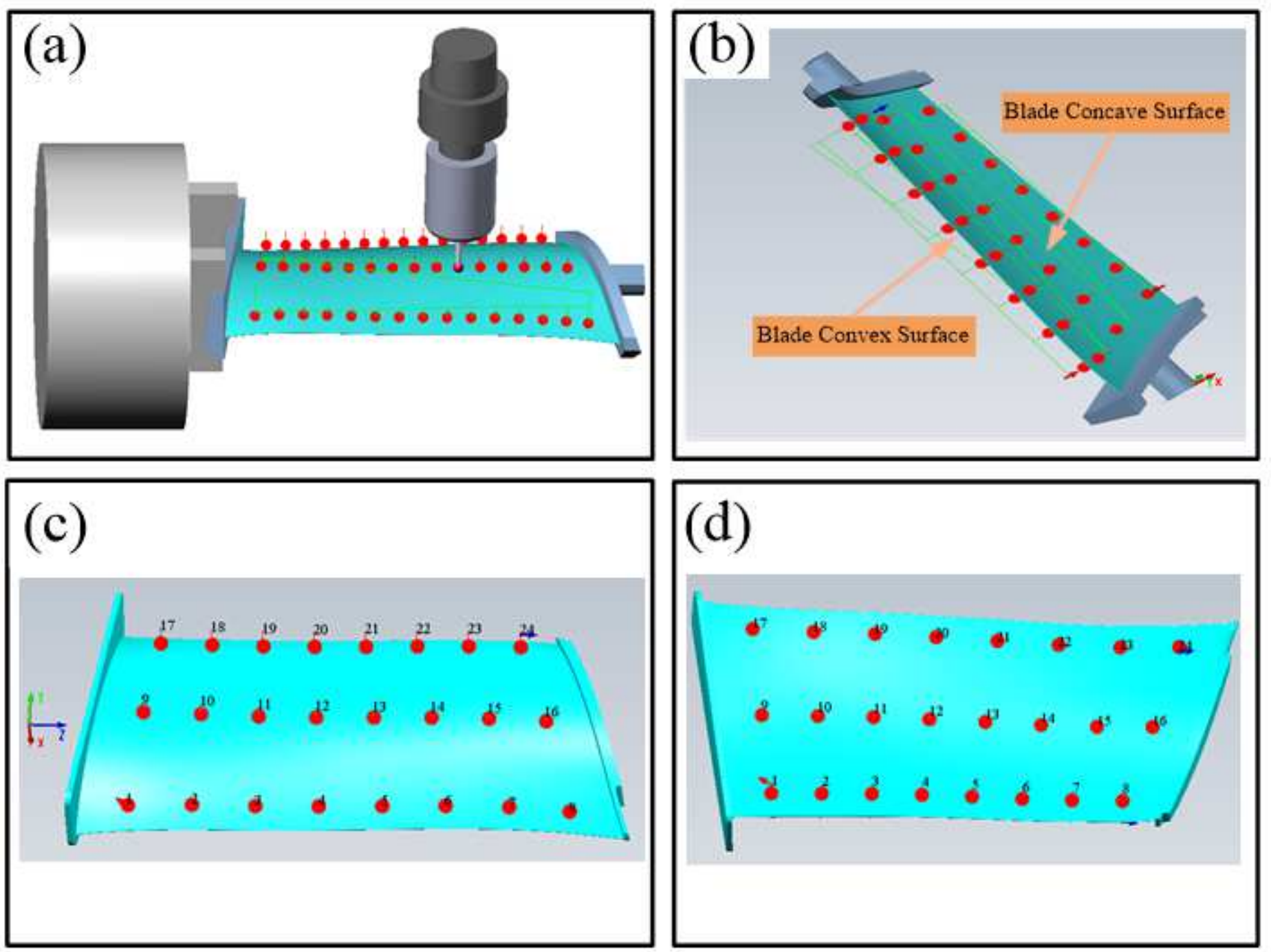

Figure 6

Blade on-machine measurement process based on the Renishaw probe, (a) On-machine measurement state, (b) Measurement path planning, (c) Blade concave profile measurement points, (d) Blade convex profile measurement points. 

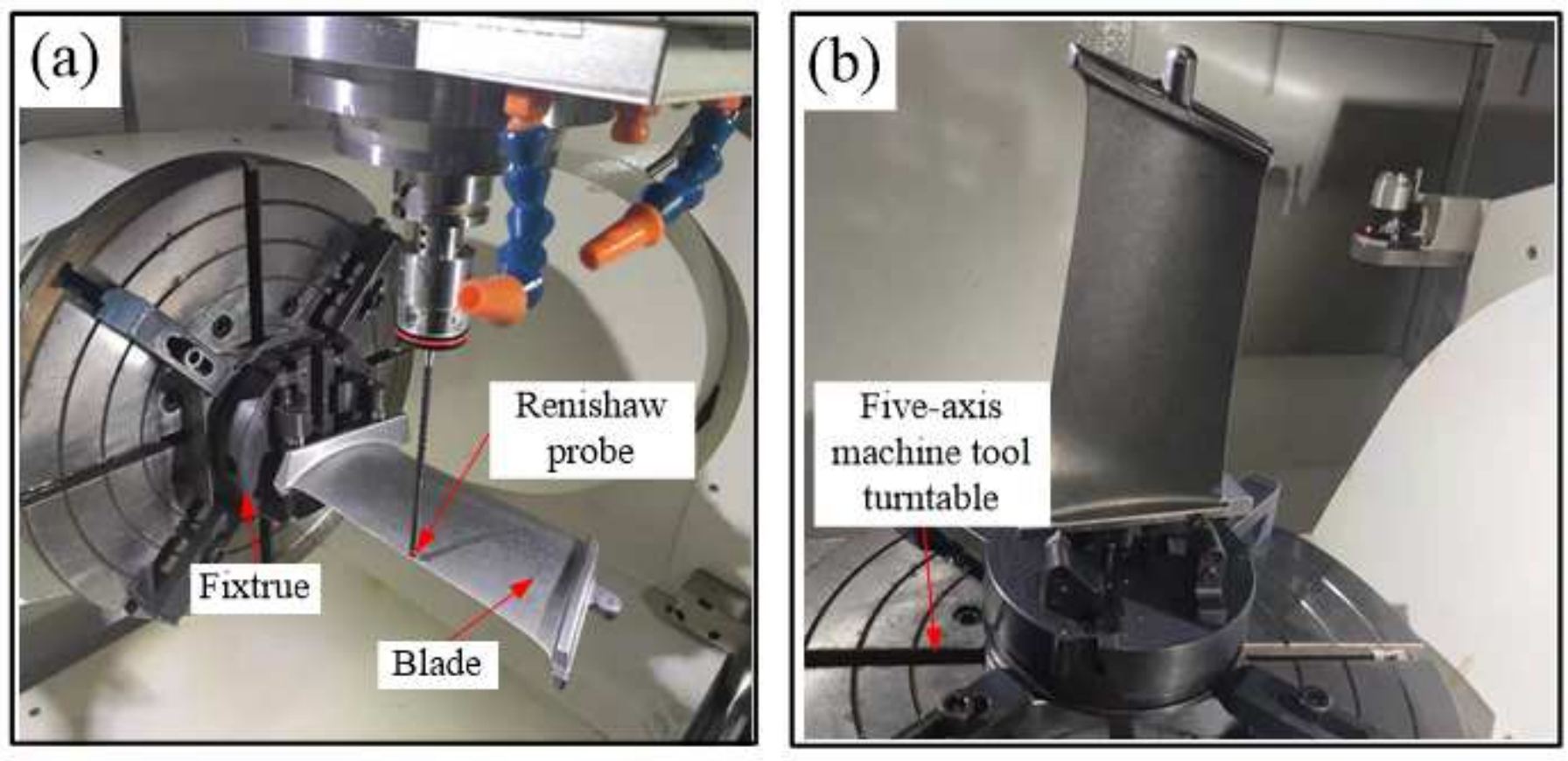

Figure 7

Blade on-machine measurement process based on the Renishaw probe, (a) Blade profile measurement, (b) Blade special measuring fixture.
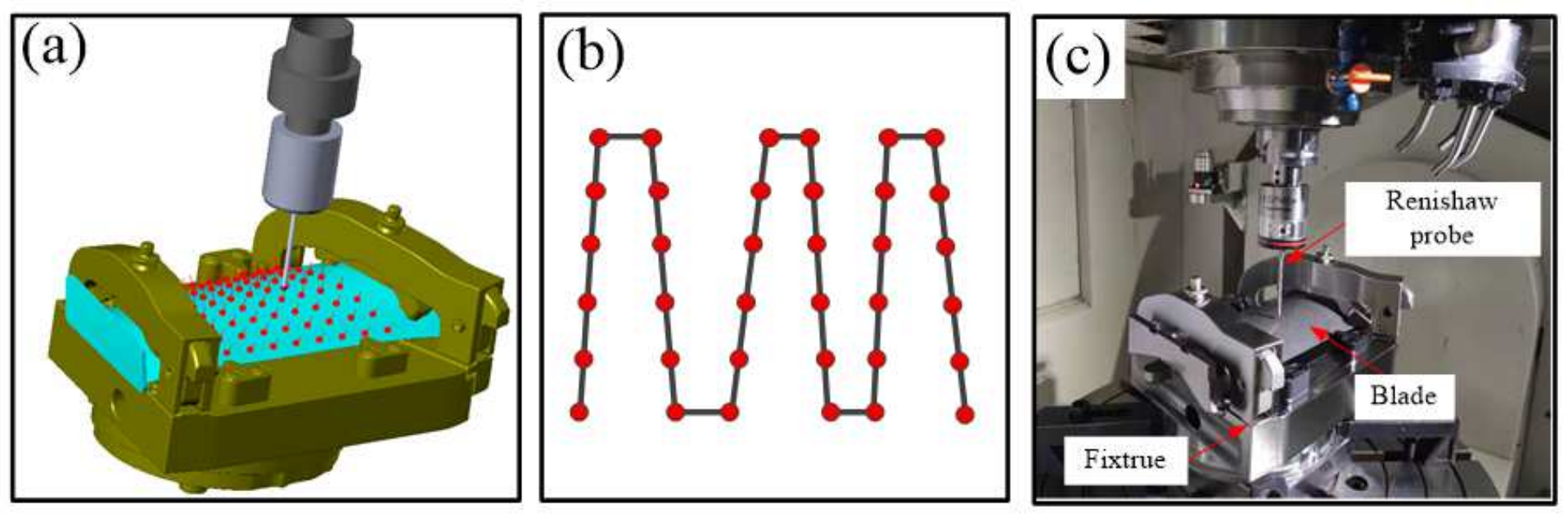

Figure 8

Blade on-machine measurement process for machining position error control, (a) Measurement points,

(b) Measurement path, (c) Measurement process of blade body. 


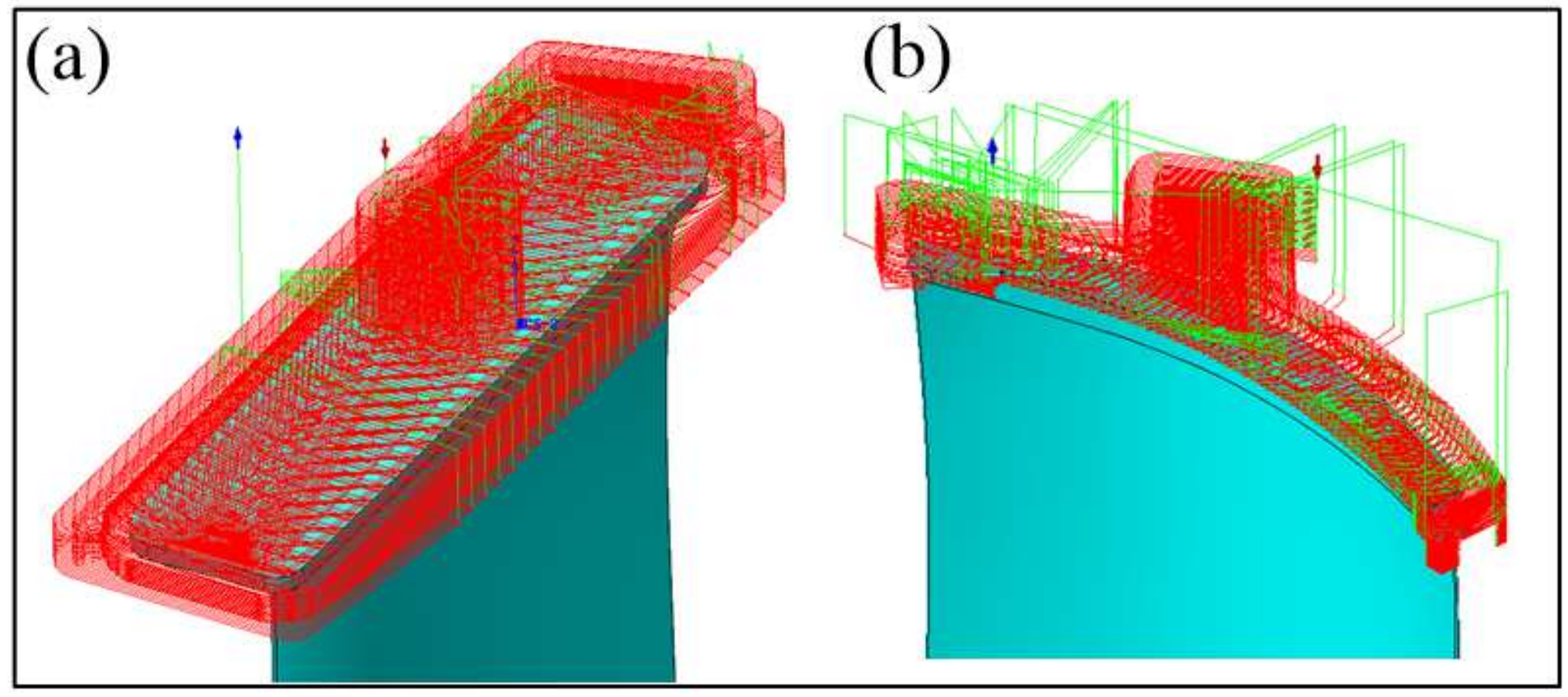

Figure 9

Tool path for roughing machining of blade tenon root, (a) Tool path of blade tenon root, (b) Tool path of blade tip
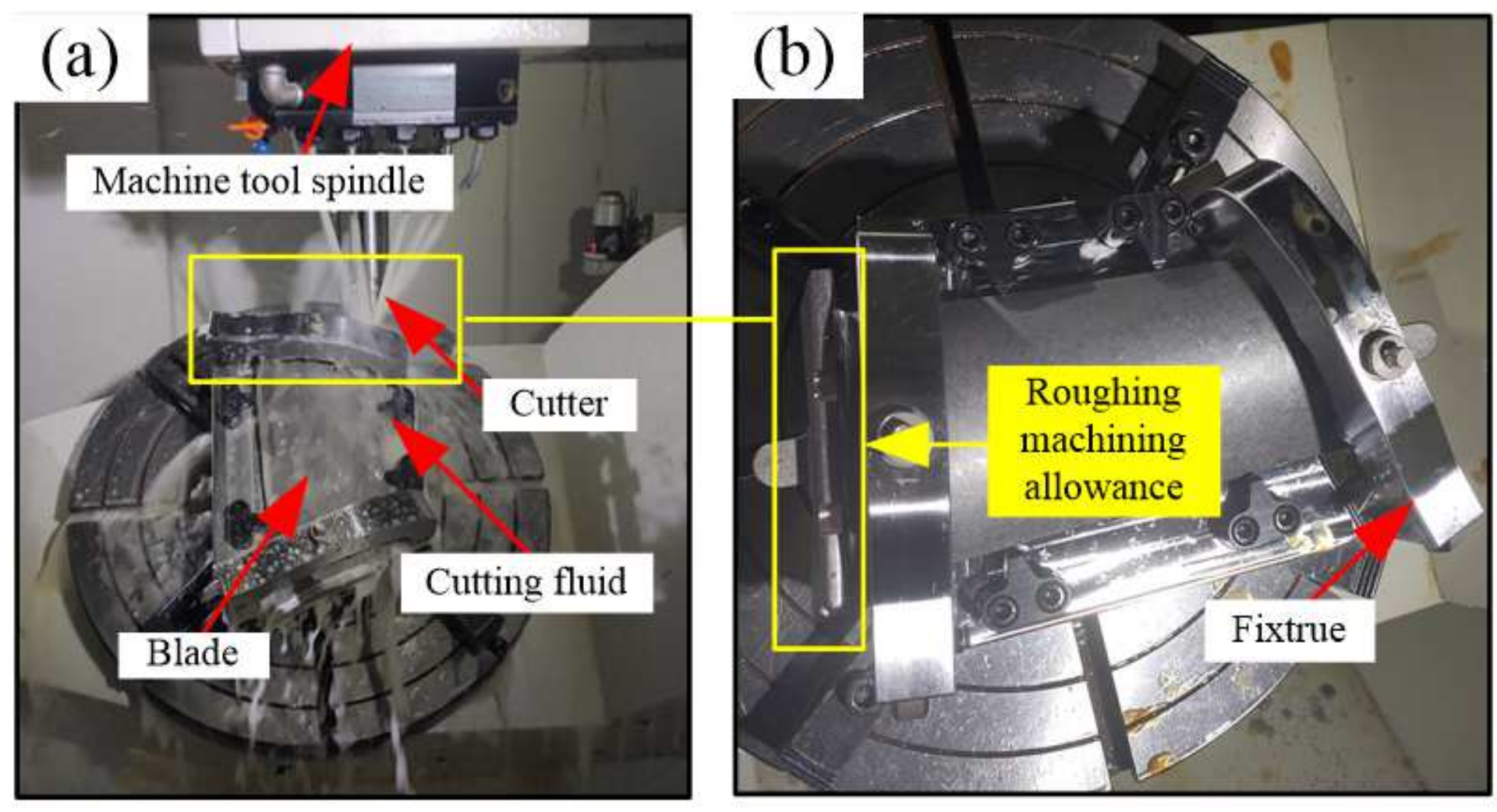

Figure 10

$\mathrm{CNC}$ roughing machining of blade 

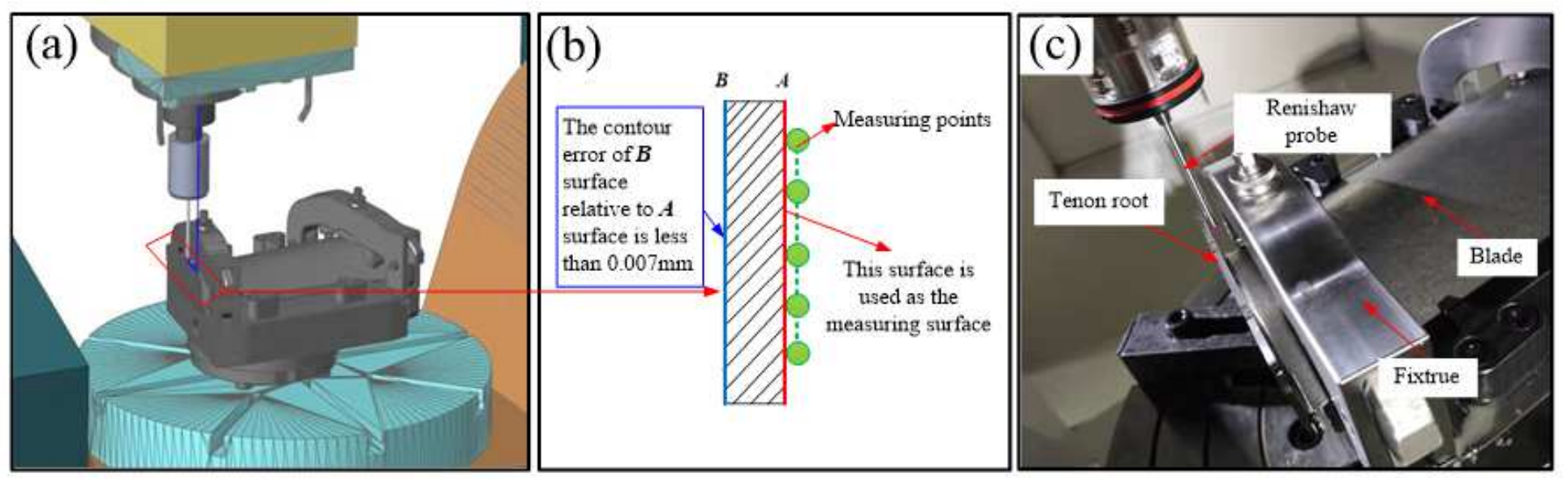

Figure 11

Blade on-machine measurement process for machining
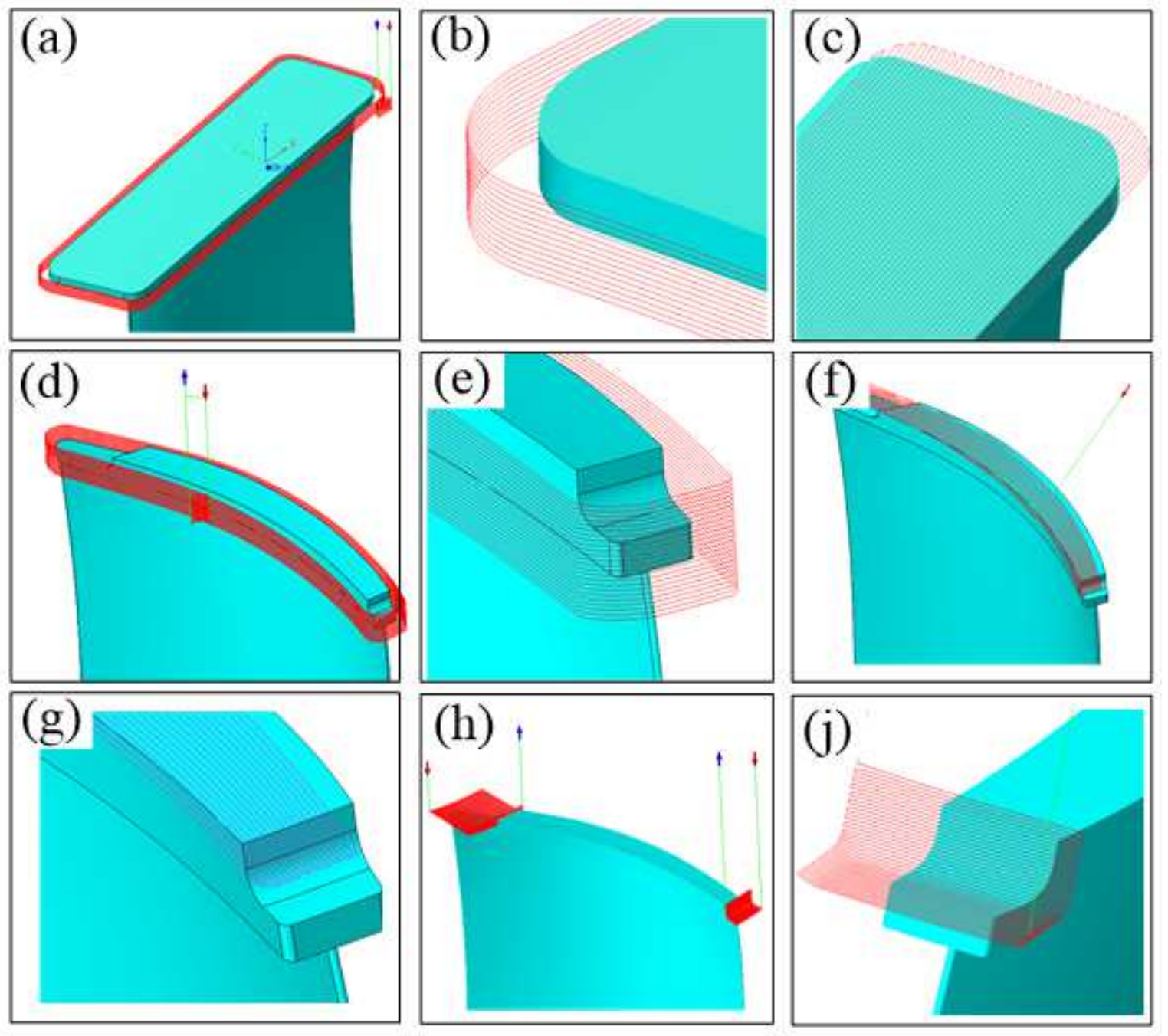

\section{Figure 12}

Tool path for finishing machining of blade tenon root and tip, (a)-(j) CNC machining model of blade tenon root and tip 

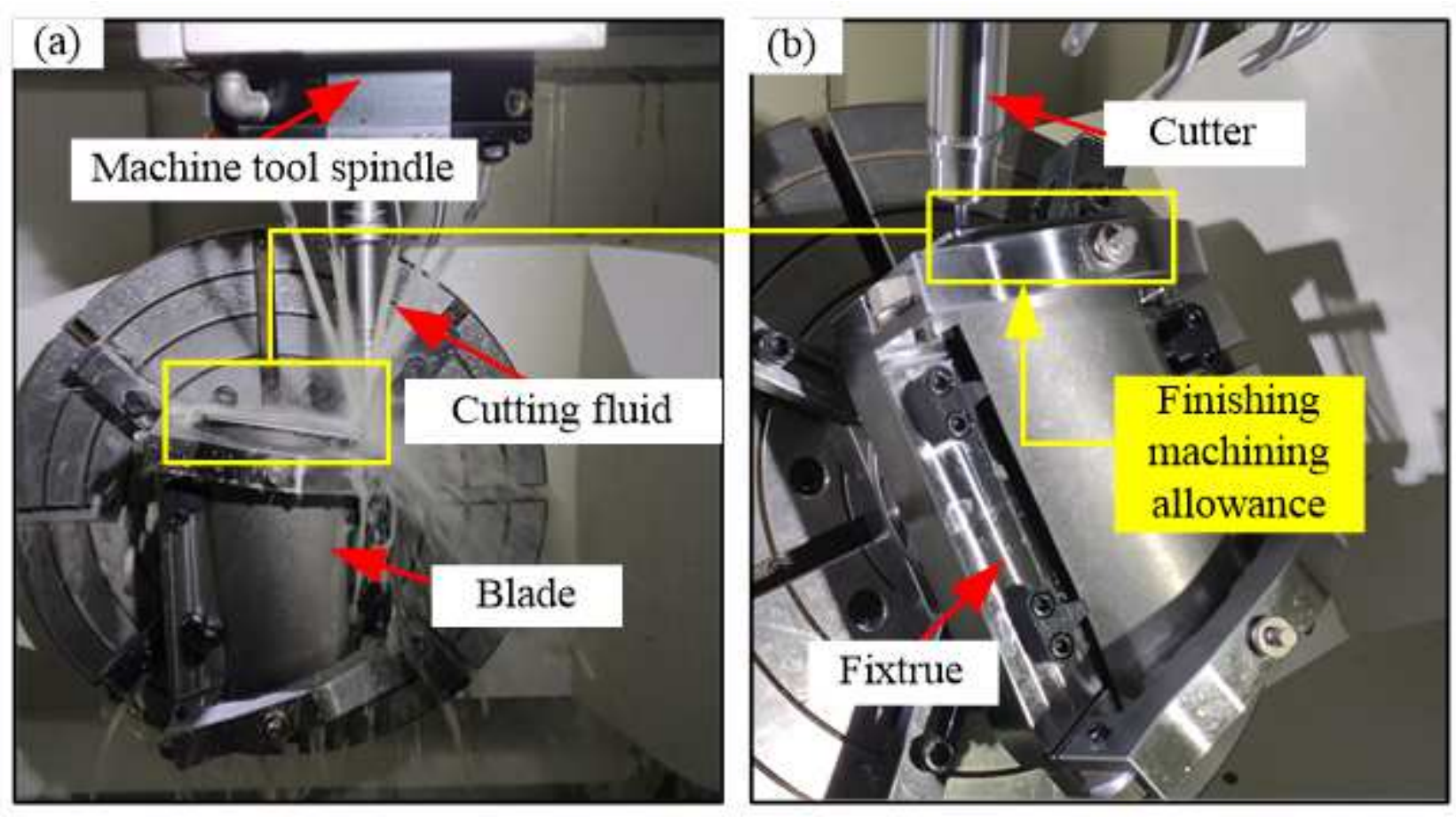

Figure 13

CNC finishing machining of blade 

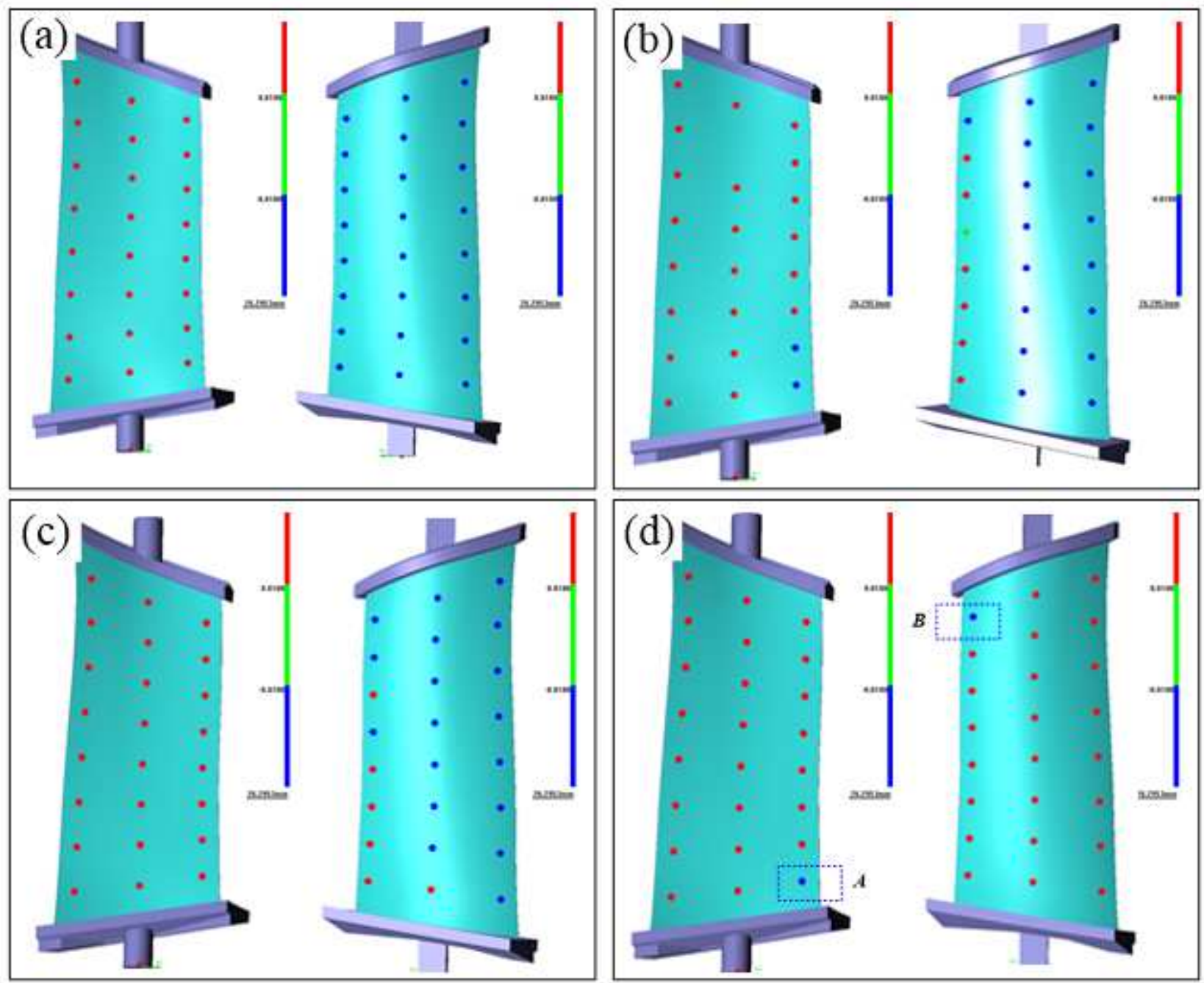

Figure 14

Single-point deviation of blade concave profile and blade convex profile, (a) In the initial installation state, (b) In the first stage of adaptive regulation, (c) In the second stage of adaptive regulation, (d) For the final adaptive regulation.
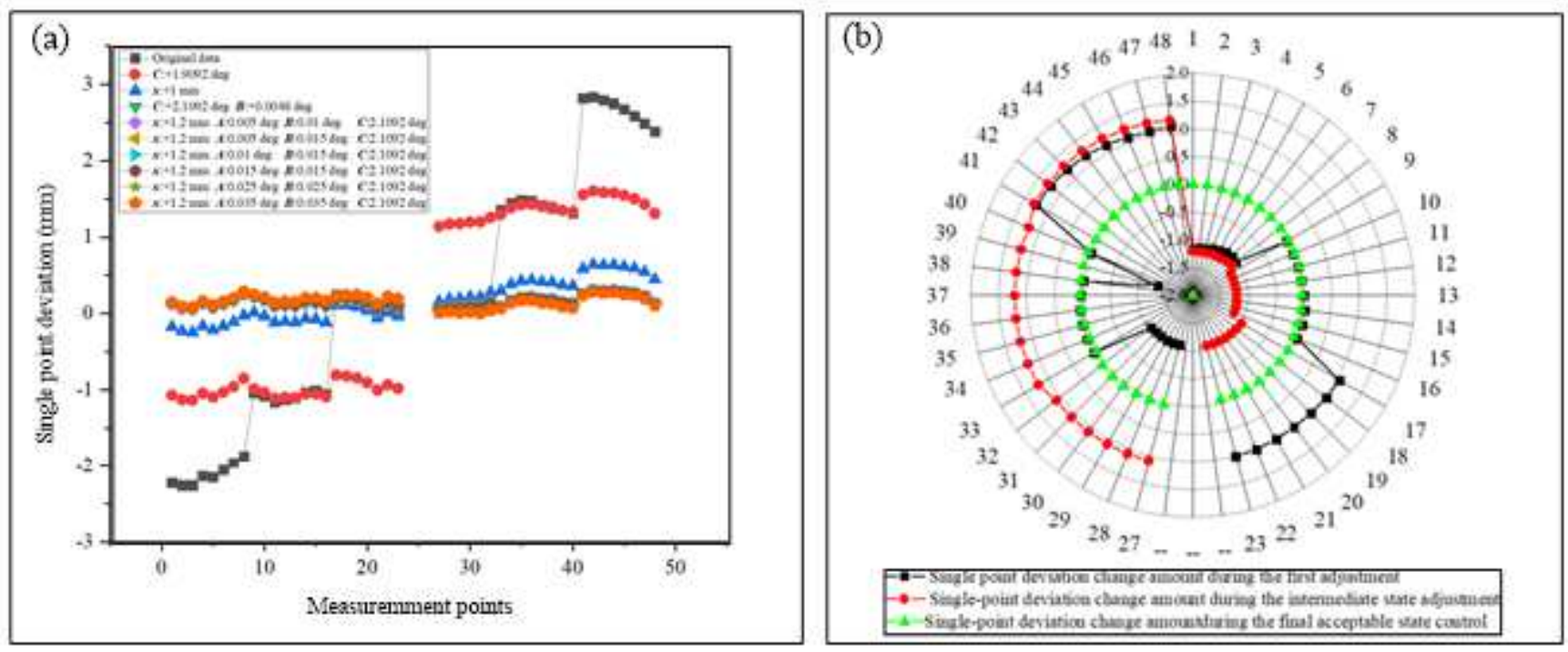
Figure 15

Single-point deviation value during adaptive regulation, (a) Deviation value, (b) Deviation change value.
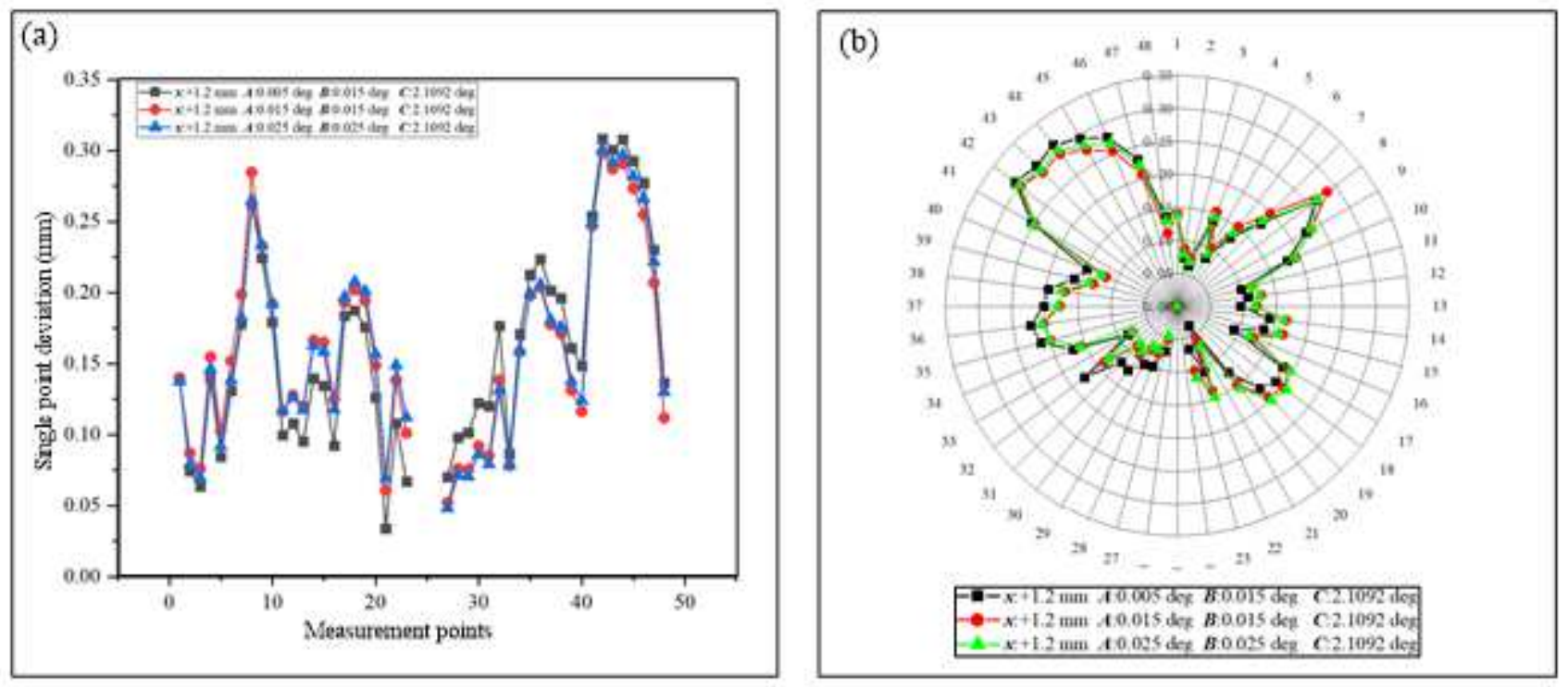

\section{Figure 16}

Single-point deviation value during the precise adjustment at the end of the adaptive regulation stage, (a) Deviation value, (b) Radar chart of single point deviation. 


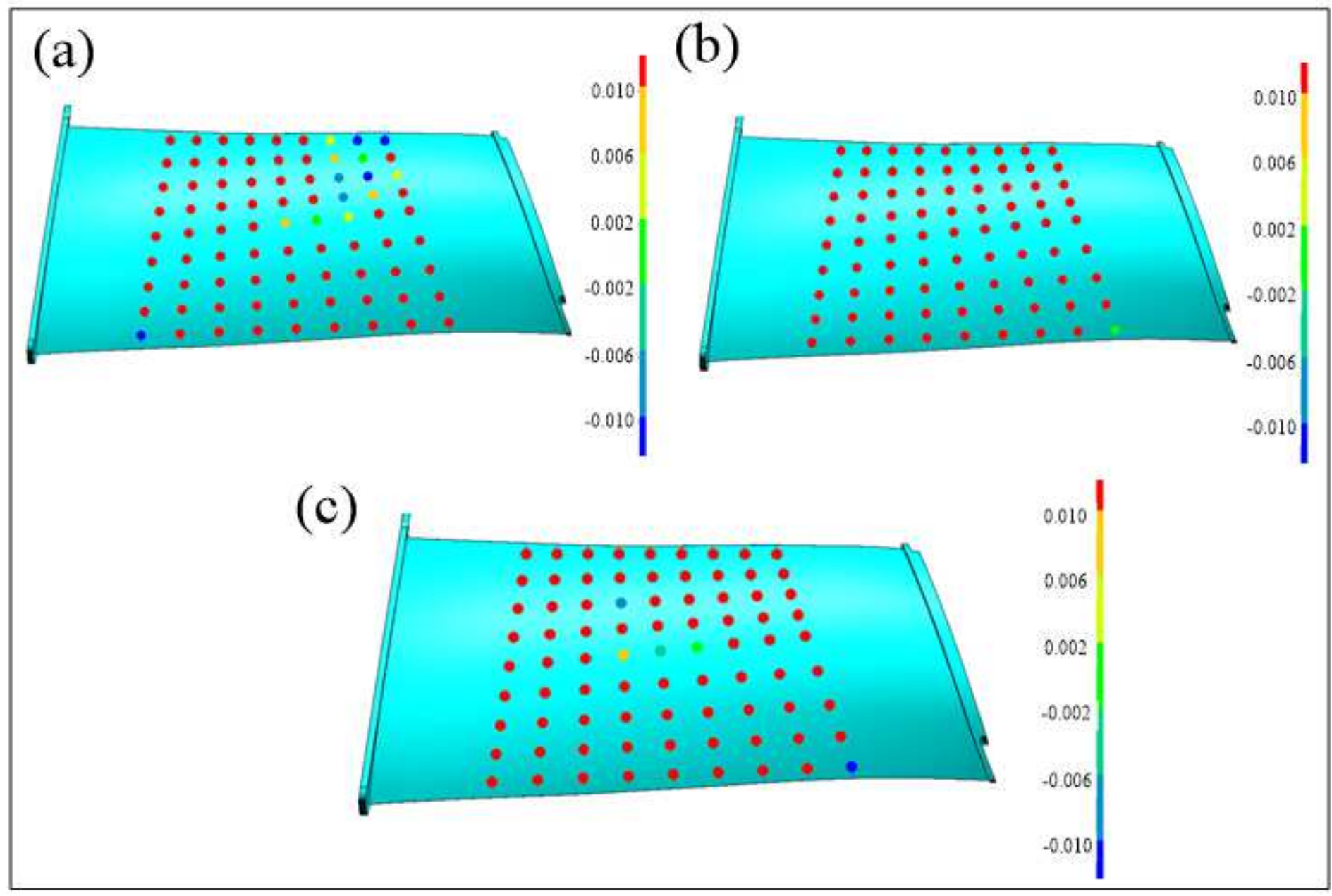

Figure 17

Measurement results of blade body deviation, (a) The measurement results of the first installation state, (b) The measurement results of the adaptive adjustment intermediate state, (c) The measurement results of the adaptive adjustment final acceptable intermediate state. 


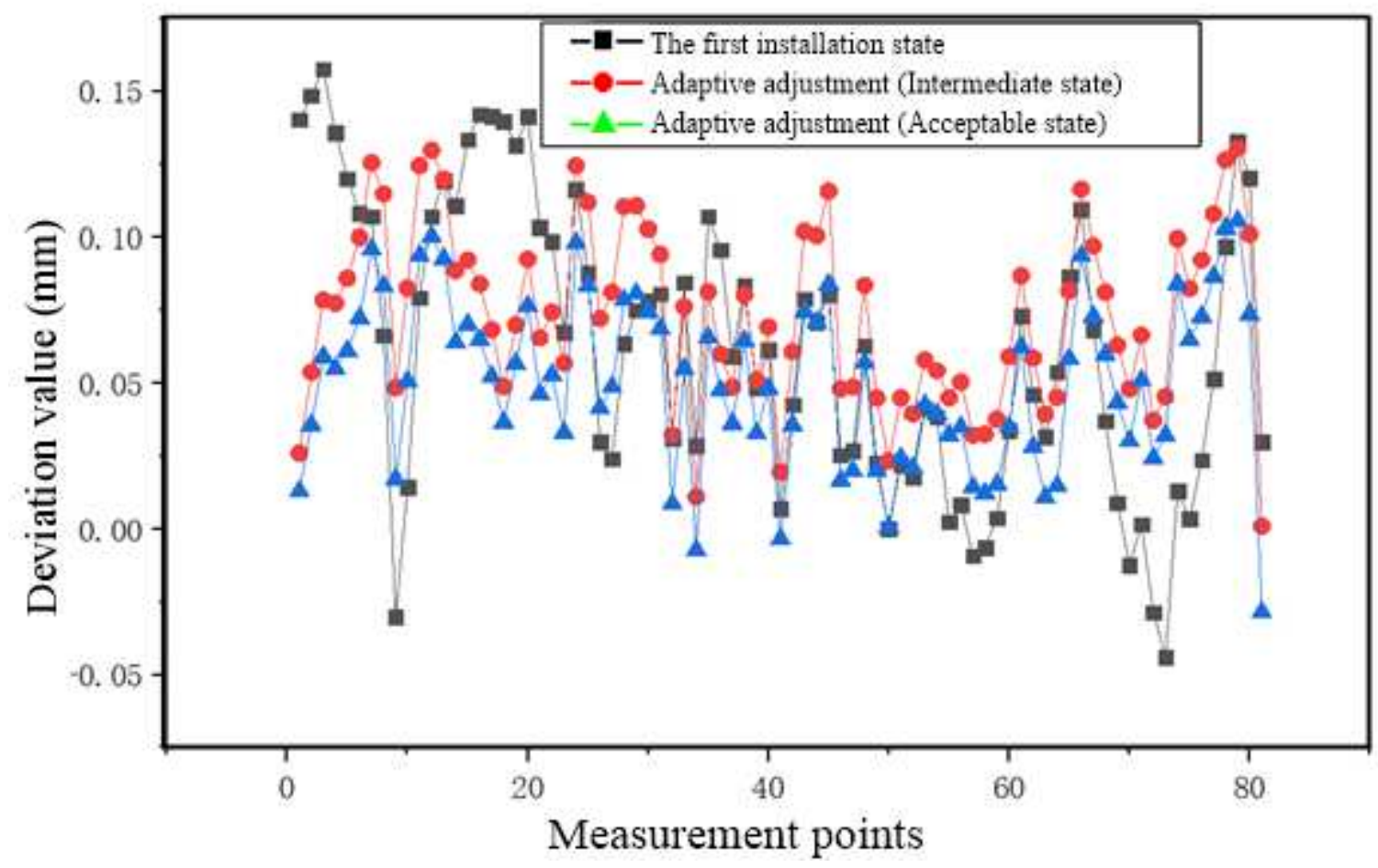

Figure 18

Measurement point deviation numerical distribution of blade body
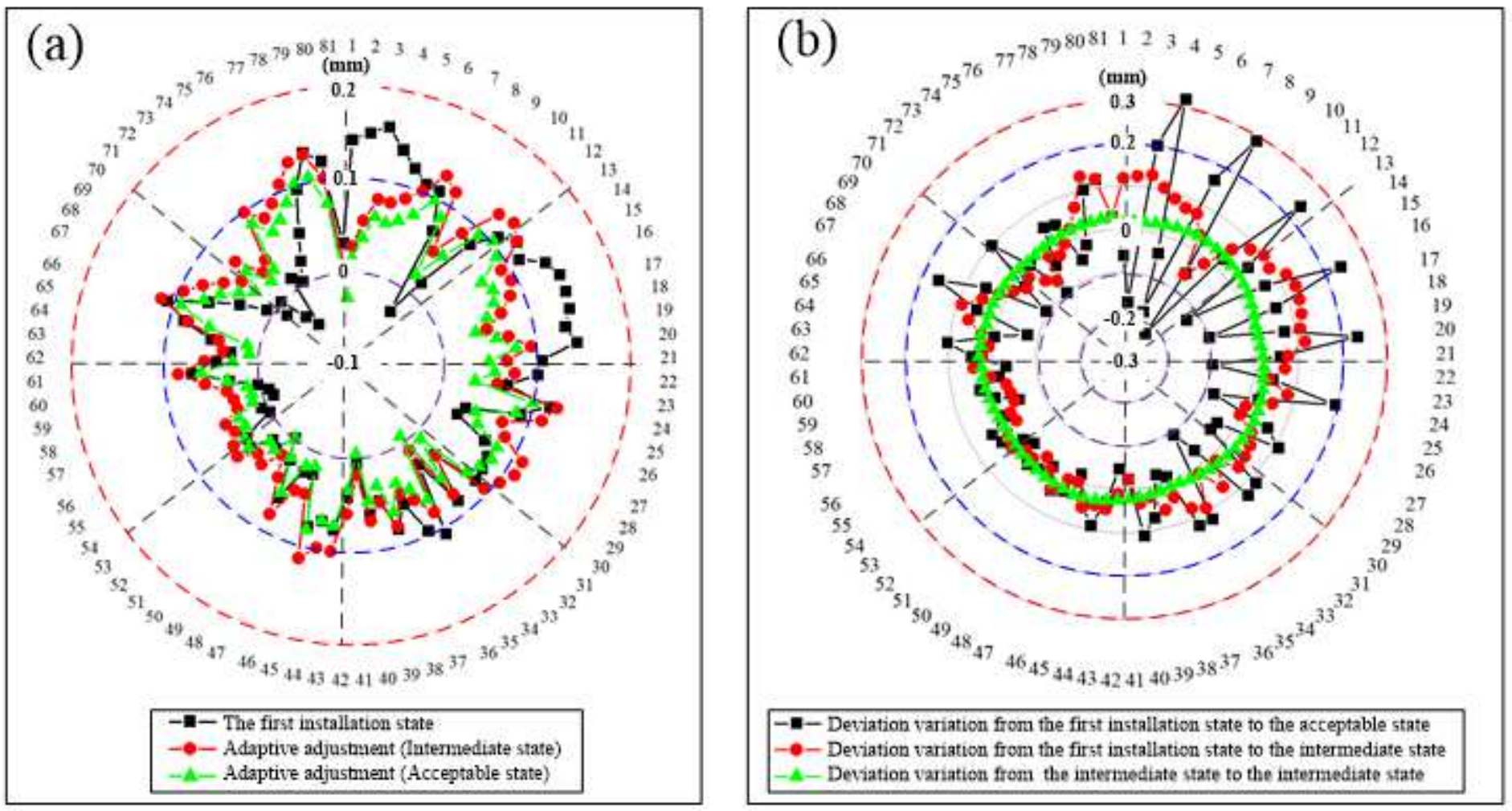

Figure 19 
Deviation numerical distribution of variation of blade body, (a) Deviation value, (b) Deviation variation amount

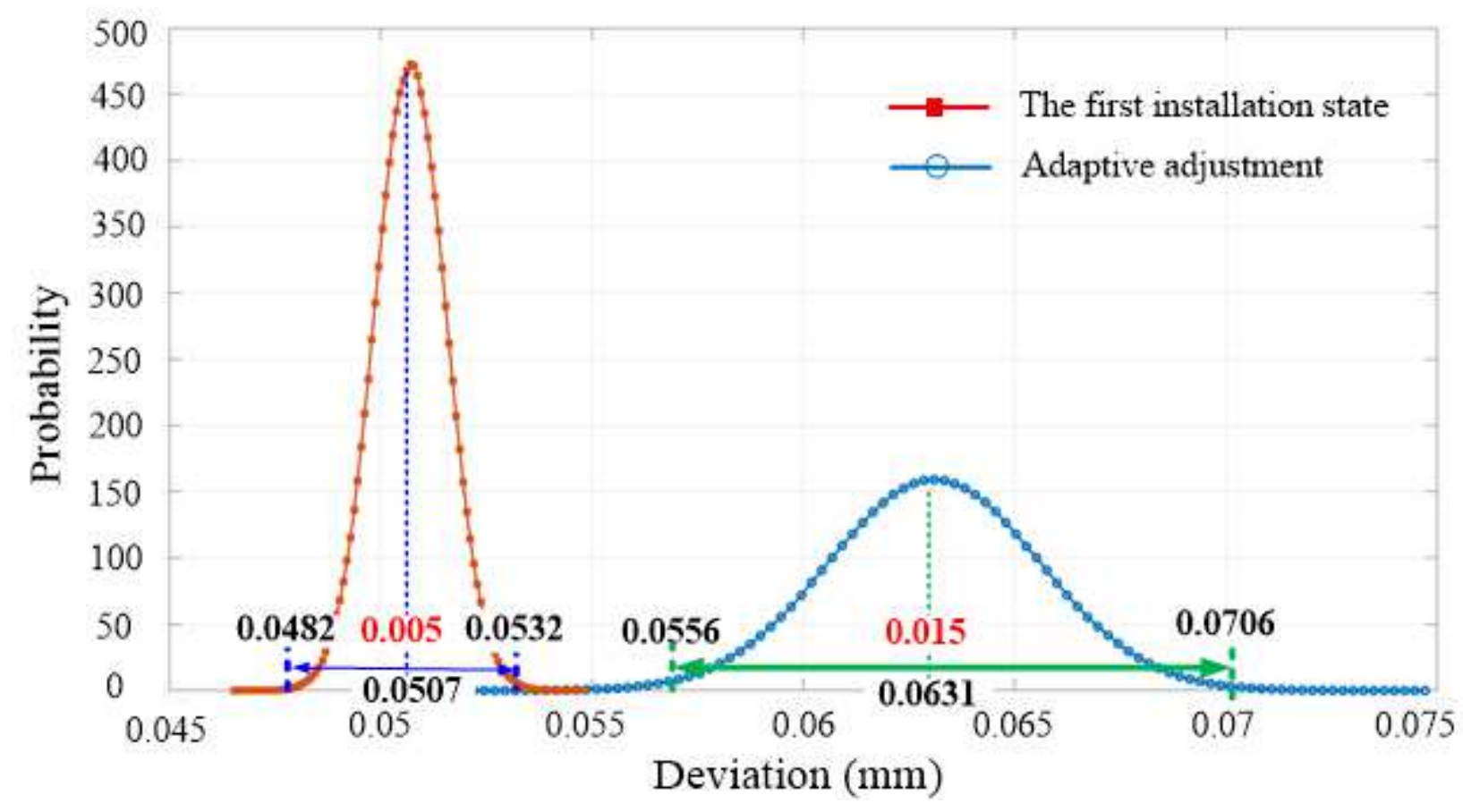

Figure 20

Normal distribution of blade body deviation value 


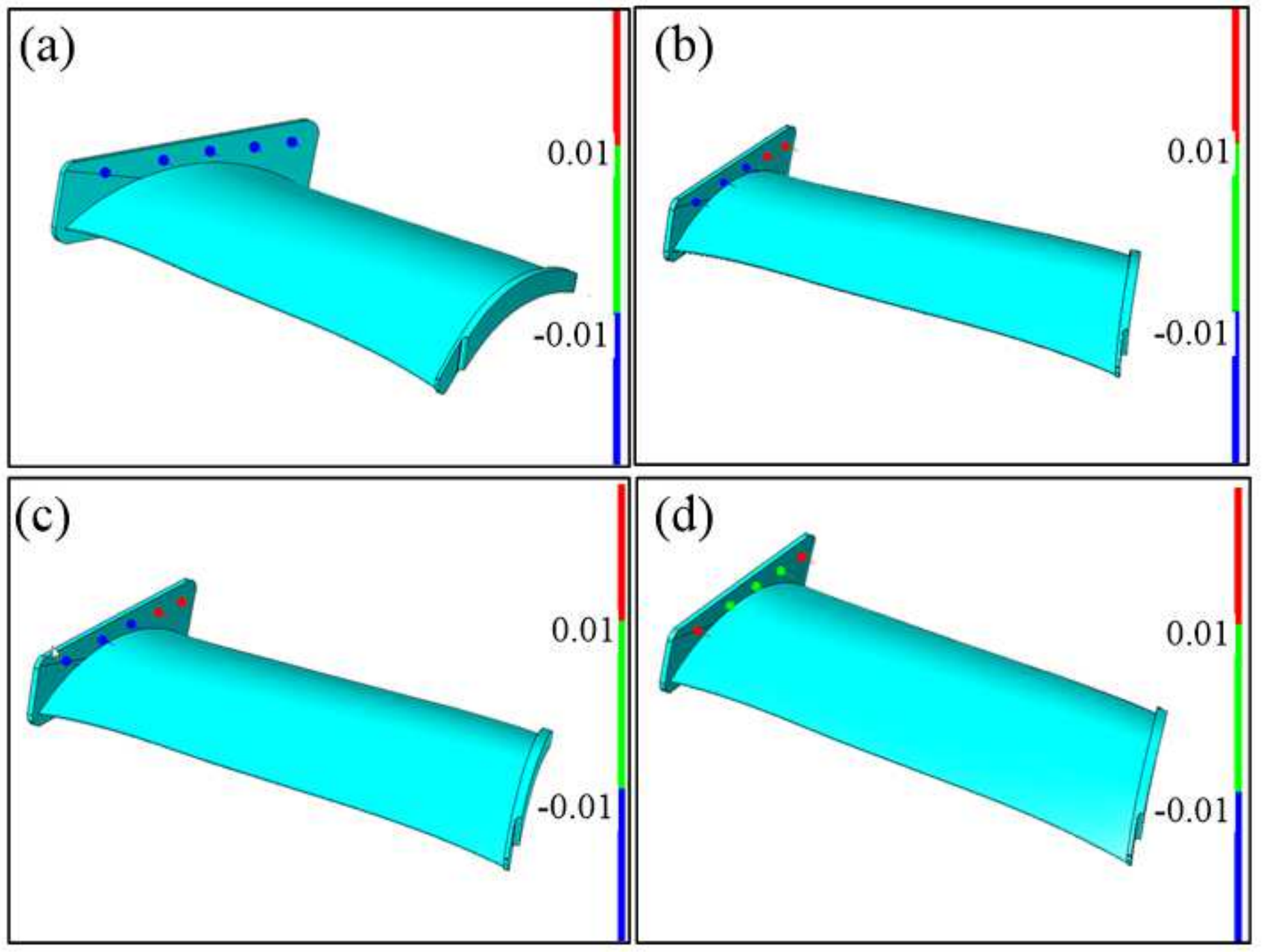

Figure 21

The deviation value of the blade tenon root side adaptive adjustment, (a) The first adaptive adjustment deviation values, (b) The second adaptive adjustment deviation values, (c) The third adaptive adjustment deviation values, (d) The final acceptable adaptive adjustment deviation values. 

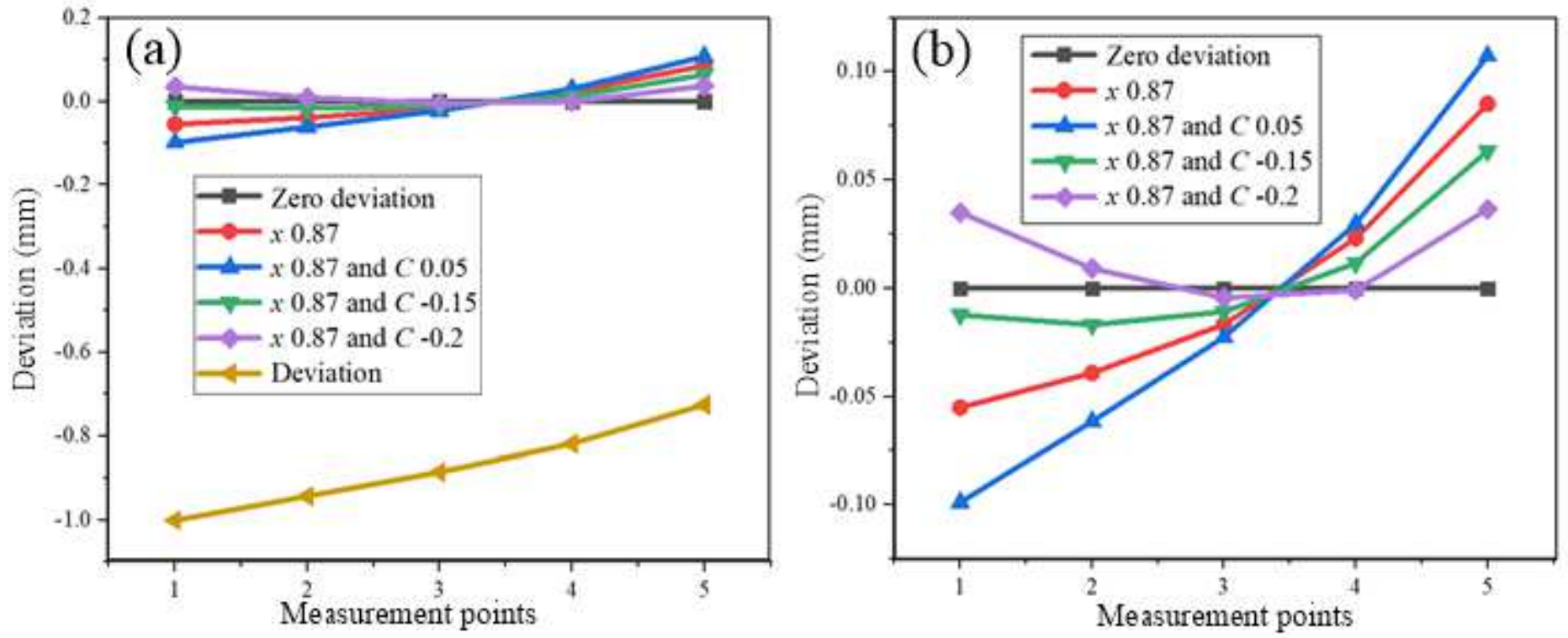

Figure 22

Deviation curve of blade tenon root, (a) Translation process, (b) Rotation process

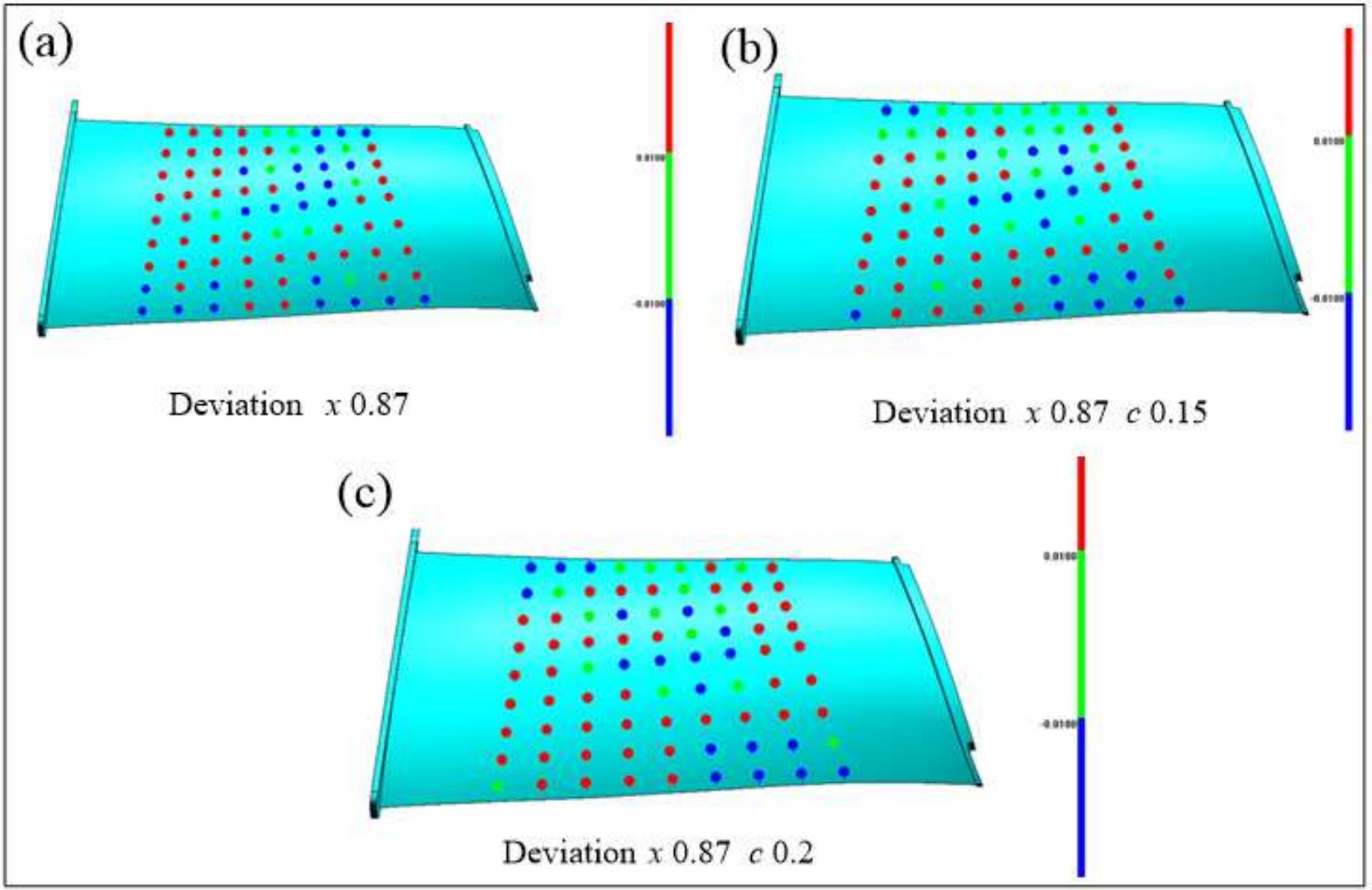

Figure 23 
Deviation of the blade body profile of the adaptive adjustment process corresponding to the measurement data of the tenon root in Figure 21, (a) Translating along $x$ axis $(0.87 \mathrm{~mm})$, (b) Rotating along the $\mathrm{C}$-axis $(0.15 \mathrm{deg})$, (c) Rotating along the $\mathrm{C}$-axis $(0.2 \mathrm{deg})$

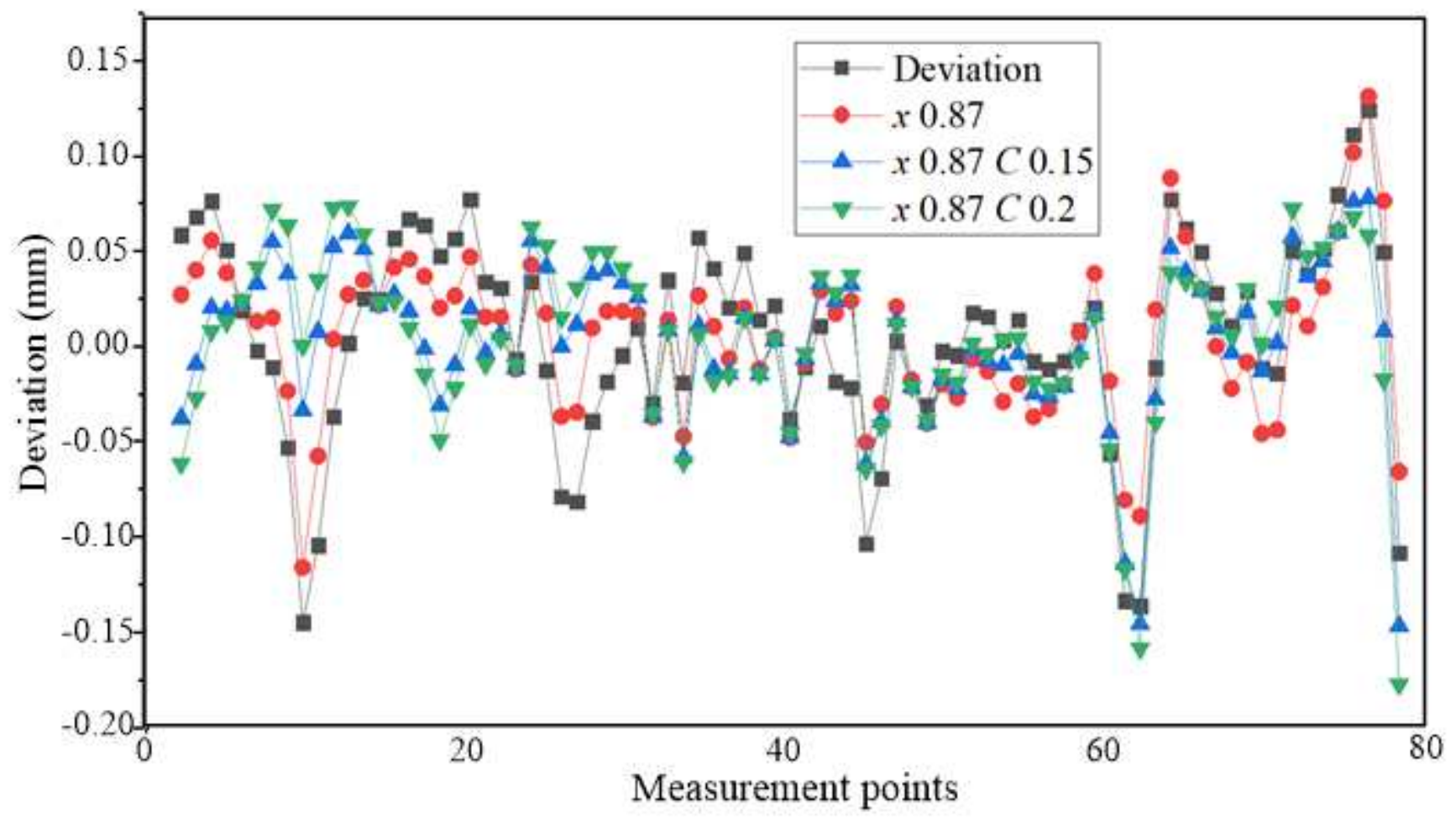

Figure 24

Profile deviation numerical distribution of blade body 

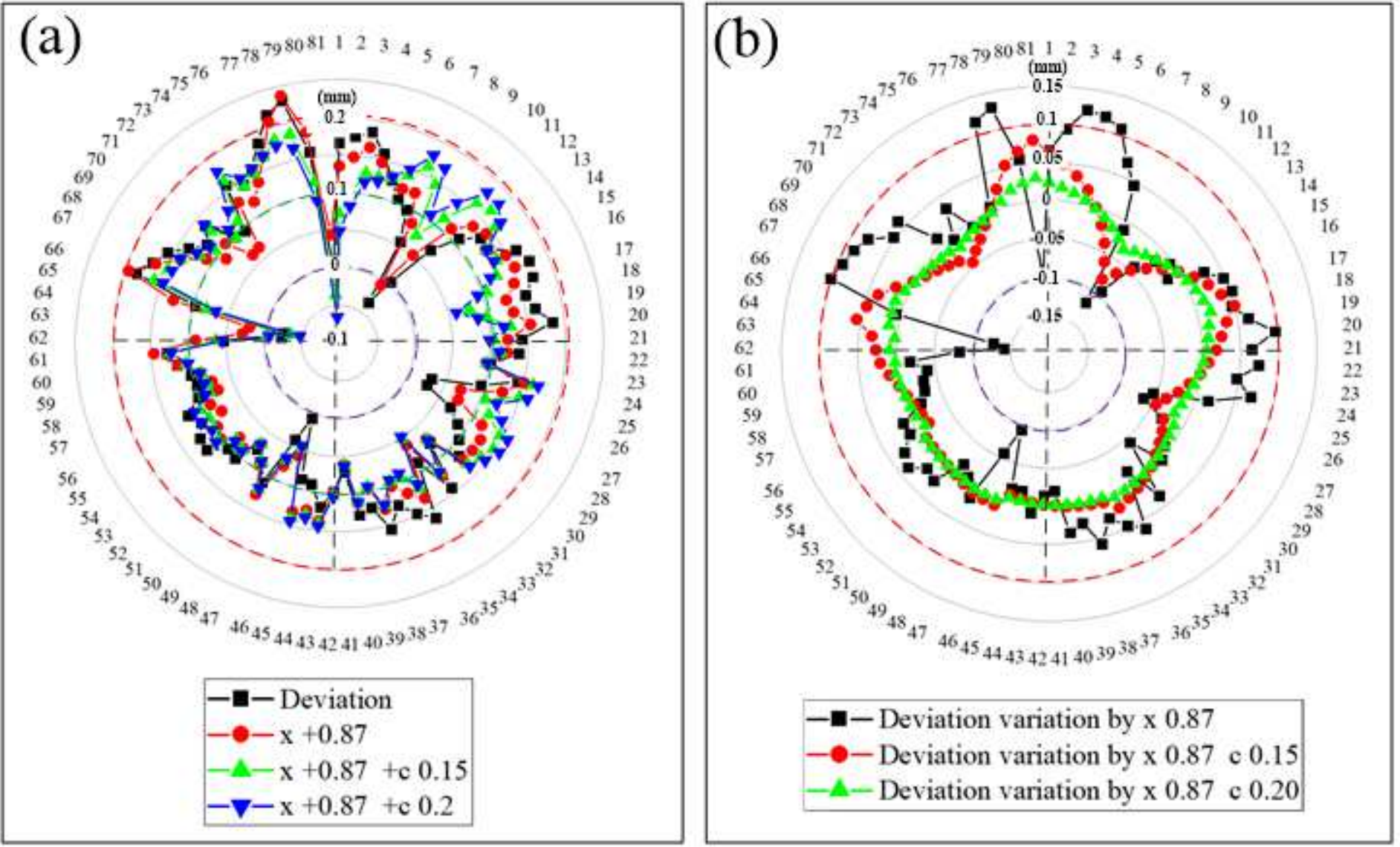

\section{Figure 25}

Numerical distribution of the deviation variation of the blade body, (a) Deviation value, (b) Deviation variation value
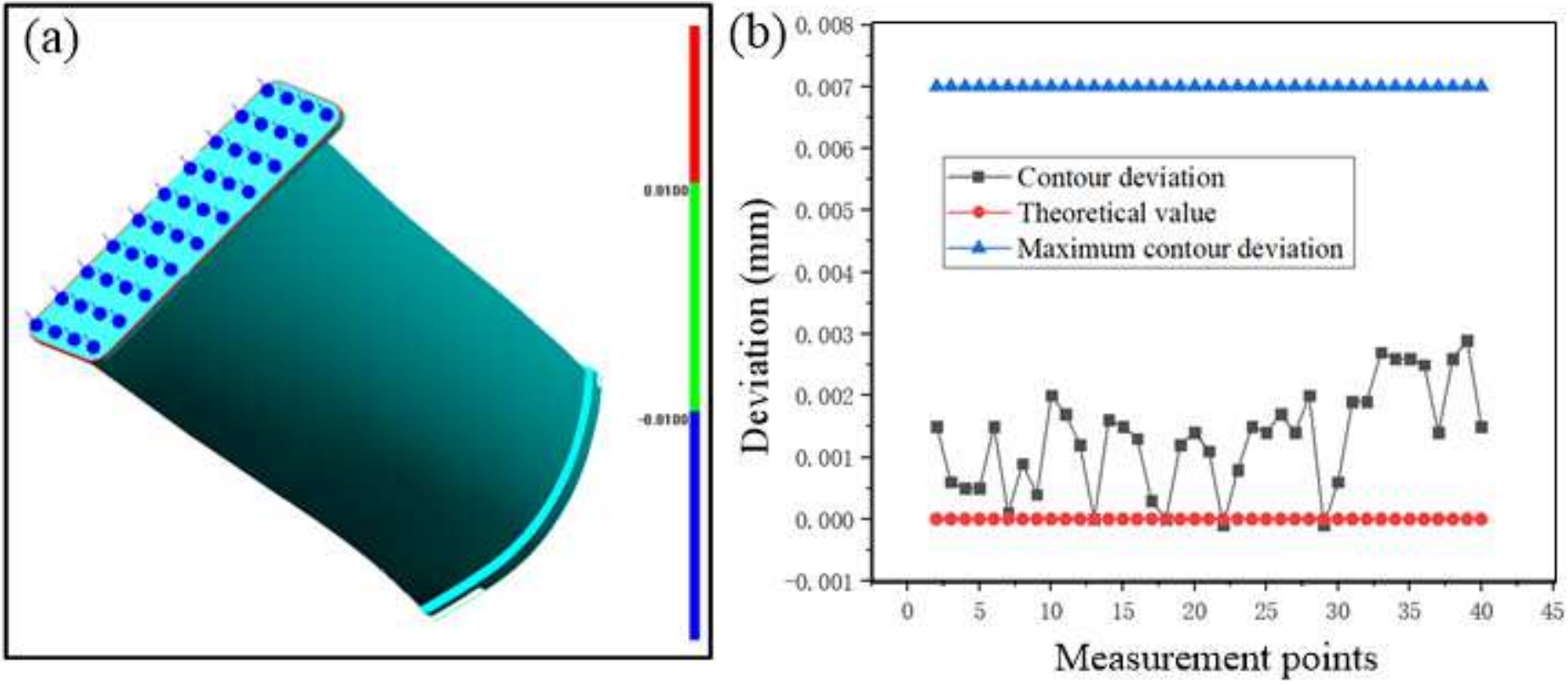

Figure 26 
Contouring error of blade tenon root side, (a) Measurement model, (b) Measurement results
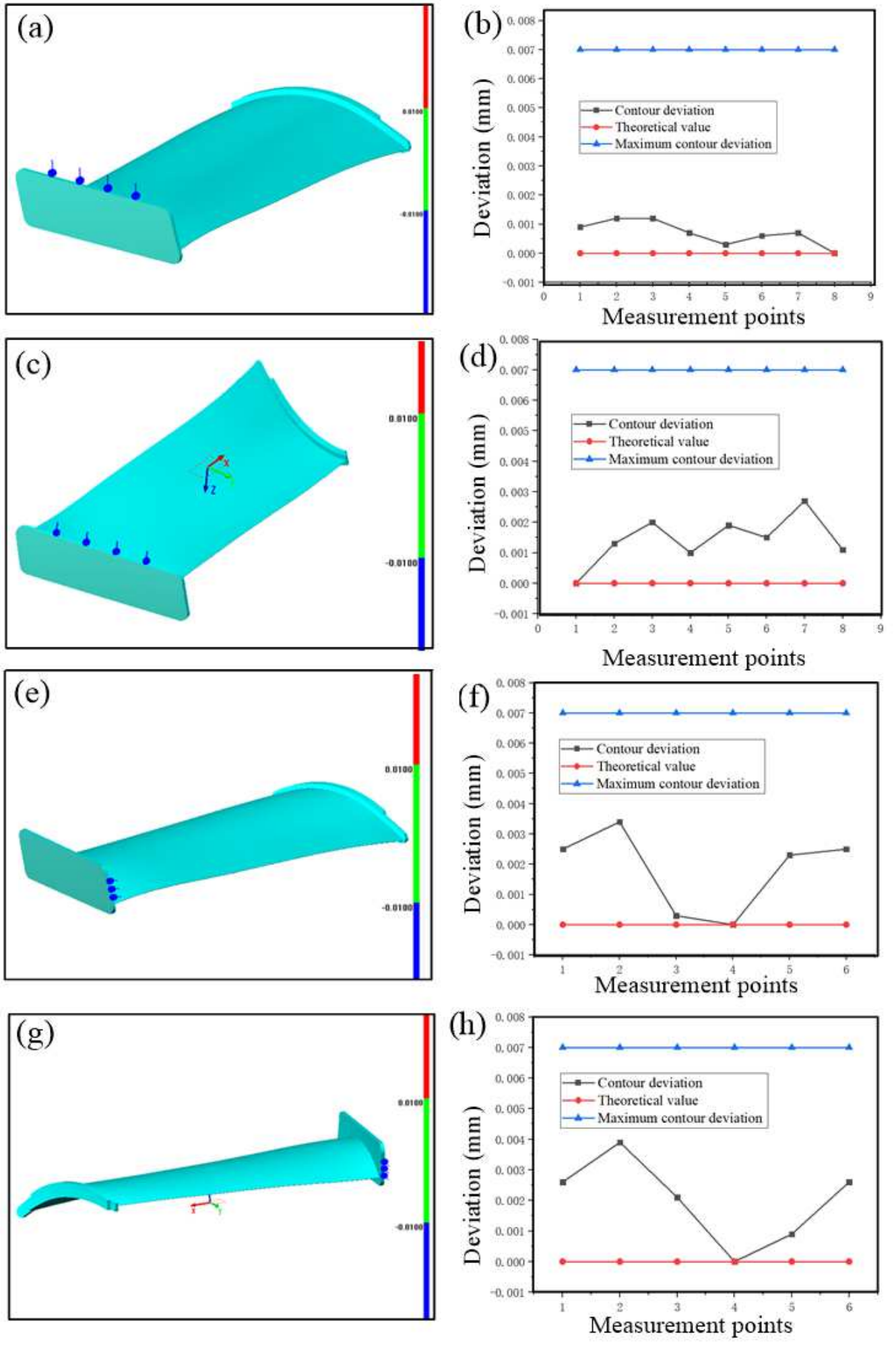

Figure 27

(a)-(h) Contouring error of blade tenon root 

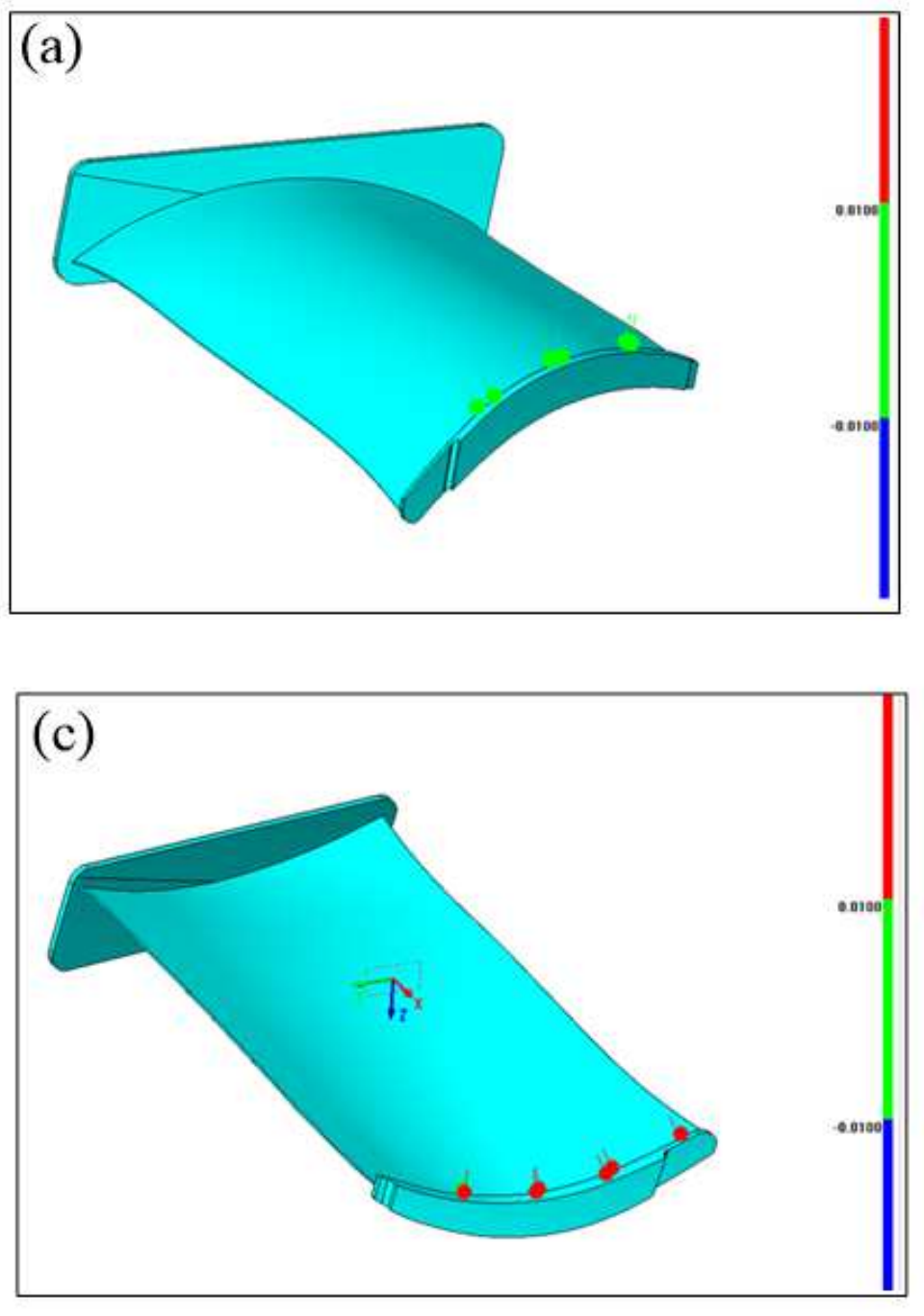

Figure 28

(a)-(d) contouring error of blade tip
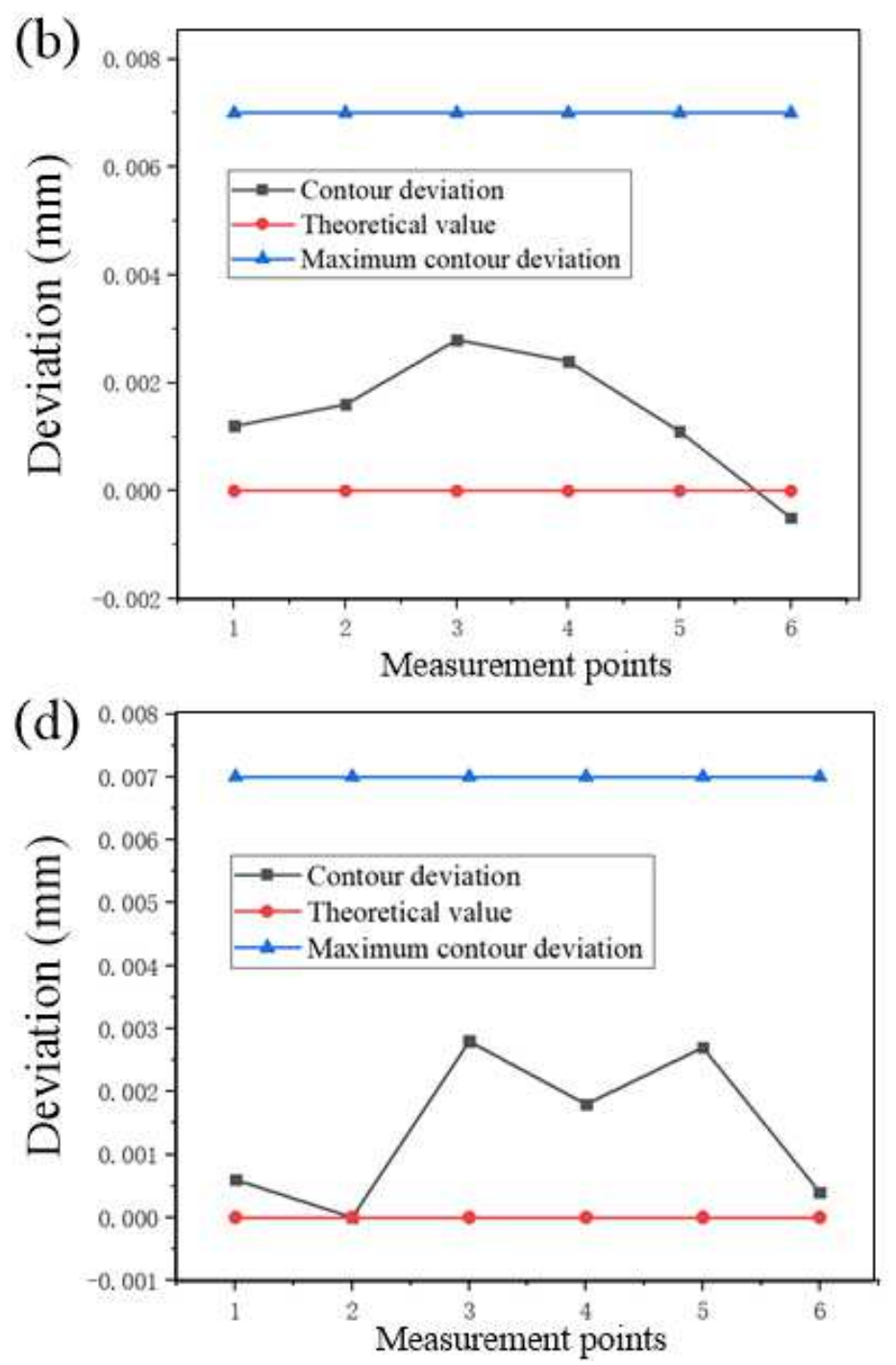


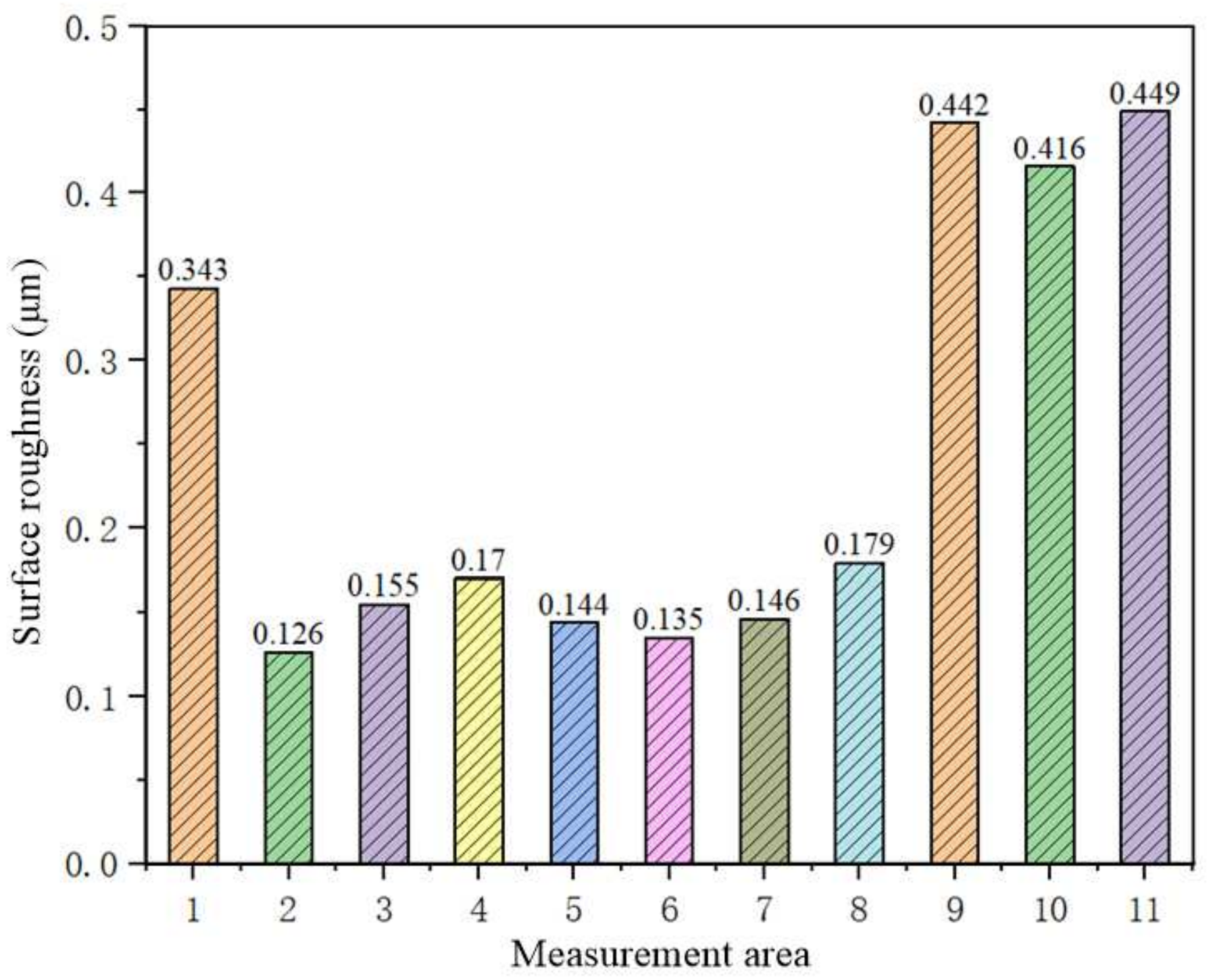

Figure 29

Blade surface roughness 
(a)

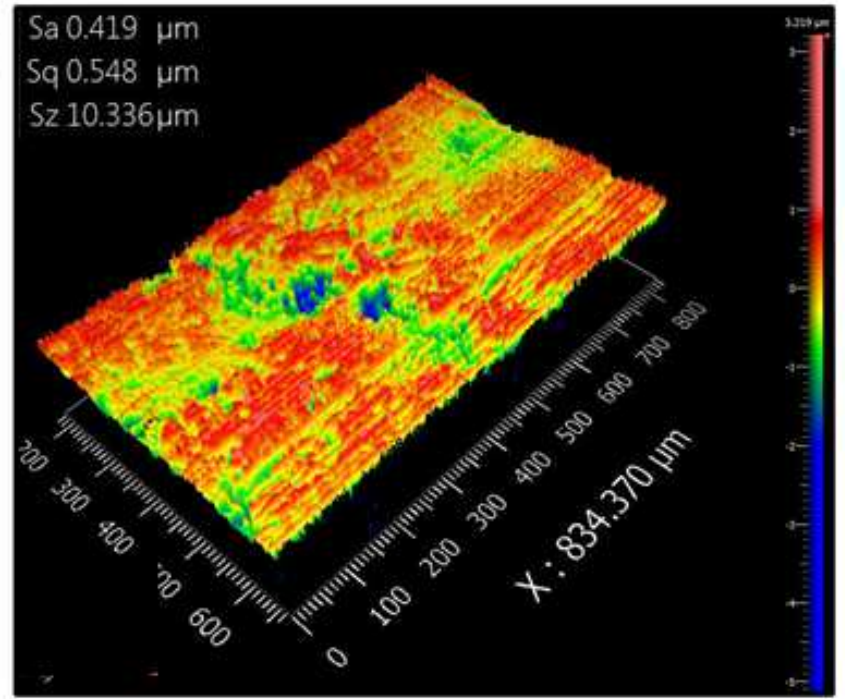

(c)

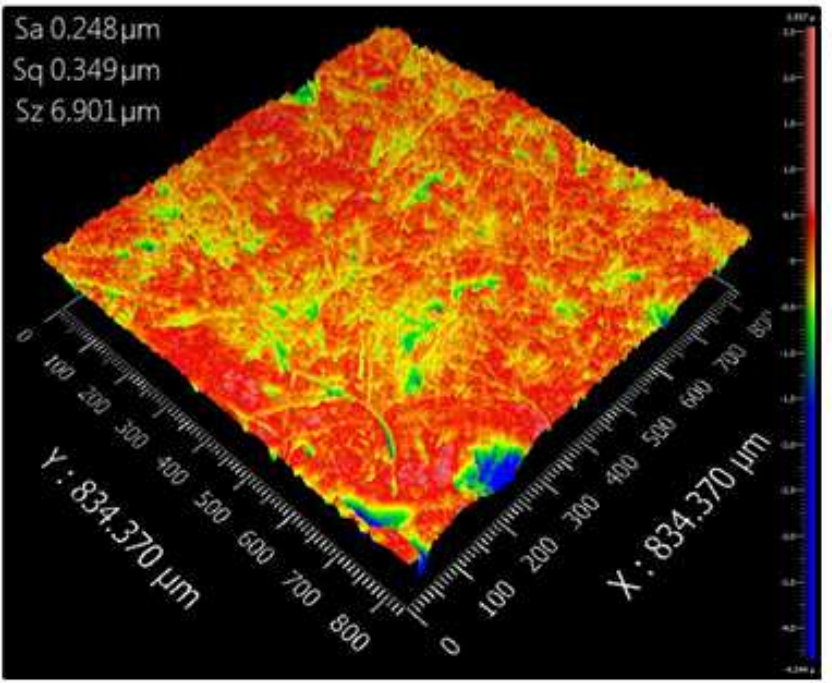

(b)

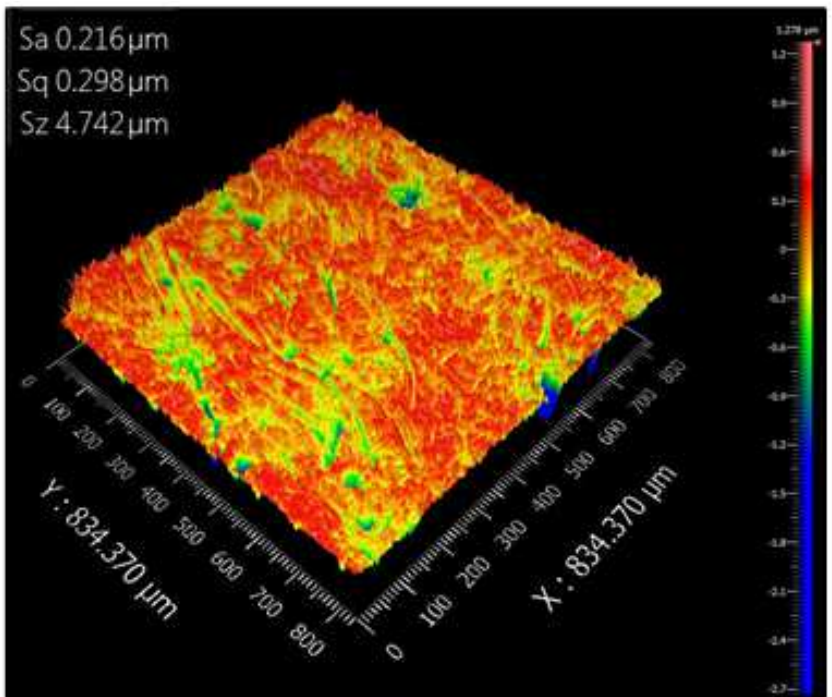

(d)

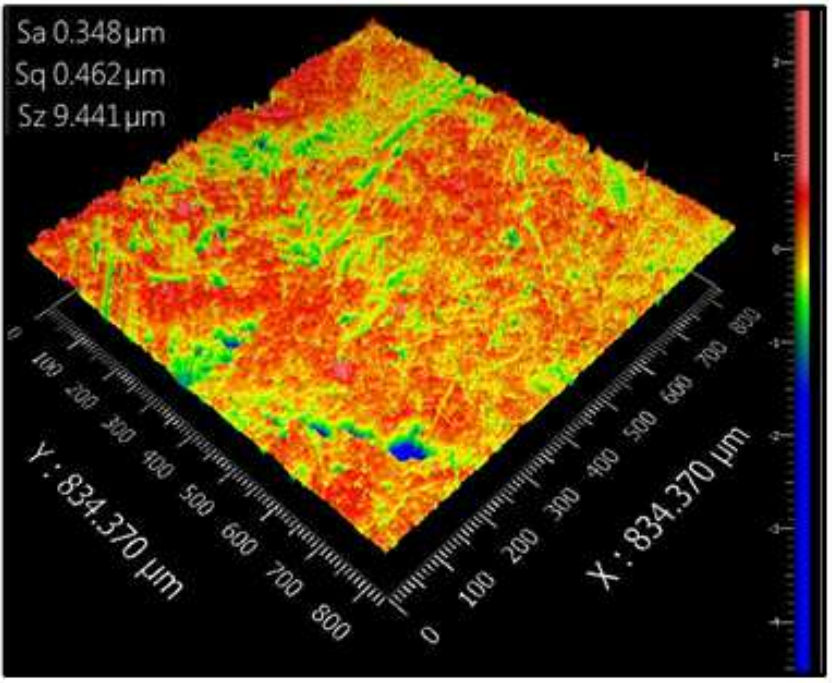

Figure 30

Micro-morphology of blade body surface, (a)-(d) Different parts of blade 
(a)

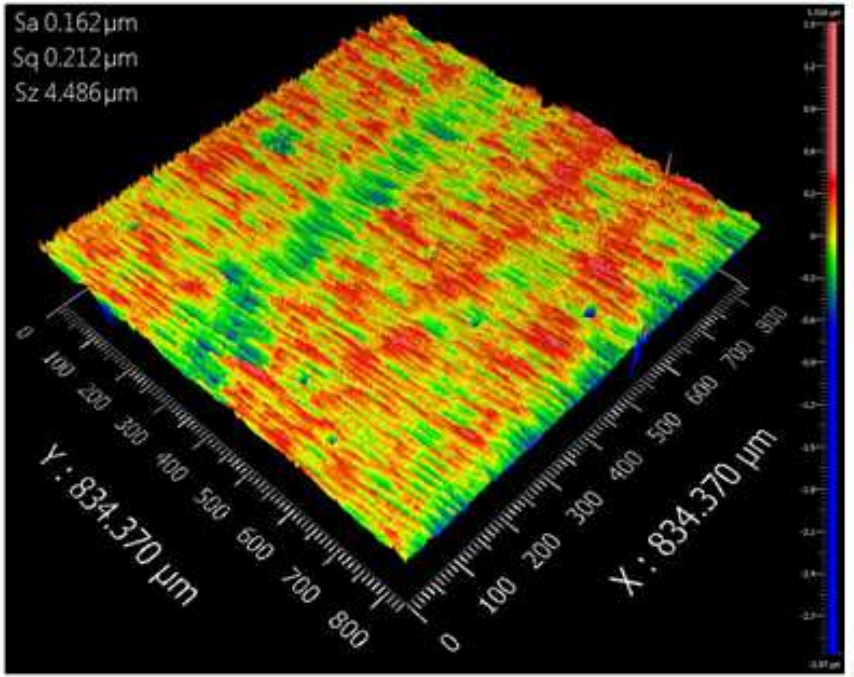

(c)

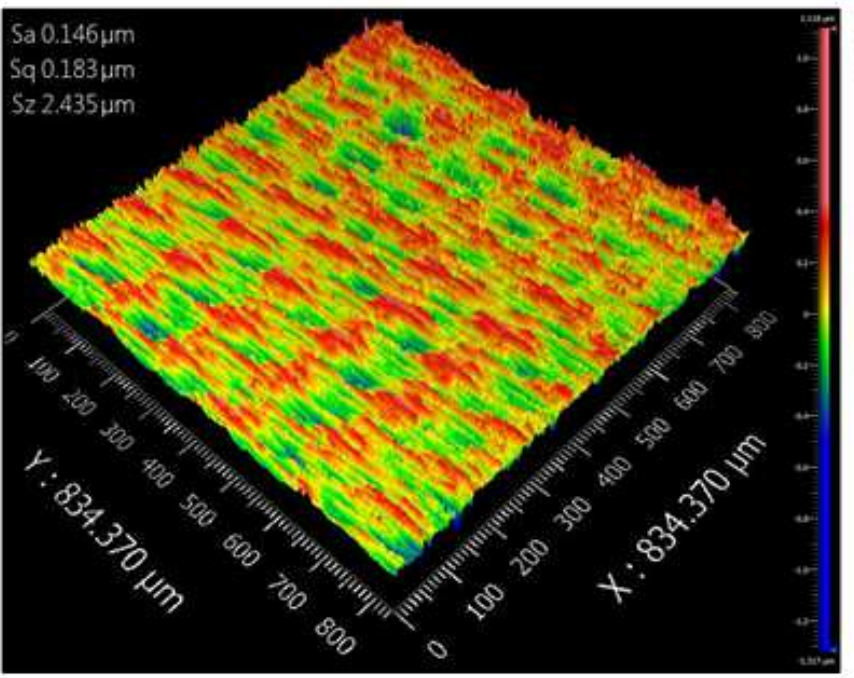

(b)

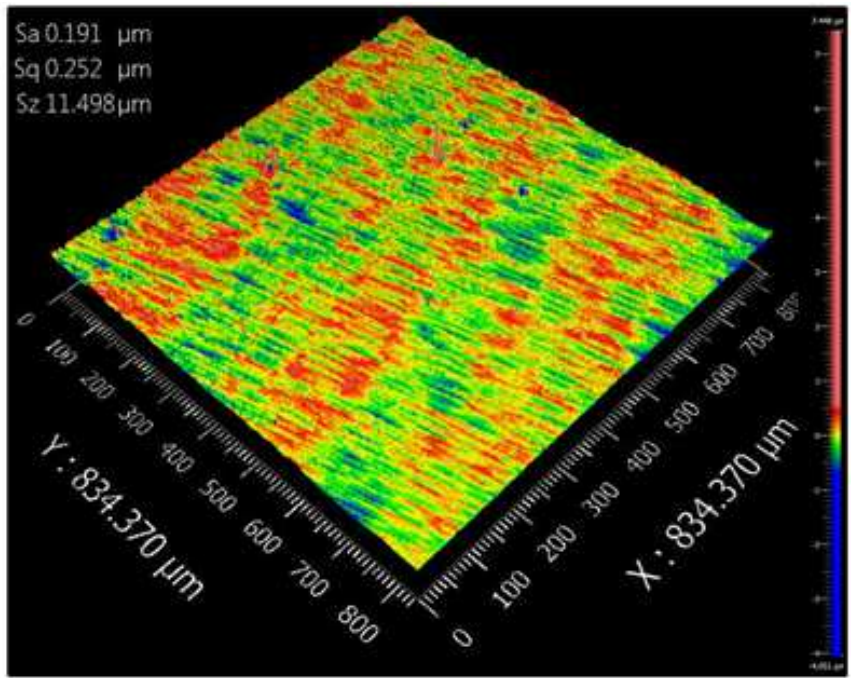

(d)

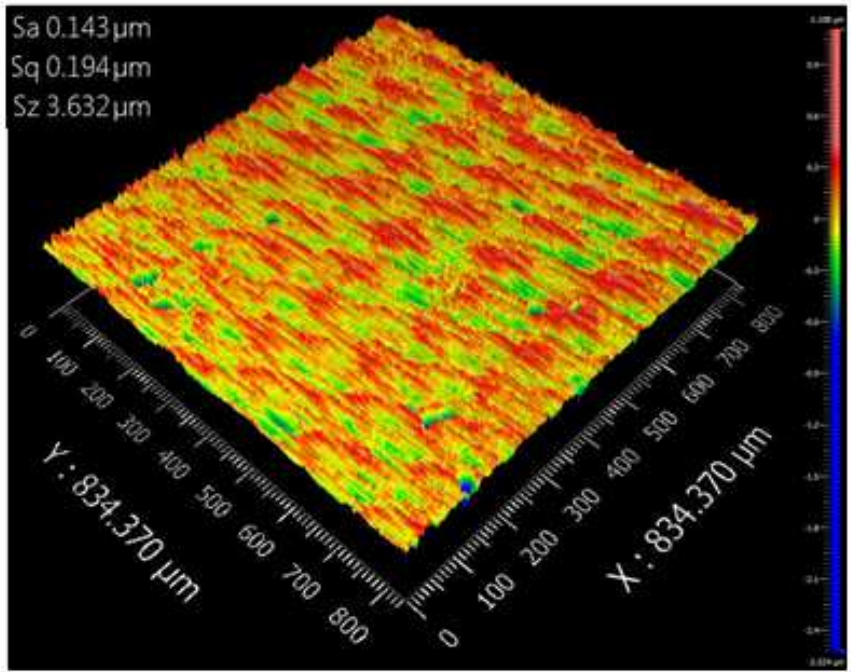

\section{Figure 31}

Micro-morphology of blade tenon root and tip surface after adaptive CNC machining process, (a)-(d) Different parts of the blade tenon root 